OPEN ACCESS

Edited by:

Marco Romano,

King's College London,

United Kingdom

Reviewed by:

Mo Atif,

Sorbonne Universités, France

Andras Perl,

Upstate Medical University,

United States

*Correspondence:

Chi Liu

liuchi1985@163.com

Linjiang Song

linjsong_scu@163.com

Qing Nian

young926@hotmail.com

${ }^{+}$These authors have contributed equally to this work

Specialty section: This article was submitted to

T Cell Biology,

a section of the journal

Frontiers in Immunology

Received: 01 December 2021

Accepted: 24 January 2022

Published: 17 February 2022

Citation:

Han Z, Ma K, Tao H, Liu H, Zhang J, Sai X, Li Y, Chi M, Nian Q, Song $L$ and

Liu C (2022) A Deep Insight Into

Regulatory T Cell Metabolism in Renal Disease: Facts and Perspectives.

Front. Immunol. 13:826732.

doi: 10.3389/fimmu.2022.826732

\section{A Deep Insight Into Regulatory T Cell Metabolism in Renal Disease: Facts and Perspectives}

\author{
Zhongyu Han ${ }^{1,2,3 \dagger}$, Kuai Ma ${ }^{4 \dagger}$, Hongxia Tao ${ }^{3 \dagger}$, Hongli Liu ${ }^{3}$, Jiong Zhang ${ }^{1,2}$, Xiyalatu Sai ${ }^{5}$, \\ Yunlong $\mathrm{Li}^{3}$, Mingxuan Chi ${ }^{1,2}$, Qing Nian ${ }^{2,6 *}$, Linjiang Song ${ }^{3 *}$ and Chi Liu ${ }^{1,2 *}$ \\ ${ }^{1}$ Department of Nephrology, Sichuan Academy of Medical Science and Sichuan Provincial People's Hospital, Sichuan Renal \\ Disease Clinical Research Center, University of Electronic Science and Technology of China, Chengdu, China, ${ }^{2}$ Chinese \\ Academy of Sciences Sichuan Translational Medicine Research Hospital, Chengdu, China, ${ }^{3}$ Reproductive \& Women- \\ Children Hospital, School of Medical and Life Sciences, Chengdu University of Traditional Chinese Medicine, Chengdu, \\ China, ${ }^{4}$ Department of Nephrology, Osaka University Graduate School of Medicine, Osaka, Japan, ${ }^{5}$ Affiliated Hospital of \\ Inner Mongolia University for the Nationalities, Tongliao, China, ' 6 Department of Blood Transfusion Sicuan Provincial People's \\ Hospital, University of Electronic Science and Technology of China, Chengdu, China
}

Kidney disease encompasses a complex set of diseases that can aggravate or start systemic pathophysiological processes through their complex metabolic mechanisms and effects on body homoeostasis. The prevalence of kidney disease has increased dramatically over the last two decades. $\mathrm{CD} 4^{+} \mathrm{CD} 25^{+}$regulatory $\mathrm{T}$ (Treg) cells that express the transcription factor forkhead box protein 3 (Foxp3) are critical for maintaining immune homeostasis and preventing autoimmune disease and tissue damage caused by excessive or unnecessary immune activation, including autoimmune kidney diseases. Recent studies have highlighted the critical role of metabolic reprogramming in controlling the plasticity, stability, and function of Treg cells. They are also likely to play a vital role in limiting kidney transplant rejection and potentially promoting transplant tolerance. Metabolic pathways, such as mitochondrial function, glycolysis, lipid synthesis, glutaminolysis, and mammalian target of rapamycin (mTOR) activation, are involved in the development of renal diseases by modulating the function and proliferation of Treg cells. Targeting metabolic pathways to alter Treg cells can offer a promising method for renal disease therapy. In this review, we provide a new perspective on the role of Treg cell metabolism in renal diseases by presenting the renal microenvironment, relevant metabolites of Treg cell metabolism, and the role of Treg cell metabolism in various kidney diseases.

Keywords: metabolic pathways, regulatory T cells, renal disease, tissue damage, immune homeostasis 


\section{INTRODUCTION}

The kidney is an important organ for excreting metabolic waste and maintaining internal environmental stability and plays an extremely important role in metabolic activities (1) (Figure 1). Treg cells are typical $\mathrm{CD} 4^{+}$cells that constitutively express high levels of the interleukin-2 (IL-2) receptor CD25, along with the transcription factor Foxp3, which plays a central role in generating and maintaining Treg cell-specific gene expression by cooperating with other transcription factors, such as runtrelated transcription factor 1 (RUNX1) and gata binding protein 3 (GATA3) (2).

Treg cells in vivo can be divided into two types (3): thymus Treg cells ( $\mathrm{t} T$ reg), which mature after positive and negative selection in the thymus and play an immunosuppressive role in peripheral blood and lymphoid tissues; and peripherally induced Treg ( $\mathrm{pTreg}$ ) cells, which originate from $\mathrm{T}$ cells after antigenic stimulation and are converted by inhibitory cytokines (Figure 2). Treg cells in vitro are induced by cytokines and other factors, often referred to as induced $\mathrm{CD} 4^{+} \mathrm{T}$ regulatory cells (iTreg). In vitro and in vivo, $\mathrm{CD} 4^{+} \mathrm{CD} 25^{+} \mathrm{Foxp}^{+}$Treg cells inhibited the activation, proliferation, and effector function of a wide range of immune cells, such as $\mathrm{CD} 4^{+}$and $\mathrm{CD} 8^{+} \mathrm{T}$ cells, natural killer (NK) cells, and NKT cells. They are indispensable for the maintenance of self-tolerance and immune homeostasis by inhibiting excessive or misdirected immune responses to foreign or autogenous targets (4).

It is important to note that phenotypic differences between tTreg cells and pTreg cells have not been clearly defined, which poses challenges in distinguishing the exact proportions of these two subpopulations in secondary lymphoid organs and nonlymphoid tissues. Studies have shown that neuropilin (Nrp-1) and Helios are highly expressed on tTreg in mice, but not on pTreg/iTreg cells $(5,6)$. Therefore, some researchers believe that tTreg cells and pTreg cells can be distinguished by Nrp-1 and Helios. However, this hypothesis has been controversial, especially when it comes to the distinction between human tTreg cells and pTreg cells $(7,8)$. Therefore, in the following review, we tried our best to use accurate classification to describe Treg cells, such as tTreg cells, pTreg cells, and iTreg cells. Where we were unable to distinguish the origins of the Treg cells from the original article, we have described the population studied using 'Treg cell' only.

Recently, increasing evidence has shown that Treg cells can take part in various renal diseases. Treg cells can play a negative regulatory role in kidney diseases and inhibit the immune response through direct cell contact or secretion of inhibitory cytokines (9). At the same time, kidney diseases, in turn, affect the function of Treg cells. For example, the number of Treg cells in patients with IgA nephritis is significantly reduced (10).

It is well known that renal disease is accompanied by significant changes in metabolic patterns (11), such as changes in glucose (12), amino acid (13), and lipid metabolism (14), which are essential for the activation and proliferation of Treg cells. Moreover, the metabolic pattern of Treg cells is also regulated by the metabolic state of nephropathy, and the type of nutrients used by Treg cells in nephropathy changes their differentiation, resulting in alterations in their phenotype and proportion. In addition to nutritional supply, the accumulated byproducts of renal metabolism significantly impair the immunosuppressive function of Treg cells, and the loss or functional deficiency of Treg cells affects the immune homeostasis of the kidney (15-18).

In the following sections, we will introduce renal microenvironment. Treg cell metabolism, the role of Treg cells in various renal diseases, and the importance of abnormalities in various metabolic pathways for the function of Treg cells, and will discuss the factors of abnormal metabolic pathways, which may be the goal of immunotherapy for related renal diseases.

\section{RENAL MICROENVIRONMENT}

The kidney is the most important organ in the human urinary system, which undertakes the important mission of filtering metabolic waste, excreting them from the body, and reabsorbing various nutrients (19). The kidney can maintain the body fluid and electrolyte balance by the distal tubule of the collecting duct through the absorption and excretion of various ions (electrolytes) in the body, such as sodium ions, phosphorus ions, calcium ions, and magnesium ions (20), at the same time, discharge the vast majority of metabolic wastes produced by the human body (21), for example, urea nitrogen, creatinine, uric acid, etc., to prevent waste products accumulate in the body, causing various disorders.

The kidney is an organ with important functions and complex structures, which determines that there are many kinds of cells involved in the microenvironment of the kidney, including immune cells and intrinsic cells of the kidney. Cytokines, chemokines, adhesion molecules, and complement secreted by immune cells and intrinsic cells of the kidney in the local immune microenvironment of kidney tissue, which plays a great role in the occurrence of kidney metabolism and injury.

\section{Immune Cells and Intrinsic Cells of the Kidney Macrophages}

Macrophages are classified into M1 macrophages and M2 macrophages (22). In healthy kidney tissue, the main function of macrophages is to phagocytose and digest cell fragments and pathogens in the form of fixed cells or free cells, and to activate lymphocytes or other immune cells to respond to pathogens.

Studies have shown that macrophages play an important role in mediating immunopathology and tissue remodeling in nonrenal disease and renal disease (23). In animal models, blocking macrophage recruitment and expression of inflammatory factors can prevent the progression of various kidney diseases (24). At the same time, the damaged kidney produces a large number of macrophages, which continuously infiltrate the kidney and produce pro-inflammatory cytokines, including TNF- $\alpha$ and IL$1 \beta$, to induce kidney inflammation (25). In addition, 


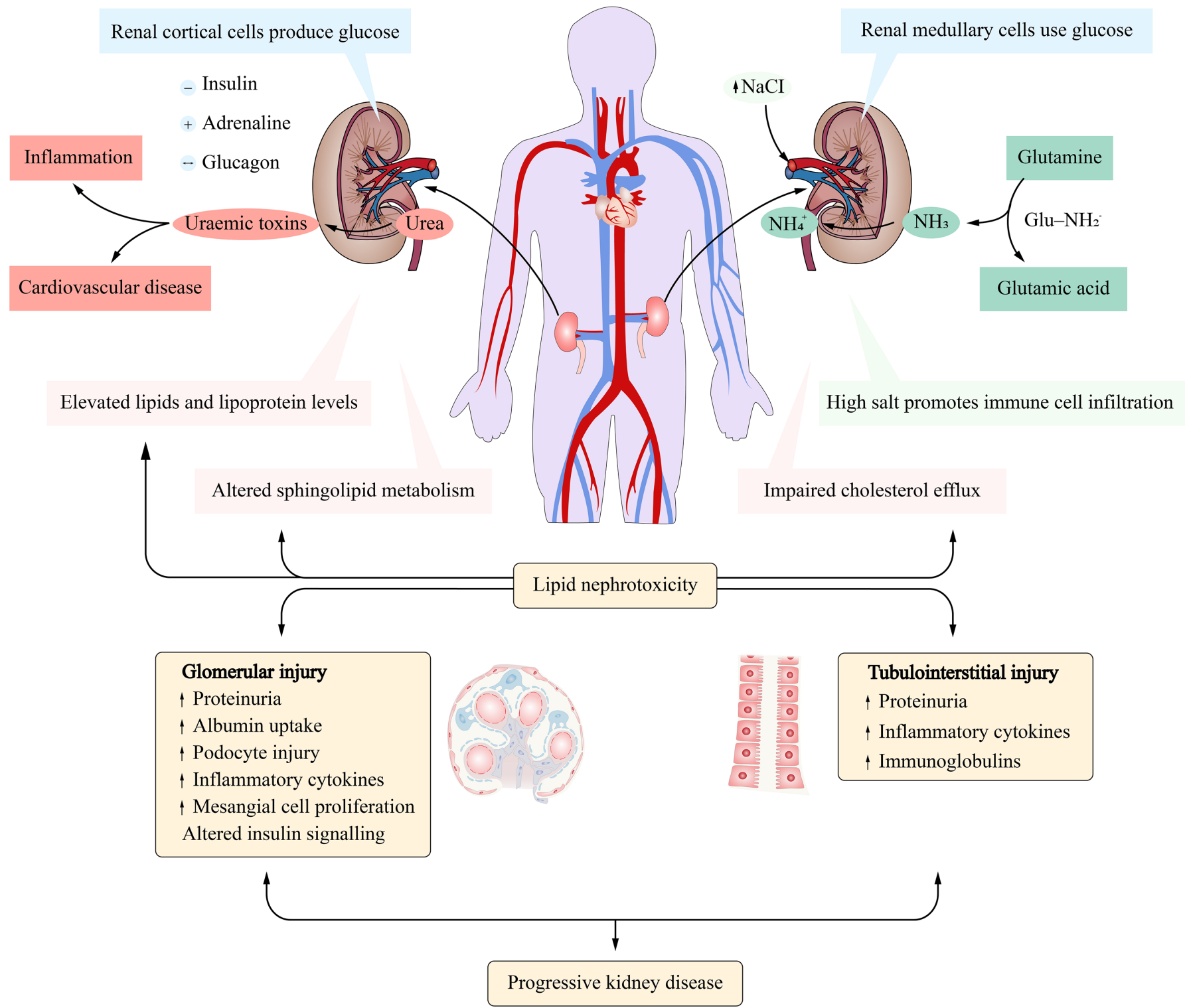

FIGURE 1 | Metabolism of substances in the kidney. Cortical cells undergo gluconeogenesis while medullary cells metabolize glucose. Glutamine is extracted from renal tubular cells and used to produce ammonia (NH3). High levels of urea cause the kidneys to produce uremic toxins. Lipid nephrotoxicity could damage the structure and function of the glomerulus and tubules. 


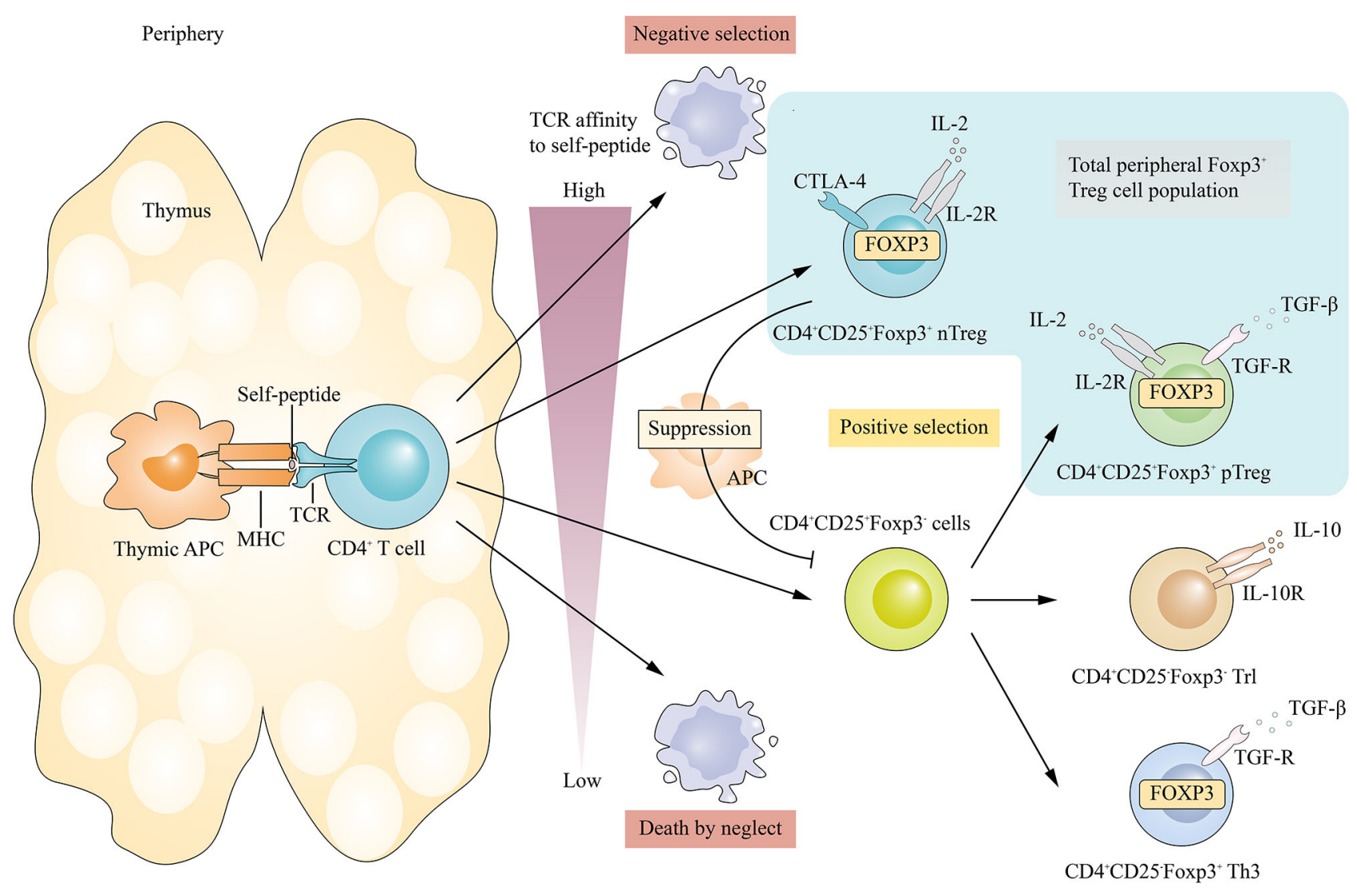

FIGURE 2 | Differentiation of Treg cells in vivo. TTreg cell development is initiated by TCR signal transduction. CD4+CD8- thymocytes that bind with high affinity to their self- peptides-MHC complex are positively selected in the thymus. Immature T cells with low affinity for their own peptide-MHC complex are also positively selected and subsequently differentiated into different subtypes, including pTreg, Tr1 and Th3.

macrophages can produce oxygenated nitric oxide Complement components can directly damage renal cells and affect the formation of matrix and blood vessels by expressing matrix metalloproteinases and vasoactive peptides (26).

\section{Mast Cells}

Mast cells have long been considered as effector cells for mediated hypersensitivity and inflammatory responses (27). Its role in the kidney has been largely overlooked in comparison to macrophages and other immune cells. In fact, in a healthy kidney, mast cells release cytokines that protect the kidney from immune damage. They also produce chymases, which produce angiotensin II (28).

Studies have shown that chymase expression is proportional to the degree of renal interstitial fibrosis $(29,30)$. Mast cell infiltration and increased chymase expression are seen in both glomerulonephritis and ischemia-reperfusion-induced renal fibrosis $(31,32)$. Mast cells can also promote the proliferation of fibroblasts through intercellular interactions (33). But some researchers have come up with evidence to the contrary. They used mast cell deficient rats to induce nephritis with Puromycin aminonucleoside (PAN) (34). After 6 weeks, it was found that the fibrosis degree of the deficient rats was more serious than that of the wild-type rats, and the expression of TGF- $\beta$ was significantly higher than that of the wild-type rats. In vitro experiments showed that heparin, as an important component of mast cells, could inhibit the expression of TGF- $\beta$ in rat fibroblasts, suggesting that mast cells may reduce the degree of fibrosis through TGF- $\beta$-dependent pathways and play a certain protective role in the kidney.

\section{Dendritic Cells}

Dendritic cells (DCs) can be divided into plasmacytoid dendritic cells (pDC) and conventional dendritic cells (cDC) (35). Immature DCs have strong migration ability, mature DCs can effectively activate primary $\mathrm{T}$ cells, and are in the central link of initiating, regulating, and maintaining immune response (36). It is rarely present in a healthy kidney and can efficiently absorb, process, and present antigens to maintain the stability of the renal internal environment.

Studies have shown that DCs induce and maintain immune responses through migration and maturation in the kidney (37). 
DCs, although rarely present in normal kidneys, are significantly increased in chronic kidney disease (CKD) and diabetic nephropathy (DN) (38). A 5/6 nephrectomy model was used to induce renal fibrosis, $\mathrm{CD} 1 \mathrm{a}^{+} \mathrm{CD} 80^{+} \mathrm{DCs}$ was found to accumulate in the renal interstitial from 1 week after modeling and peaked at 12 weeks (39). In another study, galectin 3 protects cisplatin-induced acute kidney injury by promoting TLR-2 dependent activation of the IDO1/Kynurenine acid pathway in renal DCs (40). These two studies suggest that DCs were associated with the severity of interstitial fibrosis.

\section{T Lymphocyte}

$\mathrm{T}$ cells are characterized by the expression of co-receptor molecules CD4 and CD8 on their cell surface (41). CD4 ${ }^{+} \mathrm{T}$ cells, also known as $\mathrm{T}$ helper cells (Th), recognize antigen/ MHC-II complexes on antigen-presenting cells (42) and coordinate the activation of other immune cells, including $\mathrm{B}$ cells, macrophages. $\mathrm{CD}^{+}$cells, on the other hand, called $\mathrm{T}$ cytotoxic cells, recognize antigens/MHC-I complexes and are responsible for killing pathogen-infected cells (43). In healthy kidney tissue, $\mathrm{T}$ lymphocytes protect the kidney by performing a variety of biological functions to fight infection.

Th cells are thought to play an important role in kidney disease. Th cells were divided into Th1, Th2, Th17 and Treg cells according to the different cytokines secreted (44). Th1 cells mainly secreted IFN- $\gamma$, IL-2, IL-12, and so on. Th2 cells mainly secrete IL-4, IL-5, IL-13, etc (45). Th17 cells mainly secrete IL-17. Treg cells mainly secrete IL-10 and TGF- $\beta$ (46). In a study of rats with idiopathic nephrotic syndrome, proteinuria and focal segmental glomerular injury were observed at 10 weeks of age. Renal T cell infiltration was detected before proteinuria, Th1 and Th2 cells were increased, and Th2 cells were dominant (46). But exactly what the Th1/Th2 equilibrium theory means is still up in the air. The main problem is that the activity of cytokines and other immune messengers rarely falls into strict Th1 or Th2 patterns, and some immune cells, such as Treg cells, stimulate the Th1/Th2 immune system (47). The imbalance of the Th17/ Treg ratio plays a role in tissue inflammation, autoimmune, and various diseases. Recently, researchers have proved that the increased ratio of Th17/Treg cells is related to the progression of CKD (48).

Most $\mathrm{CD}^{+} \mathrm{T}$ cells are cytotoxic, which can induce apoptosis through perforin or Fas/FasL pathway, and can also directly stimulate fibroblast proliferation and extracellular matrix production by secreting TGF- $\beta$, IL- 4 , TNF-a, and other factors, thus aggravating kidney injury (49). Depletion of $\mathrm{CD}^{+} \mathrm{T}$ cells with antibodies can reduce interstitial dilatation, reduce fibrosis, and alleviate renal parenchymal lesions and renal damage (50). On the contrary, the depletion of $\mathrm{CD} 4^{+} \mathrm{T}$ cells aggravated kidney injury, partly because the decrease of $\mathrm{CD} 4^{+} \mathrm{T}$ cells caused the increase of $\mathrm{CD} 8^{+} \mathrm{T}$ cells (50).

\section{B Lymphocyte}

$B$ cells have a variety of functions. In addition to the function of antibody secretion, B cells also have the function of releasing inflammatory cytokines, chemokines, and antigen presentation (51). In healthy kidney tissue, B cells make up a small proportion and, together with other immune cells, maintain the stability of the immune microenvironment of the kidney.

There is growing evidence that B cells play an important role in kidney disease. In lupus nephritis(LN), the researchers treated NZB/W lupus mice with a selective histone deacetylase 6 (HDAC6) inhibitor for 4 weeks and showed that HDAC6 inhibition decreased B-cell activating signaling pathways, resulting in a significant reduction in LN symptoms (52). In a clinical trial on patients with IgA nephropathy, the investigators found that toll-like receptor 7 (TLR7) can activate B cells through the TLR7- GALNT2 axis, which produces high levels of galactose-deficient IgA1 (Gd-IgA1) (53).

\section{Renal Tubular Epithelial Cells}

Renal tubule epithelial cells(RTECs) are composed of a single layer of epithelium and have different morphological characteristics and functions according to the position of renal tubules. For example, in the proximal convoluted tubules, the wall is composed of a single layer of cuboidal epithelial cells (54). The lumen is small and irregular and is an important part of tubular reabsorption. The free surface of the cell has a bristle margin, which enlarges the cell surface area and facilitates reabsorption.

RTECs are involved in the occurrence of kidney injury in many aspects. RTECs can be activated by a variety of cytokines, such as IL-1 and TNF-a produced by monocytes (55). IL-17 is a pro-inflammatory cytokine released by activated T cells. In vitro, activation of RTECs with IL-17 can promote the production of IL-6, IL-8, and MCP-1 (56). RTECs are not only important sources of cytokines and chemokines but also can produce profibrotic factors, such as TGF- $\beta$, PDGF, CTGF, etc (57). In addition, RTECs are important antigen-presenting cells that can interact with $\mathrm{T}$ cells and monocytes.

RTECs are also involved in an important process in renal fibrosis called epithelial-mesenchymal transition (EMT) (58). After EMT, morphological and proteomic changes occurred in RTECs. The so-called EMT is the process in which epithelial cells lose their cellular characteristics, such as polarity and intercellular adhesion, gain the ability to migrate and invade, enter the stroma to obtain new phenotypes, and eventually become mesenchymal cells. In renal fibrosis, EMT refers to the transformation of epithelial cells into myofibroblasts, which are the primary source of the extracellular matrix (59). The expression of various proteins, such as TGF- $\beta$, MMPs, FSP-1, and vimentin, increased after EMT. In contrast, some proteins, such as e-cadherin and keratin -18 , which are the signature proteins of epithelial cells, are also reduced in expression.

\section{Glomerular Mesangial Cells}

In healthy renal tissue, glomerular mesangial cells (MCs) only perform the functions of contraction, phagocytosis, and maintenance of normal matrix metabolism. Under pathological conditions, MCs can be transformed from a normal quiescent 
phenotype to an active proliferation/secretion phenotype with increased extracellular matrix secretion (60). The activation phenotype of MCs has myofibroblast-like characteristics and is characterized by the expression of A-SMA and ED-A fibronectin. After activation, MCs can release a variety of growth factors, such as TGF- $\beta$, CTGF, PDGF, etc. through the autocrine or paracrine form to promote self-proliferation (61). At the same time, MCs can synthesize a large amount of extracellular matrix, and mesangial matrix aggregation is the main pathological feature of glomerulosclerosis (62).

In NZB/WF1 mice, the binding of autoantibodies to MCs leads to the initiation of an inflammatory response, an earlystage marker of glomerulonephritis (63). In an in vitro model of lupus nephritis (LN), MCs participate in the inflammatory environment of LN by producing cytokines involved in leukocyte recruitment, activation, and maturation. Treatment of MCs with cytokines or patient serum induces TGF- $\beta 1$ secretion, suggesting that MCs are also involved in the fibrosis process of LN (64).

\section{Major Metabolites in the Kidney Urea}

Urea is a protein metabolite that is produced in the liver and travels through the blood to the kidneys. Some urea is retained in the blood by glomerular filtration and has the opportunity to be transported to the digestive tract as a nitrogen source for microorganisms, while some urea forms tubule fluid and is reabsorbed by the collecting tube of the kidney and returned to the blood.

Urea transporter is a membrane protein that mediates urea transmembrane transport along a concentration gradient, mainly including urea transporter B(UT-B) and urea transporter A(UTA) (65). UT-A1 is generally distributed in the apical membrane of collecting duct cells in the renal medullary loop (66), UT-A2 is distributed in the descending branch of the loop of the spinal cord (67), UT-A3 is distributed in collecting duct cells in the renal medullary loop basolateral (68), and UT-B1 is mainly distributed in the descending branches of straight small vessels of the nephron $(69,70)$.

In mouse kidneys, after the deletion of UT-A1 and UT-A3 genes, urine nitrogen excretion increased significantly. After the deletion of UT-B genes, urea in ascending branches of straight small vessels could not penetrate to descending branches of straight small vessels, and the concentration of urea in inner myelin decreased, leading to a decrease in urea circulation in the kidney (71). In conclusion, UT-B, UT-A1, and UT-A3 play irreplaceable roles in the renal urea cycle.

Aquaporin (AQP) is a membrane protein that regulates the infiltration of water into and out of cells (72). It is embedded in the cell membrane and controls the entry and exit of water molecules. Its mechanism of action is similar to urea transporter. So far, 13 aquaporin subtypes, namely AQP1-AQP12, have been identified in animals, but only AQP3, AQP7, AQP9, and AQP10 have clear permeability to urea, which are collectively referred to as water-glycerin channel (AQGP) protein (73-75). Studies have shown that AQGP can also mediate urea transport $(76,77)$.
In addition to excreting nitrogen, urea also mediates urine concentration through specific urea transport proteins $(78,79)$. The establishment of the renal medullary osmotic gradient is a necessary condition for the formation of concentrated urine. The active reabsorption of $\mathrm{NaCl}$ in the crude segment of the ascending ramus of the medullary loop is the main driving force for the establishment of the medullary osmotic gradient. Urea and $\mathrm{NaCl}$ are the main solutes for the establishment of a medullary osmotic gradient.

Proximal tubules are moderately permeable to urea and can reabsorb up to $50 \%$ of filtered urea. The collecting tubes in the distal convoluted tubules, cortex, and outer medullary part of the ascending branch of the loop are almost opaque to urea. As the tubule fluid flows through these areas, the water is reabsorbed by collecting tubes in the cortex and the outer medulla, and the concentration of urea in the tubule fluid increases. The collecting tube in the inner medullary region contains UT-A1 and UT-A3, which are activated by several factors and promote the diffusion of urea into the interstitial fluid in the inner medullary region. Urea can re-enter the medullary loop and be reused with a high concentration in the inner medullary region. Urea in the interstitial fluid of the inner medullary is in equilibrium with urea in the collecting tube so that other substances in the interstitial fluid (such as $\mathrm{NaCl}$ ) are in equilibrium with other substances in the urine to facilitate urine concentration.

Urea transporters can be mediated by several factors in the renal microenvironment that increases urea transport. In short term rapid regulation, Vasopressin signals through two cAMPdependent pathways: protein kinase A and cAMP-activated exchange proteins (80), high osmotic pressure signals through increased protein kinase $\mathrm{Ca}$, and intracellular calcium (81), thereby increasing UT-A1 and UT-A3 phosphorylation and urea transport (82-84). Vasopressin increases the abundance of UT-A1 and UT-A3 proteins in long-term regulation (85). In addition, urea transporters are affected by low-protein diets $(86$, $87)$, adrenal steroids (86, 88), hypokalemia (86), and acidosis (87).

\section{Ammonia}

Renal ammonia metabolism plays an important role in the maintenance of acid-base homeostasis (88). Almost all urinary ammonia is produced in the kidney, and glutamine in the blood flows through the kidney and is broken down into ammonia in the tubular epithelial cells (89). Urinary ammonia is mainly produced by the decomposition of glutamine, and a small amount comes from the catabolism of other amino acids (90).

In proximal tubules, glutamine uptake requires complete metabolism of glutamine through the involvement of root tip $\mathrm{Na}+$ dependent neutral amino acid transporter- 1 and basolateral sodium-coupled neutral amino acid transporter-3 (SNAT3) to produce two $\mathrm{NH} 4+$ and two HCO3- ions per glutamine (91). The resulting bicarbonate then passes through the basolateral membrane into the blood vessels via the electric-sodium coupled bicarbonate cotransporter isoform 1A (NBCE-1A).

Ammonia reabsorption occurs in the ascending part of the medullary loop. Ammonia is reabsorbed as $\mathrm{NH} 4+$ mainly 
through the transporter NKCC2 and then transported by NHE4, a sodium-hydrogen exchanger on the basolateral membrane (92). NH4+ is a weak acid, and intracellular acidification inhibits ammonia reabsorption (93). Sodium bicarbonate enters cells through electrically neutral sodium-sodium bicarbonate cotransporter subtype 1 (NBCn1) on the basolateral membrane, which appears to buffer intracellular acidification and promote ammonia reabsorption (94).

The collecting tube secretes large amounts of ammonia. The secretion of $\mathrm{NH} 3$ is accompanied by the secretion of $\mathrm{H}+(95)$. $\mathrm{NH} 3$ secretion seems to be related to the transport of ammoniaspecific transporters Rhbg and Rhcg expressed on the collector tube $(96,97)$. In addition, $\mathrm{Na}+\mathrm{K}+-\mathrm{ATPase}$ proteins are present on the basolateral side of collecting duct cells, which are involved in ammonia secretion of the intramedullary collecting duct through their ability to transport NH4+ (98).

In summary, ammonia in renal tubular epithelial cells has two pathways: on the one hand, it is discharged into the tubular fluid and excreted in urine; the other is reabsorbed into the blood. $\mathrm{NH} 3$ easily passes through the biofilm, while NH4+ does not, so the path of ammonia in the kidney depends on the relative $\mathrm{PH}$ of blood and tubular fluid. The PH of blood is generally constant, and therefore actually depends on the $\mathrm{PH}$ of the tubule fluid. When the $\mathrm{PH}$ value of the tubule fluid is acidic, the $\mathrm{NH} 3$ discharged into the tubule fluid combines with $\mathrm{H}+$ to form $\mathrm{NH} 4+$ and is discharged with urine. If the $\mathrm{PH}$ value of the tubule is high, NH3 is easily reabsorbed into the blood.

Metabolic acidosis can affect ammonia metabolism. During metabolic acidosis, acidosis stimulates the degradation of skeletal muscle protein, which binds to intrahepatic glutamine and increases extrarenal glutamine, leading to increased glutamine flow through the kidneys and increased urinary ammonia production $(99,100)$. The kidneys remove excess acid from the body by increasing ammonia metabolism (101). Notably, glucocorticoids can modulate ammonia excretion induced by acidosis, possibly by stimulating acidosis-induced extrarenal glutamine increase $(102,103)$.

Hypokalemia also results in altered ammonia metabolism in the kidneys. Metabolic alkalosis of hypokalemia is often associated with increased bicarbonate production (104). In both adults and children, increased ammonia excretion due to hypokalemia can lead to a negative nitrogen balance and impair health (105).

In addition, a protein diet also regulates ammonia excretion. A high protein diet, especially the intake of sulfur-containing amino acids, lowers PH and promotes ammonia excretion (106). Conversely, a low protein diet reduces ammonia excretion (107).

\section{$\mathrm{H}_{2} \mathrm{O}, \mathrm{Na}+$}

Water is filtered through the glomerulus and reabsorbed by the renal tubules. The glomerular filtration of protopuria was about $170-180 \mathrm{~L} / \mathrm{d}$, and the final urine was about $1.5 \mathrm{~L} / \mathrm{d}$. The reabsorption of water by the kidney can be divided into two forms: passive absorption and active absorption. About $90 \%$ of tubule fluid is reabsorbed in renal tubules, and proximal convoluted tubules reabsorb glucose, amino acids, electrolytes, and other substances, and reabsorb water by an osmotic pressure gradient, which is the main form of passive water absorption, accounting for about $80 \% \sim 90 \%$ of water reabsorption (108). The rest are absorbed actively in the medullary loops of renal tubules, distal convoluted tubules, and some collecting tubules, which are regulated by $\mathrm{ADH}$.

There are mainly 8 aquaporins in the kidney, which are AQP1, AQP2, AQP3, AQP4, AQP5, AQP6, AQP7, and AQP11. AQP1 is located at the top of proximal renal tubular epithelial cells, basolateral membrane, and descending branch of the medullary loop. AQP2, AQP3, AQP4, AQP5, and AQP6 are located in the collecting duct, AQP7 is distributed in the brush edge of the proximal convoluted tubule, and AQP11 is located in the endoplasmic reticulum of the proximal tubule cells.

$\mathrm{ADH}$ binds with AQP2 in the basement membrane of renal collecting duct epithelial cells to promote the generation of cAMP, activate adenosine cyclase in the perimembrane of tubular cells, increase intracellular cAMP, and then activate protein kinase, phosphorylation of protein located at the luminal surface of the plasma membrane of epithelial cells, and thus increase membrane permeability to water.

It is believed that the water metabolism of the kidney is related to the ball-tube balance. The colloid osmotic pressure in peritubular capillaries can regulate the reabsorption of sodium and water in proximal convoluted tubules. When the glomerular filtration rate (GFR) increases, the filtration excretion fraction (GFR/RPF) also increases. Due to the decrease of protein content in the filtrate, the protein concentration in the blood flowing into the capillaries around the renal tubules increases, and the colloid osmotic pressure in the capillaries also increases, thus promoting the reabsorption of sodium and water in proximal convoluted tubules. In addition, the hydrostatic pressure of peritubular capillaries also regulates the reabsorption of sodium and water in proximal convoluted tubules.

On the other hand, when GFR increased, the amount of $\mathrm{Na}+$ passing through the macula densa also increased, thus increasing the secretion of renin and angiotensin formation in parabulbar cells. Increased angiotensin-2 (AT-2) causes constriction of the entering arterioles, which results in a decrease in GFR and restores the ball-tube balance. Conversely, when GFR decreases, AT-2 production decreases, which causes dilation of the entering arterioles and increase of GFR, and restores the bulbal-tubular balance.

\section{Glucose}

Renal regulation of glucose metabolism mainly includes gluconeogenesis, glomerular glucose filtration, and proximal convoluted tubules glucose reabsorption. In the fasting state of normal individuals, the kidney produces $15-55 \mathrm{~g} / \mathrm{d}$ glucose through gluconeogenesis, accounting for about $20 \%-25 \%$ of all endogenous glucose. Renal gluconeogenesis is further increased after eating. Renal gluconeogenesis occurs mainly in the proximal convoluted tubules of the renal cortex and is regulated by insulin and catecholamines (109).

Under physiological conditions, the glomerular filtration of approximately $180 \mathrm{~g}$ of glucose per day is followed by almost 
complete reabsorption in the proximal convoluted tubules, so urine glucose monitoring should be negative. However, when plasma glucose concentrations reach nearly $10.0 \mathrm{mmol} / \mathrm{L}$, the renal glucose threshold will be exceeded, resulting in detectable glucose in urine (110).

The renal glucose reabsorption process is completed in the proximal convoluted tubule S1-S3 segment. The Na+ is pumped out of the cells and into the interstitial fluid by the Na+-k-ATP pump located in the basolateral membrane of renal tubules, thereby reducing the concentration of sodium ion in the cells and forming an electrochemical gradient of about $-70 \mathrm{mV}$. Glucose in the tubule fluid is actively transported to renal tubule cells by the sodium glucose cotransporter (SGLT) in a secondary, inverse concentration gradient. Finally, the glucose transporter (GLUT) binds glucose and changes its conformation, and glucose is then returned to the blood via facilitated diffusion from renal tubule cells (111).

SGLT belongs to the SLC5 gene family. SGLT1 and SGLT2 play a role in glucose reabsorption, and their differences in expression and the driving force of their cotransport function help to minimize glucose loss from urine. SGLT2, with high volume and low affinity, is mainly distributed in the proximal S1 segment of the proximal convoluted tubules of the kidney and combines actively transported sodium ions and glucose into the blood circulation in a ratio of 1:1, playing a major role in the renal glucose reabsorption function. SGLT1 is mainly distributed in the brush edge of intestinal mucosal epithelial cells and plays an important role in intestinal glucose and galactose absorption. SGLT1 is also expressed in the distal S3 segment of the proximal convoluted tubules of the kidney with a higher affinity than SGLT2. Glucose that is not bound by SGLT2 is responsible for SGLT1, and glucose and $\mathrm{Na}+$ are reabsorbed into the blood in a ratio of 1:2 (109).

Glucose transporter 1 (GLUT1) and GLUT2 are mainly related to the process of renal glucose reabsorption in the GLUT family. GLUT2 is expressed in the basolateral membrane of renal tubular cells in the S1 segment and is responsible for releasing glucose reabsorbed by SGLT2 into the blood through facilitated diffusion. GLUT1 is responsible for the release of glucose from small tubules into the blood at the proximal convoluted tubule S3 segment (112).

\section{Amino Acids}

Amino acid metabolism is closely related to the kidney. On the one hand, the absorption, release, metabolism, and excretion of amino acids by the kidney can effectively regulate the level of amino acids in the circulation system and the transport of amino acids between organs. On the other hand, orderly amino acid metabolism is beneficial to regulate renal hemodynamics and protein synthesis, maintain the integrity of renal function, and environmental acid-base balance in the body. Under the normal physiological state, the kidney mainly absorbs glutamine, citrulline, phenylalanine, S-adenosine homocysteine, and proline from the blood, and participates in the synthesis and release of serine, tyrosine, arginine, cysteine, and a small amount of threonine and lysine.
After the kidney absorbs glutamine from the blood, NH4+ and glutamate are mainly metabolized by phosphate-dependent glutamine enzyme, and only a small amount of them metabolized by $\gamma$-glutamine transferase in the distal tubules (113). Under the normal physiological state, about 70\% OF NH4 + enters the renal vein, and the rest is discharged through urine (114). When PH in the kidney increases, a high concentration of $\mathrm{NH} 4+$ inhibits glutaminase activity and increases $\mathrm{NH} 4+$ excretion to maintain acid-base balance in the body.

Citrulline is a nitrogenous product of glutamine metabolism in the intestinal tract. Most citrulline is synthesized in the intestinal tract and absorbed by the kidney (115). After the kidney absorbs a large amount of citrulline from the blood, arginine is synthesized and released into the blood with the participation of arginine succinic acid synthase and succinic acid lyase, which accounts for $10-20 \%$ of the total plasma arginine (116). Compared with the normal diet, intestinal arginine absorption is reduced in the low-protein diet, resulting in reduced urea synthesis in the liver. At the same time, because citrulline is not taken up by the liver, more citrulline in the lowprotein diet enters the kidney to synthesize arginine to maintain normal physiological function.

Arginine can be degraded to guanidine acetic acid and urea, or oxidized by nitric oxide synthase to citrulline and nitric oxide (NO). About $1 \%$ of the daily intake of arginine is used to metabolize NO, which is the main source of NO synthesis (117). NO is a small gas molecule that can regulate endothelial cell function and is of great significance in regulating glomerular hemodynamics, maintaining glomerular filtration rate, local vascular tension, and renal blood flow $(118,119)$.

Asymmetric dimethylarginine (ADMA), symmetric dimethylarginine (SDMA), and $\mathrm{N}(\mathrm{G})$-monomethyl-L-arginine (NMMA) are generated from arginine residues after methylation and proteolytic reaction. Both ADMA and NMMA can inhibit the activity of arginine synthase. NMMA is the precursor of ADMA and SDMA, and the content of NMMA is small but the inhibition effect is strongest. The kidney also plays an important role in the clearance of ADMA and SDMA. The clearance of ADMA mainly relies on renal conversion into citrulline and dimethylamine, and the remaining small amount of ADMA is excreted through urine, while SDMA is mainly cleared through renal excretion (120).

S-adenosine homocysteine is a by-product of methionine methyl transfer reaction and a precursor of homocysteine synthesis. The arteriovenous difference of S-ADENosine homocysteine was up to $40 \%$, indicating that the kidney is the main excretion site of S-adenosine homocysteine (121).

Tyrosine, as a non-essential amino acid, can be synthesized by phenylalanine 4-hydroxylase catalyzed by phenylalanine as a substrate in the body. The synthesis process of tyrosine was first discovered in the liver, and it can also be synthesized in the renal cortex in the later study (122). Moreover, tyrosine synthesized by the kidney is the main source of maintaining the level of tyrosine in the circulatory system (123). Glycine is taken up by the kidneys to synthesize serine, which only accounts for $5-7 \%$ of the total amount of serine in the body. High arginine is mainly 
derived from lysine in the kidney, which can increase intracellular arginine concentration, promote the effective synthesis of NO and improve the dysfunction of endothelial cells and cardiomyocytes (124).

\section{Causes of Renal Microcirculation Disorders}

Dietary preferences can cause gastrointestinal microbiota imbalance and translocation, resulting in renal microcirculation disorders. For example, a high-salt diet can induce oxidative stress in the kidney, resulting in increased renal perfusion pressure and immune cell infiltration, thus leading to kidney damage $(125,126)$. Meanwhile, under high-salt conditions, serum and glucocorticoid-regulated kinase 1 (SGK1)-mediated phosphorylation of forkhead box of transcription factors $\mathrm{O} 1$ (FOXO1) and forkhead box of transcription factors $\mathrm{O} 3$ (FOXO3) may lead to instability of Foxp3, thus reducing the inhibitory function of Treg cells (127) (Figure 4B). A high protein diet leads to increased urea production in the body. Excessive urea will lead to uremia toxin production in the kidney (128), thus changing the integrity of the intestinal barrier, resulting in the migration of intestinal flora into the blood, resulting in inflammation and cardiovascular diseases $(129,130)$ (Figure 1).

When the imbalance and displacement of microbial flora, a stressor, appears, it will stimulate the activation of the stress response mechanism related to metabolism, leading to excessive passive and active absorption of nutrients by the human body. Excessive absorption of nutrients cannot be efficiently and timely metabolized by the body, easy to lead to nutrient metabolism disorder. For example, lipid substances (triglyceride, cholesterol, etc.), glucose, amino acids, etc., and the disorder of metabolism of these intermediates lead to the impairment of the morphology and function of Treg cells (131-133), the blockage of renal capillaries, and then the occurrence of renal microcirculation disorders (134).

Disturbances in the microcirculation of renal resident cells (RTECs and MCs) impair the exchange of cells with external substances, leading to metabolic disturbances in renal cells (135). Due to the tiny blood vessels front-end blood-supply artery atherosclerosis in silt, the various cells of the kidney can't get enough nutrients and energy supply, leading to large proteins, lipids, creatinine, urea, renin, prostaglandins, mineral ions, etc. cannot be effectively out of shipping, and metabolism thus can lead to kidney tissue cell metabolism disorder. For example, renal tissue ischemia and hypoxia activate hypoxia-inducible factor $1 \alpha$ (HIF-1 $\alpha$ ) and destabilize Foxp3 expression, thus inhibiting Treg cell proliferation (136) (Figure 4B).

\section{Treg Cells Metabolism}

Cell metabolism is the core of T cell differentiation (137). Resting $\mathrm{T}$ cells require little energy production or consumption; however, after activation, their energy demand increases significantly, and they use glucose, amino acids, and fatty acids to meet this requirement $(138,139)$. An overview of the metabolic pathways is shown in Figure 3. Treg cells mainly utilize fatty acid and pyruvate oxidation (mitochondrial oxidative metabolism) to produce energy, which has a different signal and metabolic characteristics from other T cells (139).

\section{Glucose Metabolism in Treg Cells}

Glucose is required for the activation and proliferation of Treg cells. They can make use of glycolysis and oxidative phosphorylation for energy production (140). Glycolysis occurs in the cytoplasm by converting glucose to pyruvate (producing two ATP molecules), which is converted to lactate by lactate dehydrogenase A (LDH-A), or to acetyl-CoA by pyruvate dehydrogenase $(\mathrm{PDH})$, which then travels to the mitochondria to participate in the tricarboxylic acid (TCA) cycle, producing ATP (36 molecules) through oxidative phosphorylation (141). Moreover, the pentose phosphate pathway (PPP) that branches from the glycolysis pathway converts glucose-6-phosphate to ribose-5-phosphate for the synthesis of nucleotides.

Foxp3 itself inhibits glycolysis and promotes oxidative phosphorylation (OXPHOS), while Foxp3 deficiency dysregulates mammalian target of rapamycin complex 2 (mTORC2) and promotes glycolysis $(132,142)$. Upregulation of GLUT1 in Treg cells inhibited Foxp3 expression (142, 143). A study showed that Treg cells had higher levels of $\mathrm{C} 2$ and $\mathrm{C} 4-\mathrm{OH}$ carnitine, higher expression of fatty acid transport protein carnitine palmitoyltransferase 1A (CPT1A) and electron transport chain component cytochrome $\mathrm{C}$, and lower levels of GLUT1, a key protein expressed in pyruvate, lactic acid, and glycolysis pathways, suggesting that the energy of Treg cells depends more on oxidative phosphorylation than glycolysis (144). Moreover, some studies have shown that a high glycolysis rate is not conducive to the differentiation of Treg cells. Conversely, inhibition of glycolysis can promote the formation of Treg cells $(145,146)$. It can be explained because, mechanically, glycolysis requires activation of MYC proto-oncogene (MYC) and Foxp3 binds to the promoter of MYC to inhibit expression of MYC and MYC-dependent transcripts (147).

The glycolytic enzyme enolase 1 , relocating from the cytoplasm (where it regulates the glycolysis pathway) to the nucleus, is required for the induction and function of human pTreg cells following suboptimal $\mathrm{T}$ cell receptor (TCR) stimulation of $\mathrm{T}$ cells in the periphery (138). In the nucleus, enolase 1 binds to the epigenetic promoter region of the Foxp3 gene to inhibit transcription of specific Foxp3 exon-2 (E2) (148) (Figure 4B).

As mentioned above, pyruvate can be converted to lactic acid by LDH-A under anaerobic conditions. For example, in ischemic tissue, due to the accumulation of lactic acid caused by ischemia and hypoxia, lactic acid mediates increased HIF- $1 \alpha$ production and inhibits pTreg function, which may lose the metabolic advantage of function under low glucose conditions (149). However, in prostate cancer models, lactic acid produced by cancer-associated fibroblasts (CAFs) stimulates Treg proliferation by promoting Foxp3 activation (150). These two contradictory results are currently unclear and may be interpreted that lactic acid increases the number of Treg cells, and the inhibitory ability of Treg cells decreases during Treg proliferation. In addition, lactic acid can also be converted to pyruvate through lactate dehydrogenase B (LDH-B) (151). One study showed that in tumor cells, oxidation of lactic acid to pyruvate changed the ratio of $\mathrm{NAD}+\mathrm{NADH}$, thereby activating 


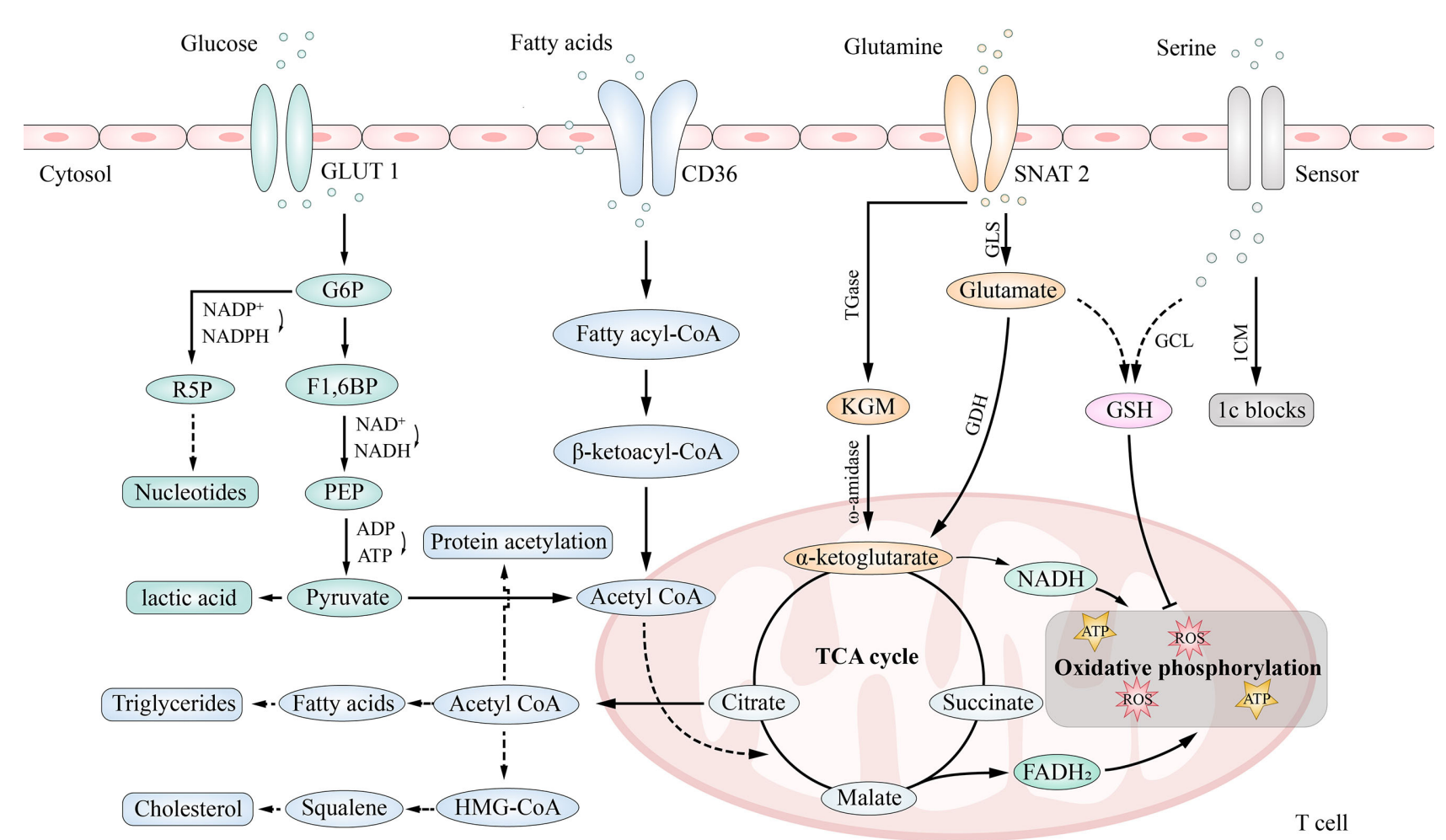

FIGURE 3 | Main metabolic pathways in T cells. T cells generate ATP by glycolysis and oxidative phosphorylation. Pentose phosphate pathway (PPP) is a branch of glycolysis pathway. Cells also generate energy by using glutamine (Gln), which is metabolized by glutaminolysis, and lipids( $\beta$-oxidation). Additionally, Serine enters the cell from the extracellular space and then, either enters one-carbon metabolism (1CM), which generating one-carbon (1C) building blocks for anabolism, or produces the ROS scavenger glutathione (GSH).

the Silencing information regulator 2 related enzyme $1 /$ proliferator-activated receptor $\gamma$ coactivator- $1 \alpha$ (Sirtuin1/PGC$1 \alpha)$ axis of NAD+ dependent deacetylase, enhancing the mitochondrial metabolism and invasion ability of prostate cancer cells (152).

Moreover, glycolysis of Treg cells can be inhibited by the binding of effector molecules on cytotoxic $\mathrm{T}$ lymphocyte antigen 4 (CTLA4) and programmed death 1 (PD-1) found on the surface of Treg cells (153). In turn, the inhibition of glycolysis can also suppress the migration of Treg cells, and to meet their glucose demand, Treg cells upregulate insulin receptors (154). Several recent studies have indicated that Treg mobility is regulated by the metabolism of glucose through glycolysis, via glucokinase (GCK) activation and phosphoinositide 3-kinase (PI3K)- protein kinase B (Akt) pathways (155).

\section{Fatty Acid Metabolism in Treg Cells}

Fatty acids are transformed into acyl-coenzyme A (FA-CoA) in the cytoplasm, and FA-CoA enters mitochondria under the action of carnitine palmityl transferase I (CPT I) and carnitine palmityl transferase II (CPT II) (156). After $\beta$-oxidation, acetylCoA is formed and enters the tricarboxylic acid cycle. Fatty acid oxidation requires the involvement of four enzymes that produce $\mathrm{NADH}$ and xanthine dinucleotide (FADH2), which are used by the electron transport chain to produce ATP (157). Acetyl-CoA in the mitochondria is transported to the cytoplasm through the citrate-pyruvate cycle for the synthesis of fatty acids, triglycerides, cholesterol, and protein acetylation (158). The fatty acid synthesis requires acetyl CoA carboxylase 1 (ACC1) (159), and the cholesterol synthesis requires the participation of acetyl-CoA and hydroxymethylglutaryl-CoA (160).

Acetyl-CoA may promote the acetylation of Foxp3 protein by activating lysine acetyltransferases (KATs) and prevent Foxp3 protein ubiquitination degradation, thus helping to maintain the function of Treg cells (161), while NAD+/NADH activates the deacetylase activity of Sirtuin-1 and inhibits Foxp3 protein (162) (Figure 4B). CPT I, a rate-limiting enzyme in fatty acid oxidation (FAO), enhances FAO efficiency, and adenosine monophosphate activated protein kinase (AMPK) induces CPT I expression $(163,164)$. In fatty acid synthesis (FAS), acetyl-CoA is carboxylated into malonyl-CoA ACC1, the rate-limiting enzyme, and its phosphorylation can inhibit FAS (165). ACC1 inhibits the polarization of Treg cells and inhibition of ACC1 can promote the induction of Treg cells in vivo and in vitro (166). The inhibition of Fatty acid Binding protein 5 (FABP5) in Treg cells can trigger the release of mitochondrial DNA (mtDNA) and the subsequent cyclic GMP-AMP synthase-stimulator of interferon genes (cGAS-STING) dependent type I interferon (IFN) signal transduction, thus inducing the production of the regulatory cytokine interleukin-10 (IL-10) and promoting the 


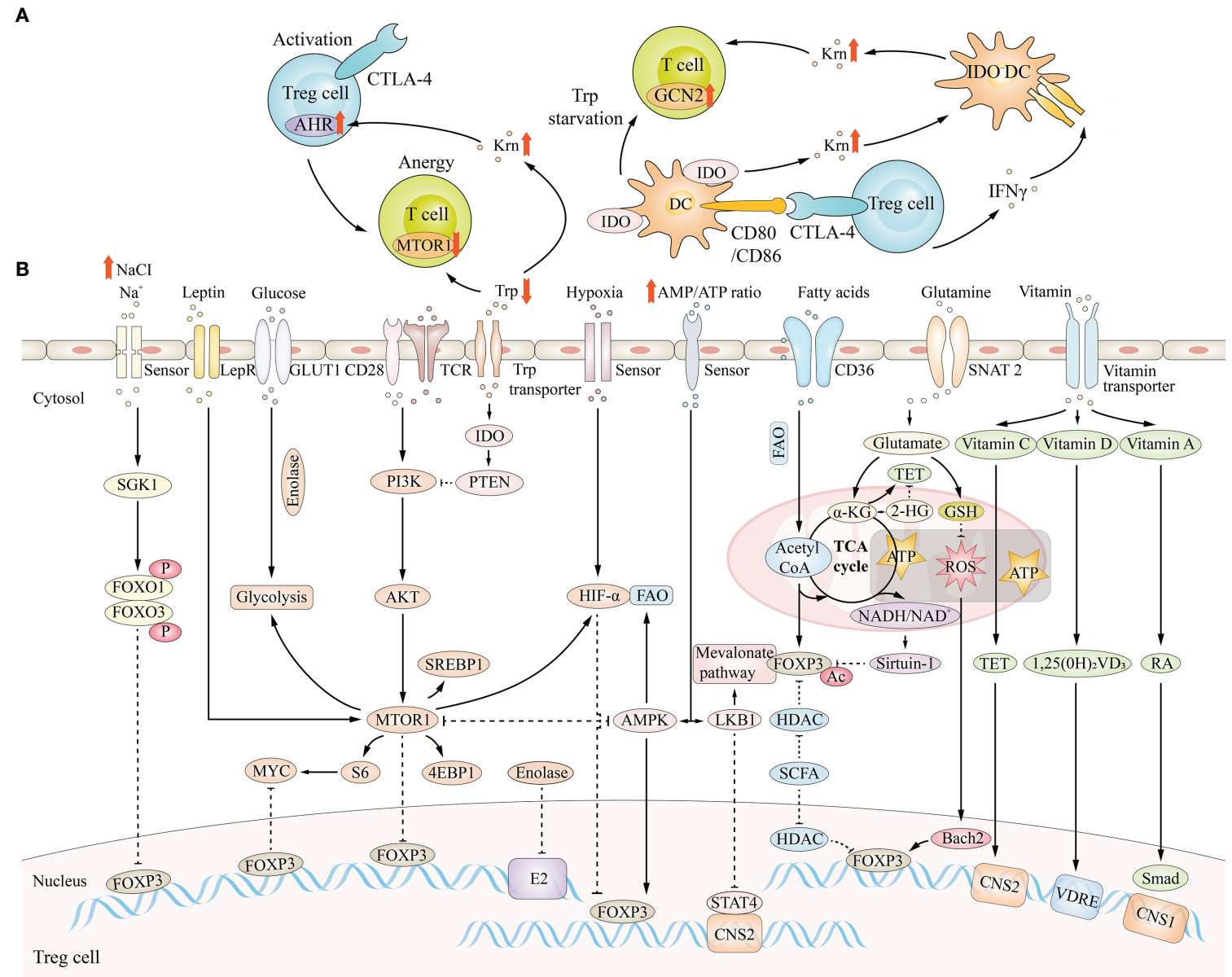

FIGURE 4 | Metabolic regulation in Treg cells. (A) Regulatory T cells have a crucial role in establishing an IFN- $\boldsymbol{\gamma}$-rich environment that activates Indoleamine 2, 3dioxygenase (IDO)- and IDO+ dendritic cells (DCs), either by forward signaling to DCs or by direct production of the cytokine. (B) Cell-intrinsic metabolic programs and environmental factors that can modulate FOXP3 expression ultimately affect Treg cells fate.

inhibitory activity of Treg cells, suggesting that FABP5 maintains mitochondrial integrity and can regulate the function of Treg cells (167).

TTreg cells and pTreg cells together constitute the Treg cell population in vivo, and they have different metabolic characteristics. PTreg cells can utilize both the mevalonate pathway and end products of glycolysis for the synthesis of fatty acids (168). During the induction of Treg cells in the periphery, increased expression of Foxp3 reprograms the cell to exert action in low-glucose environments (169). Therefore, the cell preferentially metabolizes lipids over glucose to maintain the suppressive function of $\mathrm{p}$ Treg cells, which maintains peripheral immune tolerance during tissue injury, even under metabolically challenging conditions (e.g., in ischemic tissues) (170). TTreg cells are induced and maintained by exogenous fatty acids (138). For example, Treg cells in adipose tissue express leptin receptors, and the leptin/leptin receptor axis induces an mTOR metabolic state to inhibit Foxp3 expression $(171,172)$ (Figure 4B). In addition, Treg cells in tissues are involved in suppressing inflammation and have regenerative functions in wound healing (173).

Short-chain fatty acids (SCFAs), including acetic, propionic, and butyric acids, are produced by dietary fiber and other undigested carbohydrates in the colon (174). At the molecular level, SCFAs inhibit histone deacetylase (HDAC) in Treg cells in colon tissue and enhance histone acetylation at Foxp3, promoting pTreg cells formation (175). Interestingly, SCFAsinduced IL-10+pTreg cells were not associated with suppression of the immune response in kidney hydronephrosis (C2RD), since the number of Th1 and Th17 cells increased as the number of regulatory $\mathrm{T}$ cells increased, suggesting a general increase in SCFAs-induced T-cell response in C2RD (176).

MTOR drives FAS and cholesterol production in Treg cells, while SCFAs can activate the mTOR pathway $(177,178)$. Studies have shown that the activity of mTOR- S6 kinase (S6K) in SCFAs-induced Treg cells is increased, revealing that SCFAs may regulate Treg cells through the mTOR-S6K pathway $(173,176)$. Meanwhile, with the activation of the mTOR pathway, SCFAs 
also enhance the activity of signal transducers and activators of transcription 3 (STAT3) (176). In addition, impaired Treg homeostasis in mTOR deficient mice was associated with defective lipid biosynthesis (177).

OX40 can also trigger the proliferation of lipid-rich Treg cells in naive mice (168). It has been found that OX40/OX40L signaling occurring in the hepatocellular carcinoma microenvironment may be directly involved in the FAS of Treg cells (179).

In addition, researchers found high expression of peroxisome proliferation-activated receptor gamma (PPAR $\gamma)$ in TUM-Treg cells (Treg cells extracted from the tumor bed) (168). PPAR $\gamma$ is a nuclear factor that controls fatty acid uptake and FAS in adipose tissue (180), and it is believed that excessive FAS induces PPAR $\gamma$ expression.

\section{Amino Acid Metabolism in Treg Cells}

Amino acids also play a crucial role in Treg cell regulation. 2Hydroxyglutarate (2-HG), the metabolite of glutamine, can lead to hypermethylation of the Foxp3 gene locus and then suppress Foxp3 transcription (181); this action further inhibits Treg generation. Tryptophan can produce kynurenine, which is able to combine with the aryl hydrocarbon receptor and then accelerate pTreg generation (182). Moreover, the enzymes that pTreg express participates in the synthesis of amino acids, which play an essential role in the proliferation and function of Treg cells $(183,184)$. Indoleamine-2,3-dioxygenase (IDO) is expressed on Treg cells and can inhibit mTOR signaling by phosphatase and tensin homolog (PTEN), thus promoting the generation of Treg cells (185). After tryptophan is metabolized by IDO, the metabolite kynurenine will bind to the transcription factor aryl hydrocarbon receptor (AHR), thereby activating Foxp3+ Treg cells (186), and these Treg cells will reverse or inhibit the activity of effector T cells. Kynurenine could also recruit other cell types to the regulatory response, including dendritic cells (DCs), in which the function of IDO is inhibited posttranslationally (187) (Figure 4A).

\section{mTOR/AMPK Signal Pathway in Treg Cells}

mTOR, a member of the phosphatidylinositol 3-kinase-related kinase family, induces the expression of multiple genes that play a key role in a variety of metabolic processes and is necessary for Treg differentiation, function, and survival (177) The increase in mTOR pathway activity has a negative impact on the generation and function of Treg cells (188) Transient TCR stimulation can induce the PI3K-Akt-mTOR signaling pathway to antagonize the expression of Foxp3 (189).

MTOR consists of the protein complex mTOR complex 1 (mTORC1) and mTOR complex 2 (mTORC2). Increased mTORC1 activity is not only a typical characteristic of Th1 cells and Th17 cells differentiation (190) but also has a negative impact on the generation and function of Treg cells (188). The mTORC1 signaling pathway in Treg cells is inhibited by serine/ threonine protein phosphatase $2 \mathrm{~A}$ ( $\mathrm{PP} 2 \mathrm{~A})$. In the absence of $\mathrm{PP} 2 \mathrm{~A}$, the glycolysis and oxidative phosphorylation rates of Treg cells were increased (191), as well as the expression of small subunit 1 (LAT1), a neutral amino acid transporter dependent on mTORC1 activity (177). The increase of glycolysis, oxidative phosphorylation, and LAT1 expression made Treg cells develop into Teff cells. However, whether PP2A has an effect on mTORC2 requires further study (192).

In fact, the relationship between mTORC1 and mTORC2 remains at odds. Aysegul V. Ergen et al. suggested that rapamycin inhibited mTORC1 but not mTORC2 (193). However, Rosner $\mathrm{M}$ et al. suggested that chronic treatment with rapamycin also inhibited mTORC2 activity (194). Takahito Kawata et al. argued that mTORC1 negatively regulates mTORC2 (195); Wang et al. believed that mTORC1 maintained mTORC2 activity, while mTORC2 negatively regulated mTORC1 signal activation (196). These differences may be related to researchers' experimental conditions and models, which need further study.

IDO activity reduces local tryptophan availability in the vicinity of Treg cells in the tumor microenvironment (197). A low concentration of tryptophan inhibits mTORC2 through protein kinase and prevents its phosphorylation of Akt, which helps maintain the inhibitory function of Treg cells, suggesting that the MTORC2-Akt signaling pathway has a negative regulatory effect on the differentiation of Treg cells (198).

AMPK can be activated by Treg cells and can inhibit mTORC1, reduce the expression of GLUT1 and promote fatty acid oxidation (199). Liver kinase B1 (Lkb1) is considered to be an AMPK-independent metabolic sensor in Treg cells because it stabilizes the expression of Foxp3 by changing the methylation state of CNS2 (200).

\section{Other Metabolic Pathways in Treg Cells}

As mentioned above, SGK1-mediated phosphorylation of FOXO1 and FOXO3 may lead to instability of Foxp3 under high salt conditions, thus reducing the inhibitory function of Treg cells (127). However, in another study, high salt only inhibited the function of tTreg cells and had little effect on TGF- $\beta$-induced iTreg cell function (201). This may be due to the different disease models selected by the authors.

Excessive urea will lead to uremia toxin production in the kidney, studies have shown that uremia patients have reduced Treg cells numbers and impaired function $(202,203)$ However, the specific mechanism of how urea acts on Treg cells remains unclear.

HIF- $1 \alpha$, which is activated either directly by hypoxia or via mTORC1, destabilizes Foxp3 expression (204). Moreover, HIF$1 \alpha$ is downregulated by $2-\mathrm{HG}$ through inhibiting the activity of prolyl hydroxylase (205). The vitamin A metabolite RA increases Foxp3 gene expression by maintaining Smad activation (206). Vitamin C, together with Tet methylcytosine dioxygenase, increases Foxp3 expression (207). The vitamin D3 metabolite 1,25(OH)2VD3 stabilizes Foxp3 gene expression by maintaining the state of the VDRE region (208) (Figure 4B).

In addition, we summarized some drugs that target metabolic pathways; for example, 2-deoxy-d-glucose (2-DG), a drug that can compete with glucose in binding to hexokinase II (HKII) to inhibit cellular glycolysis activity and regulate the glycolytic pathway, induces Treg cell differentiation and suppression and alleviates the progression of systemic lupus erythematosus (SLE) 
in TC mice (209). More drugs and further details are given in Table 1. These drugs can change the number and function of Treg cells by targeting their respective metabolic pathways, thus alleviating the progression of diseases.

\section{The Role of Treg Cells in Acute Kidney Injury}

Acute kidney injury (AKI) refers to a clinical syndrome in which renal function declines rapidly in a short period caused by a sudden or continuous decline in the glomerular filtration rate (212, 213). AKI has multiple etiologies, with hypovolemia, ischemia-reperfusion injury (IRI), exposure to nephrotoxic agents, and sepsis among the major causes. The immune response mediates the various stages of the occurrence, development, and repair of AKI, and Treg cells play a significant role in the entire developmental stage of AKI (210, 214). Although there is no clinical study of Treg cells in AKI, they have been indicated to protect and repair the kidney after AKI in animal models (215).

Abnormal metabolism in AKI affects the signaling pathways and the extracellular matrix environment, thereby affecting the differentiation of Treg cells. In AKI patients, due to mitochondrial damage and impaired FAO metabolism, as well as decreasing peroxisome proliferation-activated receptor alpha $(\mathrm{PPAR} \alpha)$ activity and decreasing peroxisome PGC-1 expression, the accumulation of triglycerides in AKI patients result in obvious lipid metabolism abnormalities (216-219). Treg cells express G protein-coupled receptor 43 (GPR43) in mice, which

TABLE 1 | Inhibitors of the metabolic pathways, their influence on Treg cells and disease applied.

\begin{tabular}{|c|c|c|c|c|c|c|c|}
\hline $\begin{array}{l}\text { Related } \\
\text { Mechanism } \\
\text { Pathways }\end{array}$ & Drugs & Pharmacological Effects & $\begin{array}{l}\text { Influence on } \\
\text { Treg Cells }\end{array}$ & Other biological Functions & $\begin{array}{l}\text { Experimental } \\
\text { Subject }\end{array}$ & $\begin{array}{l}\text { Associated } \\
\text { Disease }\end{array}$ & Reference \\
\hline \multirow[t]{5}{*}{$\begin{array}{l}\text { carbohydrate } \\
\text { metabolism }\end{array}$} & CG-5 & Decrease Glut1 expression & $\begin{array}{l}\text { Increase Treg } \\
\text { cells } \\
\text { differentiation }\end{array}$ & $\begin{array}{l}\text { In vitro: block glycolysis in } \\
\text { CD4+ T cells }\end{array}$ & $\begin{array}{l}\text { Lupus-prone } \\
\text { mouse model }\end{array}$ & SLE & $(220)$ \\
\hline & 2-DG & $\begin{array}{l}\text { Compete with glucose in binding to HKII } \\
\text { to inhibit cellular glycolysis activity and } \\
\text { regulate the glycolytic pathway }\end{array}$ & $\begin{array}{l}\text { Induce Treg cells } \\
\text { differentiation and } \\
\text { suppression }\end{array}$ & $\begin{array}{l}\text { In vivo: dampen Th1 and Th17 } \\
\text { cells development }\end{array}$ & Lewis rats & GBS & $(221)$ \\
\hline & & & & $\begin{array}{l}\text { Decreased ECAR and OCR in } \\
\text { TC CD } 4+T \text { cells }\end{array}$ & TC mice & SLE & (210) \\
\hline & DCA & $\begin{array}{l}\text { Inhibit the dephosphorylation and } \\
\text { deactivation of PDC to keep PDC active }\end{array}$ & $\begin{array}{l}\text { Increase Treg } \\
\text { cells expansion }\end{array}$ & $\begin{array}{l}\text { Inhibit Th17 cells survival and } \\
\text { proliferation }\end{array}$ & $\begin{array}{l}\text { C57BL/6J } \\
\text { mice }\end{array}$ & EAE & $(222,223)$ \\
\hline & $\begin{array}{l}\text { Metho- } \\
\text { trexate }\end{array}$ & $\begin{array}{l}\text { Act by competitive inhibition of } \\
\text { dihydrofolate reductase to deplete One- } \\
\text { carbon metabolism }\end{array}$ & $\begin{array}{l}\text { Increase Treg } \\
\text { cells expansion }\end{array}$ & $\begin{array}{l}\text { Deplete purine biosynthesis } \\
\text { enzymes }\end{array}$ & $\begin{array}{l}\text { Patients with } \\
\text { RA and } \\
\text { healthy } \\
\text { controls }\end{array}$ & RA & $(224)$ \\
\hline \multirow[t]{4}{*}{$\begin{array}{l}\text { Lipid } \\
\text { metabolism }\end{array}$} & $\begin{array}{l}\text { Piogli- } \\
\text { tazone }\end{array}$ & $\begin{array}{l}\text { Activate PPAR } \gamma \text { and high affinity binding } \\
\text { to the PPAR } \gamma \text { ligand-binding }\end{array}$ & $\begin{array}{l}\text { Induce VAT Treg } \\
\text { cells }\end{array}$ & $\begin{array}{l}\text { Decrease the elevated serum } \\
\text { levels of both creatinine and } \\
\text { CK-MB }\end{array}$ & C57Bl/6 mice & Obesity & $(225,226)$ \\
\hline & $\begin{array}{l}\text { Sora- } \\
\text { phen A }\end{array}$ & $\begin{array}{l}\text { Lower cellular malonyl CoA, attenuate } \\
\text { DNL and the formation of fatty acid } \\
\text { elongation products derived from } \\
\text { exogenous fatty acids }\end{array}$ & $\begin{array}{l}\text { Induce Treg cells } \\
\text { differentiation }\end{array}$ & $\begin{array}{l}\text { In vivo: inhibit TH17 cell- } \\
\text { associated inflammatory } \\
\text { diseases }\end{array}$ & TACC1 mice & EAE & $(211,227)$ \\
\hline & TOFA & $\begin{array}{l}\text { Inhibit ACCA to decrease fatty acid } \\
\text { synthesis and induce caspase activation }\end{array}$ & $\begin{array}{l}\text { Inhibit Treg cells } \\
\text { proliferation }\end{array}$ & $\begin{array}{l}\text { In vitro: reduce the MCA38 cell } \\
\text { viability in a dose-dependent } \\
\text { fashion }\end{array}$ & $\begin{array}{l}\text { Tumor-bearing } \\
\text { mice }\end{array}$ & Tumor & $(171,228)$ \\
\hline & $\begin{array}{l}\text { Etomo- } \\
\text { xir }\end{array}$ & $\begin{array}{l}\text { Bind irreversibly to the catalytic site of } \\
\text { CPT- } 1 \text { to inhibit CPT- } 1 \text { and up-regulate } \\
\text { fatty acid oxidase activity }\end{array}$ & $\begin{array}{l}\text { Abrogate Treg } \\
\text { cells } \\
\text { development and } \\
\text { suppressive } \\
\text { function }\end{array}$ & $\begin{array}{l}\text { Reduce the production of pro- } \\
\text { inflammatory cytokines in MOG } \\
\text { specific T cells and promote } \\
\text { their apoptosis }\end{array}$ & $\begin{array}{l}\text { C57BL/6J } \\
\text { mice }\end{array}$ & MS & $(229,230)$ \\
\hline $\begin{array}{l}\text { Amino acid } \\
\text { metabolism }\end{array}$ & DON & $\begin{array}{l}\text { Inhibit glutaminase and glutamine } \\
\text { transporters }\end{array}$ & $\begin{array}{l}\text { Promote Treg } \\
\text { cells generation } \\
\text { and frequency }\end{array}$ & $\begin{array}{l}\text { Decrease IFN- } \gamma \text { production and } \\
\text { proliferation in activated CD4+ } \\
\text { and CD } 8+T \text { cells }\end{array}$ & C57BL/6 mice & $\begin{array}{l}\text { Skin and heart } \\
\text { transplantation }\end{array}$ & $(231,232)$ \\
\hline \multirow[t]{2}{*}{$\begin{array}{l}\text { mTOR/AMPK } \\
\text { signal } \\
\text { pathway }\end{array}$} & $\begin{array}{l}\text { Rapa- } \\
\text { mycin }\end{array}$ & $\begin{array}{l}\text { Block mTOR downstream targets, such } \\
\text { as p70S6K phosphorylation and } \\
\text { activation }\end{array}$ & $\begin{array}{l}\text { Enhance nTreg } \\
\text { cells proliferation } \\
\text { and function }\end{array}$ & $\begin{array}{l}\text { Suppress proliferation of CD4+ } \\
\text { CD25- effector T-cells }\end{array}$ & $\begin{array}{l}\text { Patients with } \\
\text { type } 1 \\
\text { diabetes and } \\
\text { healthy } \\
\text { controls }\end{array}$ & $\begin{array}{l}\text { Type } 1 \\
\text { diabetes }\end{array}$ & $(233-235)$ \\
\hline & $\begin{array}{l}\text { Metfor- } \\
\min \end{array}$ & $\begin{array}{l}\text { Activate AMPK in liver cells leads to } \\
\text { decreased ACC activity, induction of fatty } \\
\text { acid oxidation, and inhibition of } \\
\text { adipogenic enzyme expression }\end{array}$ & $\begin{array}{l}\text { Induce Treg cells } \\
\text { differentiation }\end{array}$ & $\begin{array}{l}\text { Inhibit IL-17, p-STAT3, and } \\
\text { p-mTOR expression }\end{array}$ & C57BL/6 mice & IBD & $(236,237)$ \\
\hline
\end{tabular}

2-DG, 2-deoxy-d-glucose; ACC, acetyl-coa carboxylase; CK-MB, creatine kinase-mb; DCA, dichloroacetate; DON, 6-diazo-5-oxo-L-norleucine; EAE, experimental autoimmune encephalomyelitis; ECAR, extracellular acidification rate; GBS, Guillain-Barré syndrome; IBD, inflammatory bowel disease; MS, multiple sclerosis; OCR, oxygen consumption rate; RA, rheumatoid arthritis; SLE, systemic lupus erythematosus; TOFA, 5-tetradecyl-oxy-2-furoic acid. 
when bound to SCFAs results in enhanced differentiation and function (238). Recent work by Field C. et al. demonstrated that inhibiting the lcFA-FAO metabolic pathway may be more favorable as an approach to increasing the suppressive function of Treg cells (167). It is plausible that various intermediates produced during FAO, such as acetyl-CoA, and reduced FADH/ NADH, could interfere with Treg cell function through yet unknown mechanisms (167). Mitochondrial dysfunction is also one of the important characteristics of AKI (239); the accumulation of cytochrome $\mathrm{C}$ in the mitochondria causes the oxidative respiratory chain to fail to proceed normally, and mitochondrial respiration is weakened, which further affects the metabolism of lactic acid in the kidney tissue, causing metabolic acidosis (240). In this situation, Treg cells can convert lactate to pyruvate. Moreover, Foxp3 can modulate LDH to prevent lactate formation and form pyruvate (241). While lactate may negatively impact $\mathrm{T}$-cell proliferation as a whole, it does not impact Treg cell immunosuppression (242). There are also serious changes in protein metabolism in AKI, and the rapid catabolism of proteins leads to a negative nitrogen balance (243). In a long-term high catabolic state, the activity and metabolism of Treg cells will be affected, resulting in a weakened immune response and anti-infection mechanism (244). Active metabolism in AKI will cause hypoxia, which is associated with increased levels of the HIF-1 complex (245). HIF-1 $\alpha$ forms a complex structure with its counterpart HIF-1 $\beta$, which then binds to specific hypoxic response elements (HREs) (243) to influence Treg cell metabolism/function.

\section{Ischemia-Reperfusion Injury (IRI)}

The phenomenon that after blood reperfusion is resumed under certain conditions, some animals or patients have cellular functional metabolic disorders and structural damage that are not reduced but aggravated this is called IRI (246). IRI is a vital cause of AKI and a serious complication secondary to major surgery (247). Endogenous Treg cells can mediate immune responses, reduce the existence of costimulatory molecules after renal IRI, and improve renal IRI (248). Oxidative stress, inflammation, and apoptosis are well-known characteristics of the kidney after AKI (249). In vitro and in mice, IRI causes persistent mitochondrial damage and energy loss (250), increased reactive oxygen species (ROS) generation, and decreased ATP synthesis in iTreg/pTreg cells. Upregulation of Treg cell lipogenic genes in the kidneys of IRI mice leads to an associated elevation of lipid deposition $(250,251)$, indicating the presence of excessive FAS in Treg cells of IRI mice. The tryptophan metabolite kynurenine was increased in plasma and kidney tissues from IRI mice $(250,251)$. After the elimination of pTreg/iTreg cells in renal IRI mice by anti$\mathrm{CD} 25$ + antibody in vivo and in vitro, renal injury and inflammation were aggravated, and renal function and mortality continued to deteriorate (252). Adoptive transfer therapy of iTreg cells after IRI can increase the repair rate of mouse kidneys (253). In addition (254), Treg effectively prevents the accumulation of neutrophils and mononuclear phagocytes during renal reperfusion, and its pathway has not been fully understood yet.

\section{Sepsis-Induced Acute Kidney Injury}

Severe sepsis can also lead to AKI (255). Although the pathophysiological mechanisms are not fully understood, it is clear that the inflammatory cascade characteristic of sepsis is associated with AKI (256). Different from AKI caused by IR, renal tubular cells in septic AKI are slightly vacuolated and a large number of renal tubular cells undergo apoptosis, without obvious renal tissue necrosis (257). In the septic AKI mouse model, renal tubular cell apoptosis was reduced and renal function was significantly improved after Treg cells were removed, which was completely contrary to the findings in IR mice, since the depletion of Treg cells led to the deterioration of renal function after IR (254). There was no significant change in renal function after IL-10 blockade in IR mice, but in septic AKI, renal function was significantly improved after IL-10 blockade, suggesting that IL-10 reduced the proliferation of Treg cells, thereby improving the survival rate of patients with sepsis (258). The opposite role of Treg cells in septic-induced AKI and IR-induced AKI maybe that Treg cells only play a protective role in aseptic inflammation-mediated AKI, which needs further study to explain.

\section{Cisplatin Nephrotoxicity}

Cisplatin, one of the most effective chemotherapeutic drugs, can induce damage in the renal vasculature, which leads to reduced blood flow and ischemic injury in the kidney, thereby inducing an AKI model (259). Cisplatin has been widely used to treat malignant tumors of various organs. It is known that cisplatin concentrates on epithelial cells in the proximal tubule S3 segment (260), where it induces necrotic and apoptotic cell death and is associated with an extensive pro-inflammatory immune response. Salt may ameliorate symptoms (261, 262). Some studies have shown nephrotoxicity in clinical trials of cisplatin chemotherapy (259), and the use of cisplatin is limited because of its nephrotoxicity (263). CD4+CD25+Foxp3+ Treg cells showed a protective effect in the cisplatin nephrotoxicity test in mice (264). Oxidative stress has been considered an essential component that results in cisplatin nephrotoxicity both in vivo and in vitro $(265,266)$. Cisplatin aggregates in the mitochondria of renal epithelial cells and disrupts the respiratory chain, resulting in a decrease in ATP production and an increase in ROS production, which cause inhibition of mitochondrial activation (259, 263, 264). Mitochondrial dysfunction and oxidative stress exist in cisplatin-mediated acute renal injury (267), which causes impaired synthesis of Treg cells (268).

With the in-depth understanding of AKI disease and Treg cells, AKI, which was previously thought to have little relationship with immune abnormalities, is partly caused by abnormal metabolism of immune cells, such as Treg cells. However, the immune cells involved in AKI disease are not only Treg cells. What is the proportion of Treg cells interacting with other immune cells in AKI disease? Does targeted Treg therapy for AKI affect other abnormalities in immune cell 
function? How do Treg cells affect intrinsic renal immune response in cisplatin-induced AKI? These all require followup research.

\section{The Role of Treg Cells Metabolism in CKD}

$\mathrm{CKD}$ is the chronic process resulting from a variety of kidney diseases, as well as a heterogeneous illness influencing the morphology and function of the kidney (269). A diverse set of components can activate various molecular mechanisms of kidney damage, such as genes, metabolism, autoimmunity, malignancy, toxins, and the environment (270). All these injuries contribute to different categories of vascular, glomerular, and tubulointerstitial renal diseases, which culminate in decreased kidney function and result in CKD syndrome (271).

Tissue damage in CKD is directly or indirectly mediated by the immune system, and the dysfunction of immune cells promotes CKD inflammation and renal fibrosis (272). Treg cells play a protective role in CKD by inhibiting inflammation and immunity, but the number of pTreg cells in the peripheral blood of CKD patients is significantly reduced (273). TGF- $\beta 1$ is an inducer of Treg cells, which are released after renal cell injury (274). Treg cells can be transformed into Foxp3+IL-17+ T cells under inflammatory conditions in the kidney and then produce a large amount of TGF- $\beta 1$, leading to CKD inflammation and renal fibrosis (275) (Figure 5). A study illustrated that an elevated ratio of Th17 cells and a reduced ratio of Treg cells exist in CKD patients, reflecting that an enhanced Th17/Treg cell rate is related to the progression of $\mathrm{CKD}$ and the severity of kidney disease (48).

The state of reduced renal function that results from CKD causes marked alterations in Treg cell metabolism. Typical alterations include increased intracellular ROS (276), high levels of 8-hydroxy-2 deoxyguanosine (8-OHdG) (277), enhanced carbohydrate metabolism (278), and abnormal lipid metabolism (279). ROS stabilize the nuclear factor of an activated $\mathrm{T}$ cell (NFAT) in the nucleus and bind to CNS2 to promote Foxp3 expression (280), and interestingly, it can directly inhibit the enzymatic activity of several elements in the cellular respiratory chain, while complex III per se is key to promoting Treg cell suppressive function $(242,281)$. 8-OHdG (277) is a marker of oxidative DNA stress. Oxidative stress can induce the activation of the PI3K/Akt/mTOR signaling pathway and induce the phosphorylation of mTOR in CKD patients (282), increasing mTOR activation in cells, which negatively affects the protective effect of Treg cells on the kidney. Dietary fiber, a kind of carbohydrate, can be converted into SCFAs, which are a main source of nutrients for Treg cells. Therefore, a high fiber diet can potentially attenuate systemic inflammation and CKD progression (278). Dyslipidemia in CKD patients is largely due to changes in low-density liptein cholesterol (LDL-C) levels (283). Researchers have indicated that proteasome inhibition by ox-LDL leads to CD4+CD25+ Treg apoptosis, affecting the number and suppressive capability of these Treg cells in chronic hemodialysis (HD) patients (284). In addition, in Ldlr-/- mice, Treg cells were found to control very-low-density lipoprotein (VLDL) levels by regulating the lipoprotein binding protein, sortilin 1, protecting against the development of CKD (279).

\section{Diabetic Nephropathy}

Diabetic glomerulosclerosis is a leading factor of CKD and endstage renal disease (ESRD), and an autoimmune renal disease secondary to diabetes mellitus type 1 (T1DM) or diabetes mellitus type 2 (T2DM) (285). Diabetic nephropathy (DN) is characterized by glomerular hypertrophy, basement membrane thickening, the accumulation of extracellular matrix components, and kidney inflammation, which are crucial in promoting the development and progression of DN (286). Recently, the morbidity and mortality of DN have been increasing rapidly worldwide (287-290). Some studies have demonstrated that there is an imbalance in the Treg/Th17 cell ratio in patients with T1DM, which may be related to the progression of microangiopathy (291). Treg cells are correlated with diabetes and DN, and T2DM patients have a low level of Treg cells relative to Th1 or Th17 $(292,293)$. The increase in the number of Th17 cells leads to an increase in the release of proinflammatory factors such as IL-17, which triggers local tissue inflammation and promotes the development of DM complications (291). The level of Treg cells in the peripheral blood of patients with type 2 diabetic nephropathy (T2DN) decreased, and the use of anti-CD25 antibodies to eliminate Treg cells aggravated kidney damage, while adoptive transfer of Treg cells reduced blood sugar and improved diabetic nephropathy (210).

The progression of diabetic nephropathy is also influenced by oxidative stress (294), lipid metabolism (295), and mTOR activation (296). Excessive ROS can damage mitochondria and increase the production of lipid peroxides (297) in Treg cells. Normally, sodium-dependent glucose transporter 2 (SGLT-2)reabsorbed glucose is utilized by mitochondria to synthesize ATP by oxidative phosphorylation (OXPHOS) (298). However, mitochondrial dysfunction occurs following inhibition of OXPHOS, which results in decreased ATP production (299), and loss of mitochondrial membrane potential $(\Delta \Psi \mathrm{m})$ and can ultimately lead to increased ROS from various sites of the electron transport chain (ETC), including complex III, which is key to promoting Treg cell suppressive function (298). Interestingly, Treg-specific knockout of complex III is associated with reduced immunosuppressive capacity and increased DNA methylation status, but it has no relevance to FOXP3 expression (281).

Abnormal metabolism and accumulation of lipids in the kidney play a crucial role in the pathogenesis of DN (300). Abnormalities in lipid metabolism make Treg cells unable to obtain sufficient energy to complete their functions (301). During a state of high ATP consumption, there is a proportional increase in intracellular AMP and HIF-1 $\alpha$ (302) (Figure 5). The proportional increase in AMP leads to AMPK phosphorylation and activation by liver kinase B1 (Lkb1) (300), which is crucial for Treg cell metabolism and function. Excessive HIF- $1 \alpha$ leads to decreased Treg differentiation, as HIF- $1 \alpha$ can 


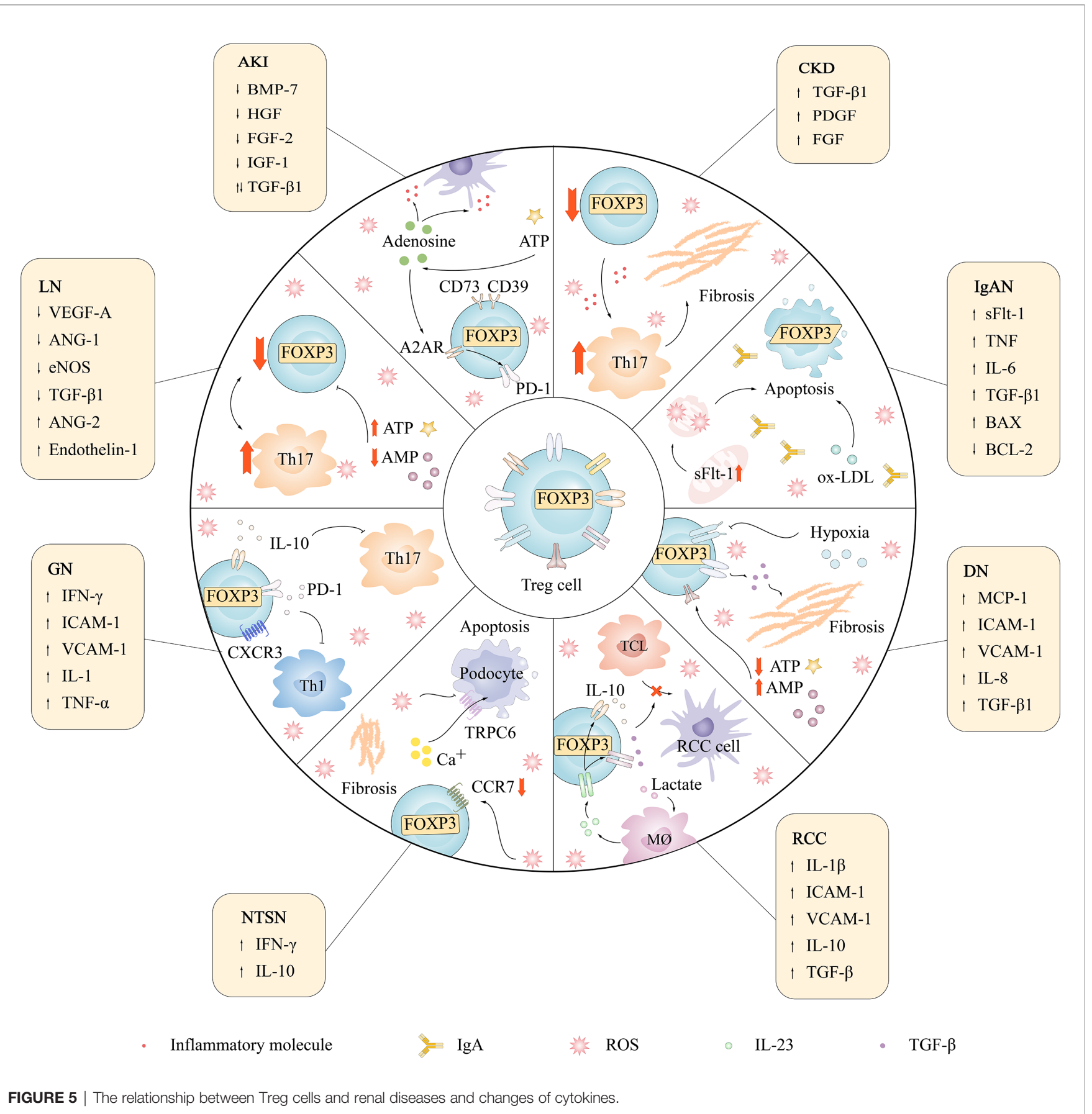

promote FOXP3 ubiquitination and subsequent proteasome degradation $(136,146)$

Activation of the mTOR pathway is upregulated in renal diseases such as DN (303). The PDK1/Akt/mTORC1 signaling pathway is activated in the glomerular mesangial cells of patients with DN, which induces the high expression of S6K1 and 4EBP1 (304), causing excessive cell proliferation and hypertrophy (305). mTORC1 activity plays an important role in Treg cell activation, function, and increased metabolic demands. mTORC2 is also involved in regulating hypertrophy of mesangial cells induced by high glucose, and inhibition of $\mathrm{mTORC} 2$ can reduce the phosphorylation levels of PKC II and Akt, suppress mTORC1 activity, and prevent mesangial cell hypertrophy (306). Some data suggest that mTORC2 inhibition promotes Treg cell activation status, Th2-like differentiation, and immunosuppressive function (142). In addition, the PI3K/AKT/mTORC1 signaling pathway is involved in extracellular matrix (ECM) deposition and tubulointerstitial fibrosis. On the one hand, mTORC1 stimulates the proliferation of fibroblasts and the synthesis of collagen; on the other hand, mTORC1 increases the expression of TGF- $\beta 1$, which 
mediates the development of DN fibrosis $(307,308)$. Therefore, blocking the mTOR pathway can significantly increase the number of Treg cells, which promotes the improvement of diabetic nephropathy.

Although these studies suggest a possible link between Foxp3+ Treg cells and the progression of CKD disease, however, due to the complex etiology of $\mathrm{CKD}$, the proportion of immune abnormalities is not known at present, and we only describe CKD from the perspective of abnormal metabolism of Treg cells. Further studies are still needed to understand the exact role of Treg in more targeted treatment plans.

\section{The Role of Treg Cell Metabolism in Lupus Nephritis}

SLE is a prototypic systemic autoimmune disease, as well as a multisystem heterogeneous disease (309). Immune abnormalities interact with various other factors, leading to a decrease in $\mathrm{T}$ lymphocytes and a decline in Treg cell function in SLE (310). LN is an autoimmune disease secondary to SLE, characterized by cell proliferation and immune complex deposition, accompanied by significant clinical manifestations of renal damage (311). Studies have demonstrated that the metabolic patterns of Th17 cells and Treg cells affect the balance of both cell types (312) (Figure 5). Th17 cells mainly rely on glycolysis to provide energy (313), while Treg cells mainly rely on fatty acid oxidation pathways to provide energy (314). Inhibition of glycolysis and fatty acid oxidation can promote the development and differentiation of Treg cells, and inhibit the differentiation of Th17 cells (315). Deficient or scarce Treg cells have been found both in murine models of SLE and in human SLE studies (316). Studies have shown that peripheral blood Treg cells decline in number and abnormal Treg cell phenotypes are present in SLE patients (317). Sirolimus has been shown to be an effective retention steroid for the treatment of renal and non-renal manifestations of SLE (318).

Cellular metabolism regulates the differentiation and function of $\mathrm{T}$ cells, thus participating in the initiation and progression of SLE inflammation. These characteristics are as follows:

(1) Mitochondrial hyperpolarization: T cells are chronically mobilized, and their mitochondria are hyperpolarized in SLE patients and lupus-prone mice (319, 320); thus, the high mitochondrial transmembrane potential will be expressed in Treg cells from SLE patients (138). The hyperpolarization of mitochondria affects the process of reducing oxygen to water by electron and proton transfer during oxidative phosphorylation, leading to increased oxygen consumption and ROS generation, thereby reducing energy synthesis $(320,321)$. ROS can oxidize proteins and cause DNA mutations, causing cell damage and cell aging, and excessive ROS will attack the protease complex on the oxidative respiratory chain, leading to mitochondrial dysfunction, reducing ATP production, inhibiting mTORC1, and promoting the differentiation of $\mathrm{T}$ cells into Treg cells $(319,320,322)$, which is a vital cause of Treg cell functional deterioration. Furthermore, in lupus-susceptible mice, blocking of Rab geranylgeranyl transferase with Rab geranylgeranyl transferase inhibitor (3-PEHPC) could reverse dynamin-related protein 1 (Drp1) consumption, mitochondrial accumulation, and nephritis, confirming that HRES-1/Rab4 regulation of mitochondrial homeostasis is the pathogenesis and potential therapeutic target of SLE (323).

(2) Hyperactivated carbohydrate metabolism: Excessive activation of glucose metabolism leads to the accumulation of energy in T cells (324). Increased ATP content weakens AMP-AMPK signal transduction and then activates mTORC1 in SLE patients (325). The enhancement of mTORC1 activity could inhibit Treg cell activation and function (326).

(3) Enhanced lipid synthesis: Acetyl-CoA is produced by the $\beta$ oxidation of fatty acids while cholesterol is generated via the catalysis of hydroxy methylglutaryl coenzyme A (HMG-CoA) reductase (327). The key enzyme ACC (acetyl-CoA carboxylase) that inhibits the FAS and cholesterol synthesis can also inhibit the expression of Th17 and promote the differentiation of Treg cells (131), thereby reducing the autoimmune response of SLE patients. Studies have shown that the synthesis of lipid rafts (including glycosphingolipids and cholesterol) in SLE patients is increased, and CD4+ T cells from active SLE patients have more lipid raft synthesis than CD4+ T cells from healthy individuals (328), which influences the proliferation and function of Treg cells. In particular, cholesterol biosynthesis was demonstrated mechanistically to be important in promoting Treg cell activation, proliferation, and function (329).

(4) Amino acid dysfunction: Catabolism of the amino acid tryptophan generates metabolic intermediates such as kynurenine that can bind the aryl hydrocarbon receptor on $\mathrm{T}$ cells and promote pTreg cell induction (182). The binding of CTLA4 on Treg cells to the costimulatory molecules CD80 and CD86 on antigen-presenting cells (APCs) induces amino acid-consuming enzyme (such as IDO and arginase 1) expression in Treg cells (330). The activities of these enzymes reduce the availability of amino acids (for example, tryptophan, arginine, histidine, and threonine) to surrounding $\mathrm{T}$ cells, inhibiting mTOR signaling via the lipid phosphatase PTEN and blocking the proliferation of Teff cells, thus promoting Treg cell induction (183).

(5) Highly activated mTOR pathway: High activation of the mTOR pathway may increase protein synthesis, leading to protein accumulation in Treg cells (331), enhancing cell metabolism, promoting the autophagy system of Treg cells, and leading to dysfunction and reduced differentiation of Treg cells $(332,333)$. A study demonstrated that mTORC2 plays a proinflammatory role in blocking Treg generation in SLE. mTORC2 can activate the Akt signaling pathway and promote glucose metabolism, while Treg cells are mainly powered by FAO (334). Therefore, the activation of mTORC2 will inhibit the development and differentiation of Treg cells, and mTORC2 blockade is important to lineage stabilization and functional maturation of Treg cells except for Treg cell differentiation. Additionally, Treg cells effects 
appear to be significantly modulated in humans compared to mice, which may be explained by the fact that blocking mTOR with rapamycin can complete nephritis blocking in several lupus-susceptible strains without affecting Treg cells in mice.

Dietary habits and nutritional factors can regulate Th17/Treg cell balance by affecting $\mathrm{T}$ cell metabolism. A balanced diet may help prevent and manage SLE. A low cholesterol diet could improve Th17/Treg cell balance by activating liver $\mathrm{x}$ receptor $\alpha$ and $\beta$ (LXRs), which are nuclear receptors modulating cholesterol metabolism (335). High glucose intake can induce Th17 cells by upregulating mitochondrial ROS in T cells, thus enhancing self-immunity (336). Long-chain fatty acids enhance Th17 cell differentiation, whereas short-chain fatty acids derived from a fiber-rich diet expand Treg cells and reduce IL-17 production (315).

\section{The Role of Treg Cell Metabolism in Other Kidney Diseases}

In addition to the three kidney diseases mentioned above, there are also several related to Treg cell metabolisms, such as IgA nephropathy, glomerulonephritis, nephrotoxic serum nephritis, and renal cell carcinoma.

\section{IgA Nephropathy}

IgA nephropathy (IgAN) is an autoimmune disease, and its immune pathogenesis is a multilevel process (337). In patients with $\lg \mathrm{AN}$, the level of abnormally glycosylated circulating IgA increases, which induces the formation of autoantibodies of IgA and IgG and then forms a circulating immune complex of autoantibodies of $\operatorname{IgA}$ and $\operatorname{lgG}$ (338). These immune complexes contribute to mesangial cell proliferation and excessive production of extracellular matrix, cytokines, and chemokines, eventually leading to glomerular sclerosis $(11,19$, 339-341).

In IgAN patients, serum soluble fms-like tyrosine kinase 1 (sFlt-1) levels are remarkably enhanced, and subsequently, sFlt-1 raises the mitochondrial membrane potential, facilitating mitochondrial-mediated apoptosis (342). A study has shown that patients with less histological injury and proteinuria have higher urinary mtDNA copy numbers, which suggests that mitochondrial damage occurs in the early stage of IgAN $(209,343)$.

A study showed that patients with IgAN have a higher prevalence of dyslipidemia (319). Excessive ox-LDL content will weaken the immunosuppressive function of Treg cells, and ox-LDL can induce apoptosis of Treg cells by activating P38/ MAPK (344), mitochondria (345), and lysosome signaling pathways (Figure 5). In addition, ox-LDL can induce cells to produce endogenous ROS (340), which increases the production of lipid peroxides in Treg cells. The damage of oxidized lipids to cells leads to abnormal cell lipid metabolism and impaired exportability, thus inducing apoptosis of Treg cells $(341,346)$.

Some studies have shown that in rats with IgAN, p-mTOR and phosphorylation of p70 S6 kinase (P-S6K1) are upregulated, which indicates that the mTOR pathway is highly activated and participates in the development of IgAN (343, 347-350).

\section{Glomerulonephritis}

GN encompasses a wide variety of kidney diseases (351). Many GNs due to immunologically mediated glomerular damage result in renal dysfunction and proteinuria (352). Treg cells are essential for the autoimmune pathogenesis of GN in the kidney (353), as such, the activation of STAT3 in Treg cells induces the expression of CC chemokine receptor 6 (CCR6) on the cell surface (354) and promotes the transport of Treg cells to the inflammatory area of Th17 cells that also highly express CCR6 through the tight colocalization of CCR6 (355), thereby suppressing the immune response of pathogenic Th17 cells during the GN process. Treg cells can also use CC chemokine receptor 7 (CCR7) expressed on their own surface to migrate to the site of CCR7 + T cell activation and inhibit the activation of $\mathrm{T}$ cells (356). Treg cells with defective IL-10Ra expression can significantly reduce the production of IL-10 during GN, while Treg cells can significantly downregulate Th17 cells through IL10 receptor signal transduction (357) (Figure 5). IL-10Ra is a key component that controls the immune function of Th17 cells in the GN process, and a large number of IL-10Ra-deficient T cells differentiate into Th17 cells, which aggravates the condition of GN (349). In addition, IL-6 stimulates Treg cells to produce cells, which have both pro-inflammatory and anti-inflammatory effects (329). ITreg cells can secrete the anti-inflammatory factors IL-10 and IL-35, as well as the pro-inflammatory factor IL-17 (350), and by inhibiting Th2 cells with anti-inflammatory effects, they mediate pro-inflammatory effects in GN (356). Treg cells also inhibit Th1 cells. Nosko et al. showed that Treg cells in which the transcription factor T-bet is activated enhance the ability of Treg cells to downregulate Th1 cell responses by inducing the expression of CXC chemokine receptor type 3 (CXCR3) (358). Studies have also reported that Treg cells inhibit GN driven by the Th1 immune response through the PD-1/programmed cell death-ligand 1 (PD-L1) pathway, and mediate renal protection (359) (Figure 5).

The kidney is rich in mitochondria, which meet its high energy demand through the oxidative phosphorylation process (360). Several studies have demonstrated that in glomerulonephritis nephropathy rats, the number of mitochondria in tubular epithelial cells is reduced and cristae structure is destroyed. Albumin and free fatty acid stimulation of cultured human tubular cells in vitro increased mitochondrial ROS, which led to mitochondrial damage $(361,362)$. Generating enough acetyl-CoA to feed into the Krebs cycle and then generating sufficient ATP through the mitochondria is an important process in Treg cells (363). Although the mechanism was not uncovered, the induction of Foxp3 in iTreg cells correlated with increased expression of mitochondria-associated genes (364) Mitochondrial dysfunction can cause abnormal metabolism of Treg cells, and the protective effect of Treg cells on the kidney is limited.

In addition to oxidative stress, GN can also undergo the deposition of lipid-associated molecules, including oxidized cholesterol, apolipoprotein (Apo), and ox-LDL. Oxidative and 
helix-related molecules accumulate on the glomerular basement membrane (GBM) along with other molecules (320, 365). oxLDL can induce apoptosis of Treg cells by activating P38/MAPK (366). AMPK activity together with protein phosphatase $2 \mathrm{~A}$ (PP2A) restrains the mammalian target of rapamycin complex 1 (mTORC1) signaling, thus promoting Foxp3 expression and the proliferation of Treg cells $(333,367)$.

In patients with little immune deposition glomerulonephritis, a large amount of the glomerulus and even more cells in the tubulointerstitial area express mTOR (368). Upon Treg cell activation, the increase in mTOR signaling upregulates interferon regulatory Factor 4 (IRF4) (367), which further promotes genes for cellular growth, glycolysis, OXPHOS, and fatty acid metabolism, among others (369). These data suggest that promoting $\mathrm{mTORC} 1$ activity can promote the activation and function of Treg cells and support glycolysis and the OXPHOS metabolic pathway (369).

\section{Nephrotoxic Serum Nephritis}

Nephrotoxic serum nephritis (NTSN) nephritis is a type of focal segmental glomerulosclerosis (FSGS) that occurs in many kinds of renal disease and ultimately leads to kidney inflammation and fibrosis (370). The histological features of nephrotoxic serum nephritis are the accumulation of macrophages, cholesterol, and cholesteryl esters, as well as the deposition of extracellular matrix in sclerotic glomeruli. The disease is characterized by rapid inflammation and infiltration of leukocytes in the kidneys (371). In a mouse model with NTSN, Treg cells are endogenous immunosuppressive cells that protect kidney tissues from inflammation-mediated damage (372).

Increased mitochondrial ROS generation and mitochondrial oxidative damage are present in the glomeruli of patients with nephrotoxic serum nephritis, inhibiting the protective effect of Treg cells on the kidney (373) so that the expression of CCR7 on Treg cells is downregulated and affects the recruitment of Treg cells to the lymph nodes of NTSN (374). ROS can change the expression of transient receptor potential cation channel, subfamily C, member 6 (TRPC6) protein, or TRPC6 channel activity in kidney cells, thereby regulating $\mathrm{Ca} 2+$ signal transduction and mediating podocyte apoptosis (375) (Figure 5). Research has shown that the knockout of TRPC6 plays a protective role in NTSN (376). The accumulation of ROS in mitochondria induces mitochondrial dysfunction and apoptosis, eventually causing glomerular disease (377), which includes nephrotoxic serum nephritis. In addition, experiments have shown that the NTSN of CCR7 knockout mice is more serious, and abundant inflammatory cell infiltration was observed (378).

\section{Renal Cell Carcinoma}

Renal cell carcinoma (RCC) is one of the most common tumors and arises from the renal parenchyma urinary tubular epithelial system (379). There are many pathological types of renal cell carcinoma, of which clear cell renal cell carcinoma (ccRCC) is the most common (380). Renal cancer cells have a vigorous metabolism competing with immune cells for nutrients, thereby changing the metabolic mode of immune cells, and subsequently affecting their function and differentiation (381). Furthermore, substances produced by renal cancer cells, such as lactic acid and ROS, can cause damage to immune cells and reduce their antitumor effect (382).

Deletion of the von Hippel-Lindau (VHL) tumor suppressor gene in renal cancer cells leads to the accumulation of HIF- $1 \alpha$ and an increase in Clut2 expression, which promotes aerobic glycolysis in renal cancer cells and leads to metabolic reprogramming of renal cancer cells (383). This aerobic glycolysis mode of cancer cells is called the "Warburg effect" (382). Hypoxia-mediated expression of HIF-1 $\alpha$ selectively upregulates the expression of inhibitory ligands, such as PDL1, and promotes $\mathrm{T}$ cell immunosuppression (384). Such hypoxia-mediated changes also promote Treg cell differentiation and homeostasis (385). The propagation of kidney cancer cells is highly dependent on glycolysis (386), which affects the function of Th17 cells that also rely on glycolysis but does not affect the survival of Treg cells that depend on fatty acid oxidation.

The proliferation of renal cancer cells consumes a lot of glutamine and competes with the surrounding macrophages for glutamine in the extracellular matrix (387). This is related to the promotion of the expression of ASCT2 and SLCIA5 by MYC (388) in renal cancer cells, leading to a large amount of glutamine being transported into the cell, which in turn activates the PI3K-Akt-mTOR signaling pathway and promotes the metabolism of glutamine and the synthesis of protein (389). The metabolic waste products of amide will promote the differentiation of Treg cells (382). In addition, lactate can induce the secretion of IL-23 by macrophages infiltrated by tumor cells (169). IL-23 activates the JAK/STAT pathway of Treg cells, increases the phosphorylation of STAT3, activating the proliferation of Treg cells, promotes the expression of IL-10 and TGF- $\beta$, thus inhibiting the killing effect of TCL on renal cancer cells (390, 391) (Figure 5).

IDO is overexpressed in a variety of cancers (392-394). IDO activity reduces local tryptophan availability in the proximity of Treg cells (395). A low concentration of tryptophan activates a stress response pathway in Treg cells through the protein kinase general control nonderepressing-2, which inhibits mTORC2 and prevents it from phosphorylating Akt, plus contributes to the maintenance of Treg suppressive function (395-397).

A large amount of lipid accumulation is found in renal cell carcinoma. HIF- $1 \alpha$ in renal cell carcinoma inhibits the activity of CPT1 on the outer mitochondrial membrane and prevents the $\beta$ oxidation of fatty acids (398), which is important for the differentiation of Treg cells, and its blockade could prevent the accumulation of this immunosuppressive population (199). AMPK in renal cancer cells, a sensor of nutrient deprivation and metabolic stress, is inactivated in the AMPK-GATA3ECHS1 signaling pathway (399), inhibiting the expression of the transcription factor GATA3 and leading to a decrease in the synthesis of ECHS1. AMPK activation can promote the formation of Treg cells while reducing Th1 and Th17 cells (199), thus, leading to unwanted immune modulation in the context of RCC. In addition, the inactivation of AMPK reduces the activation of adipose triacylglyceride lipase (ATGL) and 
inhibits the decomposition of triglycerides into fatty acids, thereby inhibiting the catabolism of fatty acids; at the same time, the inactivation of AMPK weakens the inhibitory effect on acetyl-CoA carboxylase (ACC) and promotes the synthesis of fatty acids. Berod et al. showed that inhibition of ACC1 restrains the differentiation of Th17 cells and promotes the differentiation of anti-inflammatory Foxp3+ Treg cells $(400,401)$.

\section{CONCLUSION}

The immune system searches for pathogens and other danger signals in vivo at all times. In recent years, the field linking immunity and metabolism has expanded rapidly (402). In renal diseases, $\mathrm{T}$ cells are involved in different abnormal metabolic pathways, such as increased oxidative stress, mitochondrial dysfunction, enhanced glycolysis, abnormal lipid synthesis, glutaminolysis, and highly activated mTOR, which all influence Treg cell proliferation and differentiation.

Inhibition of different metabolic pathways via drugs can modify Th17 cells to Treg cells. For example, inhibition of glycolysis (209, 403-405), lipid synthesis (328, 406, 407), and mTOR signaling $(211,408,409)$ can control inflammation and alleviate disease activity in lupus mice and SLE patients (Table 1). Short-chain fatty acids, which are derived from a fiber-rich diet, can downregulate IL-17 production and amplify Treg cells (410-412). Treg cell metabolism therapy has great potential in many forms of renal diseases. Promoting the proliferation or function of Treg cells by mediating various metabolic pathways are also possible treatments in the future for multifarious diseases that affect the kidney.

\section{REFERENCES}

1. Fazelian S, Moradi F, Agah S, Hoseini A, Heydari H, Morvaridzadeh M, et al. Effect of Omega-3 Fatty Acids Supplementation on Cardio-Metabolic and Oxidative Stress Parameters in Patients With Chronic Kidney Disease: A Systematic Review and Meta-Analysis. BMC Nephrol (2021) 22(1):160. doi: 10.1186/s12882-021-02351-9

2. Kitagawa Y, Ohkura N, Sakaguchi S. Epigenetic Control of Thymic Treg-Cell Development. Eur J Immunol (2015) 45(1):11-6. doi: 10.1002/eji.201444577

3. Deng G, Song X, Greene MI. Foxp3 in T Cell Biology: A Molecular and Structural Perspective. Clin Exp Immunol (2020) 199(3):255-62. doi: 10.1111/ cei. 13357

4. Liu Y, Peng B, Wu S, Xu N. Epigenetic Regulation of Regulatory T Cells in Kidney Disease and Transplantation. Curr Gene Ther (2017) 17(6):461-8. doi: 10.2174/1566523218666180214093813

5. Kanamori M, Nakatsukasa H, Okada M, Lu Q, Yoshimura A. Induced Regulatory T Cells: Their Development, Stability, and Applications. Trends Immunol (2016) 37(11):803-11. doi: 10.1016/j.it.2016.08.012

6. Shevach EM, Thornton AM. Ttregs, Ptregs, and Itregs: Similarities and Differences. Immunol Rev (2014) 259(1):88-102. doi: 10.1111/imr.12160

7. Szurek E, Cebula A, Wojciech L, Pietrzak M, Rempala G, Kisielow P, et al. Differences in Expression Level of Helios and Neuropilin-1 do Not Distinguish Thymus-Derived From Extrathymically-Induced CD4+Foxp3 + Regulatory T Cells. PLoS One (2015) 10(10):e0141161. doi: 10.1371/ journal.pone.0141161
It is important to note that many studies involving the immune metabolism of Treg cells have been based on model animal studies (mostly mice) or in vitro human cells. Pharmacological or genetic manipulation of metabolic processes in mouse models of human autoimmune diseases offers new opportunities to treat human diseases, but it is not clear how Treg cell immune metabolism is altered in many people with kidney disease. Therefore, we can make inferences based on published articles, but cannot be sure that these experimental results are consistent in animal and human kidney disease. This is a knowledge gap in Treg cell immune metabolism. Treg metabolism may become a target for future treatment of various kidney diseases.

\section{AUTHOR CONTRIBUTIONS}

$\mathrm{ZH}, \mathrm{KM}$, and HT were involved in the conception of the study. $\mathrm{ZH}, \mathrm{KM}, \mathrm{LS}$, and QN were involved in writing the article. HL, JZ, $\mathrm{XS}, \mathrm{YL}, \mathrm{MC}$, and CL critically revised the manuscript. All authors read and approved the final manuscript.

\section{FUNDING}

The work was supported by the Foundation of Popularization project Department of Sichuan Health commission (19PJYY0731); The Foundation of Key R\&D plan of Sichuan Province (2019YFS0538); and The project of 2020 High-level Overseas Chinese Talent Returning Funding.

8. Milpied P, Renand A, Bruneau J, Mendes-da-Cruz DA, Jacquelin S, Asnafi $\mathrm{V}$, et al. Neuropilin-1 is Not a Marker of Human Foxp3+ Treg. Eur J Immunol (2009) 39(6):1466-71. doi: 10.1002/eji.200839040

9. Landwehr-Kenzel S, Zobel A, Hoffmann H, Landwehr N, SchmueckHenneresse M, Schachtner T, et al. Ex Vivo Expanded Natural Regulatory T Cells From Patients With End-Stage Renal Disease or Kidney Transplantation are Useful for Autologous Cell Therapy. Kidney Int (2018) 93(6):1452-64. doi: 10.1016/j.kint.2018.01.021

10. Yang S, Chen B, Shi J, Chen F, Zhang J, Sun Z. Analysis of Regulatory T Cell Subsets in the Peripheral Blood of Immunoglobulin a Nephropathy (Igan) Patients. Genet Mol Res (2015) 14(4):14088-92. doi: 10.4238/2015.October. 29.28

11. Saenz-Pipaon G, Echeverria S, Orbe J, Roncal C. Urinary Extracellular Vesicles for Diabetic Kidney Disease Diagnosis. J Clin Med (2021) 10 (10):2046. doi: 10.3390/jcm10102046

12. Klawitter J, Pennington A, Klawitter J, Thurman JM, Christians U. Mitochondrial Cyclophilin D Ablation is Associated With the Activation of Akt/P70s6k Pathway in the Mouse Kidney. Sci Rep (2017) 7(1):10540. doi: 10.1038/s41598-017-10076-9

13. Ping F, Guo Y, Cao Y, Shang J, Yao S, Zhang J, et al. Metabolomics Analysis of the Renal Cortex in Rats With Acute Kidney Injury Induced by Sepsis. Front Mol Biosci (2019) 6(152):152. doi: 10.3389/fmolb.2019.00152

14. Galgani M, De Rosa V, La Cava A, Matarese G. Role of Metabolism in the Immunobiology of Regulatory T Cells. J Immunol (2016) 197(7):2567-75. doi: 10.4049/jimmunol.1600242 
15. Shevach EM. Regulatory T Cells in Autoimmmunity*. Annu Rev Immunol (2000) 18:423-49. doi: 10.1146/annurev.immunol.18.1.423

16. Josefowicz SZ, Lu LF, Rudensky AY. Regulatory T Cells: Mechanisms of Differentiation and Function. Annu Rev Immunol (2012) 30:531-64. doi: 10.1146/annurev.immunol.25.022106.141623

17. Wing K, Sakaguchi S. Regulatory T Cells Exert Checks and Balances on Self Tolerance and Autoimmunity. Nat Immunol (2010) 11(1):7-13. doi: 10.1038/ ni. 1818

18. Alikhan MA, Huynh M, Kitching AR, Ooi JD. Regulatory T Cells in Renal Disease. Clin Transl Immunol (2018) 7(1):e1004. doi: 10.1002/cti2.1004

19. Sarder HAM, Li X, Funaya C, Cordat E, Schmitt MJ, Becker B. Saccharomyces Cerevisiae: First Steps to a Suitable Model System to Study the Function and Intracellular Transport of Human Kidney Anion Exchanger 1. mSphere (2020) 5(1):e00802-19. doi: 10.1128/mSphere. 00802-19

20. Furuya M, Hasumi H, Yao M, Nagashima Y. Birt-Hogg-Dubé SyndromeAssociated Renal Cell Carcinoma: Histopathological Features and Diagnostic Conundrum. Cancer Sci (2020) 111(1):15-22. doi: 10.1111/ cas. 14255

21. Jang C, Hui S, Zeng X, Cowan AJ, Wang L, Chen L, et al. Metabolite Exchange Between Mammalian Organs Quantified in Pigs. Cell Metab (2019) 30(3):594-606.e3. doi: 10.1016/j.cmet.2019.06.002

22. Hooftman A, O'Neill LAJ. The Immunomodulatory Potential of the Metabolite Itaconate. Trends Immunol (2019) 40(8):687-98. doi: 10.1016/ j.it.2019.05.007

23. Huen SC, Cantley LG. Macrophages in Renal Injury and Repair. Annu Rev Physiol (2017) 79:449-69. doi: 10.1146/annurev-physiol-022516-034219

24. Janssen U, Ostendorf T, Gaertner S, Eitner F, Hedrich HJ, Assmann KJ, et al. Improved Survival and Amelioration of Nephrotoxic Nephritis in Intercellular Adhesion Molecule-1 Knockout Mice. J Am Soc Nephrol (1998) 9(10):1805-14. doi: 10.1681/asn.V9101805

25. Than A, Liu C, Chang H, Duong PK, Cheung CMG, Xu C, et al. SelfImplantable Double-Layered Micro-Drug-Reservoirs for Efficient and Controlled Ocular Drug Delivery. Nat Commun (2018) 9(1):4433. doi: 10.1038/s41467-018-06981-w

26. Niknejad H, Peirovi H, Jorjani M, Ahmadiani A, Ghanavi J, Seifalian AM. Properties of the Amniotic Membrane for Potential Use in Tissue Engineering. Eur Cell Mater (2008) 15(88-99). doi: 10.22203/ecm.v015a07

27. Biedermann T, Kneilling M, Mailhammer R, Maier K, Sander CA, Kollias G, et al. Mast Cells Control Neutrophil Recruitment During T Cell-Mediated Delayed-Type Hypersensitivity Reactions Through Tumor Necrosis Factor and Macrophage Inflammatory Protein 2. J Exp Med (2000) 192(10):144152. doi: $10.1084 /$ jem.192.10.1441

28. Groschwitz KR, Ahrens R, Osterfeld H, Gurish MF, Han X, Abrink M, et al. Mast Cells Regulate Homeostatic Intestinal Epithelial Migration and Barrier Function by a Chymase/Mcpt4-Dependent Mechanism. Proc Natl Acad Sci U S A (2009) 106(52):22381-6. doi: 10.1073/pnas.0906372106

29. Matsumoto T, Wada A, Tsutamoto T, Ohnishi M, Isono T, Kinoshita M, et al. Chymase Inhibition Prevents Cardiac Fibrosis and Improves Diastolic Dysfunction in the Progression of Heart Failure. Circulation (2003) 107 (20):2555-8. doi: 10.1161/01.Cir.0000074041.81728.79

30. Kanemitsu H, Takai S, Tsuneyoshi H, Yoshikawa E, Nishina T, Miyazaki M, et al. Chronic Chymase Inhibition Preserves Cardiac Function After Left Ventricular Repair in Rats. Eur J Cardiothorac Surg (2008) 33(1):25-31. doi: 10.1016/j.ejcts.2007.09.040

31. Yamada M, Ueda M, Naruko T, Tanabe S, Han YS, Ikura Y, et al. Mast Cell Chymase Expression and Mast Cell Phenotypes in Human Rejected Kidneys. Kidney Int (2001) 59(4):1374-81. doi: 10.1046/j.1523-1755.2001. 0590041374.x

32. Miyazawa S, Hotta O, Doi N, Natori Y, Nishikawa K, Natori Y. Role of Mast Cells in the Development of Renal Fibrosis: Use of Mast Cell-Deficient Rats. Kidney Int (2004) 65(6):2228-37. doi: 10.1111/j.1523-1755.2004.00629.x

33. de Souza Junior DA, Mazucato VM, Santana AC, Oliver C, Jamur MC. Mast Cells Interact With Endothelial Cells to Accelerate In Vitro Angiogenesis. Int J Mol Sci (2017) 18(12). doi: 10.3390/ijms18122674

34. Wu K, Zhou T, Sun G, Wang W, Zhang Y, Zhang Y, et al. Valsartan Inhibited the Accumulation of Dendritic Cells in Rat Fibrotic Renal Tissue. Cell Mol Immunol (2006) 3(3):213-20.
35. Oberkampf M, Guillerey C, Mouriès J, Rosenbaum P, Fayolle C, Bobard A, et al. Mitochondrial Reactive Oxygen Species Regulate the Induction of CD8 (+) T Cells by Plasmacytoid Dendritic Cells. Nat Commun (2018) 9(1):2241. doi: 10.1038/s41467-018-04686-8

36. Padua D, Massagué J, et al. Roles of Tgfbeta in Metastasis. Cell Res (2009) 19 (1):89-102. doi: 10.1038/cr.2008.316

37. Lin J, Wang H, Liu C, Cheng A, Deng Q, Zhu H, et al. Dendritic Cells: Versatile Players in Renal Transplantation. Front Immunol (2021) 12:654540. doi: 10.3389/fimmu.2021.654540

38. Zhang F, Wang C, Wen X, Chen Y, Mao R, Cui D, et al. Mesenchymal Stem Cells Alleviate Rat Diabetic Nephropathy by Suppressing CD103(+) DcsMediated CD8(+) T Cell Responses. J Cell Mol Med (2020) 24(10):5817-31. doi: $10.1111 / j \mathrm{cmm} .15250$

39. Strutz F, Neilson EG. The Role of Lymphocytes in the Progression of Interstitial Disease. Kidney Int Suppl (1994) 45:S106-10.

40. Volarevic V, Markovic BS, Jankovic MG, Djokovic B, Jovicic N, Harrell CR, et al. Galectin 3 Protects From Cisplatin-Induced Acute Kidney Injury by Promoting TLR-2-Dependent Activation of IDO1/ Kynurenine Pathway in Renal Dcs. Theranostics (2019) 9(20):5976-6001. doi: $10.7150 /$ thno.33959

41. Velin D, Narayan S, Bernasconi E, Busso N, Ramelli G, Maillard MH, et al. PAR2 Promotes Vaccine-Induced Protection Against Helicobacter Infection in Mice. Gastroenterology (2011) 141(4):1273-82, 1282.e1. doi: 10.1053/ j.gastro.2011.06.038

42. Steinitz KN, van Helden PM, Binder B, Wraith DC, Unterthurner S, Hermann C, et al. CD4+ T-Cell Epitopes Associated With Antibody Responses After Intravenously and Subcutaneously Applied Human FVIII in Humanized Hemophilic E17 HLA-DRB1¹501 Mice. Blood (2012) 119 (17):4073-82. doi: 10.1182/blood-2011-08-374645

43. Kuhn NF, Lopez AV, Li X, Cai W, Daniyan AF, Brentjens RJ. CD103(+) Cdc1 and Endogenous CD8(+) T Cells are Necessary for Improved CD40LOverexpressing CAR T Cell Antitumor Function. Nat Commun (2020) 11 (1):6171. doi: 10.1038/s41467-020-19833-3

44. Zhu J, Yamane H, Paul WE. Differentiation of Effector CD4 T Cell Populations $\left(^{*}\right)$. Annu Rev Immunol (2010) 28:445-89. doi: 10.1146/ annurev-immunol-030409-101212

45. Hamza T, Barnett JB, Li B. Interleukin 12 a Key Immunoregulatory Cytokine in Infection Applications. Int J Mol Sci (2010) 11(3):789-806. doi: 10.3390/ ijms 11030789

46. Galkina E, Ley K. Immune and Inflammatory Mechanisms of Atherosclerosis ${ }^{*}$ ). Annu Rev Immunol (2009) 27:165-97. doi: 10.1146/ annurev.immunol.021908.132620

47. Mima T, Nishimoto N. Clinical Value of Blocking IL-6 Receptor. Curr Opin Rheumatol (2009) 21(3):224-30. doi: 10.1097/BOR.0b013e3283295fec

48. Zhu X, Li S, Zhang Q, Zhu D, Xu Y, Zhang P, et al. Correlation of Increased Th17/Treg Cell Ratio With Endoplasmic Reticulum Stress in Chronic Kidney Disease. Med (Baltimore) (2018) 97(20):e10748. doi: 10.1097/ $\mathrm{md} .0000000000010748$

49. Nakano Y, Hisaeda H, Sakai T, Zhang M, Maekawa $Y$, Zhang T, et al. Granule-Dependent Killing of Toxoplasma Gondii by CD8+ T Cells. Immunology (2001) 104(3):289-98. doi: 10.1046/j.1365-2567.2001.01319.x

50. Wang Y, Wang Y, Feng X, Bao S, Yi S, Kairaitis L, et al. Depletion of CD4(+) T Cells Aggravates Glomerular and Interstitial Injury in Murine Adriamycin Nephropathy. Kidney Int (2001) 59(3):975-84. doi: 10.1046/j.1523-1755.2001. 059003975.x

51. Schwartz N, Goilav B, Putterman C. The Pathogenesis, Diagnosis and Treatment of Lupus Nephritis. Curr Opin Rheumatol (2014) 26(5):502-9. doi: 10.1097/bor.0000000000000089

52. Ren J, Catalina MD, Eden K, Liao X, Read KA, Luo X, et al. Selective Histone Deacetylase 6 Inhibition Normalizes B Cell Activation and Germinal Center Formation in a Model of Systemic Lupus Erythematosus. Front Immunol (2019) 10(2512):2512. doi: 10.3389/fimmu.2019.02512

53. Zheng N, Xie K, Ye H, Dong Y, Wang B, Luo N, et al. TLR7 in B Cells Promotes Renal Inflammation and Gd-Igal Synthesis in Iga Nephropathy. JCI Insight (2020) 5(14):e136965. doi: 10.1172/jci.insight.136965

54. Zhang C, Chen Y, Sun S, Zhang Y, Wang L, Luo Z, et al. A Conserved LDLReceptor Motif Regulates Corin and CD320 Membrane Targeting in Polarized Renal Epithelial Cells. Elife (2020) 9. doi: 10.7554/eLife.56059 
55. Yoo JY, Cha DR, Kim B, An EJ, Lee SR, Cha JJ, et al. LPS-Induced Acute Kidney Injury is Mediated by Nox4-Sh3yl1. Cell Rep (2020) 33(3):108245. doi: 10.1016/j.celrep.2020.108245

56. Alcorn JF, Crowe CR, Kolls JK. TH17 Cells in Asthma and COPD. Annu Rev Physiol (2010) 72:495-516. doi: 10.1146/annurev-physiol-021909-135926

57. Chen B, Wang P, Liang X, Jiang C, Ge Y, Dworkin LD, et al. Permissive Effect of GSK3 $\beta$ on Profibrogenic Plasticity of Renal Tubular Cells in Progressive Chronic Kidney Disease. Cell Death Dis (2021) 12(5):432. doi: 10.1038/s41419-021-03709-5

58. Lovisa S, LeBleu VS, Tampe B, Sugimoto H, Vadnagara K, Carstens JL, et al. Epithelial-to-Mesenchymal Transition Induces Cell Cycle Arrest and Parenchymal Damage in Renal Fibrosis. Nat Med (2015) 21(9):998-1009. doi: $10.1038 / \mathrm{nm} .3902$

59. Fan JM, Ng YY, Hill PA, Nikolic-Paterson DJ, Mu W, Atkins RC, et al. Transforming Growth Factor-Beta Regulates Tubular EpithelialMyofibroblast Transdifferentiation In Vitro. Kidney Int (1999) 56(4):145567. doi: 10.1046/j.1523-1755.1999.00656.x

60. Harir N, Boudot C, Friedbichler K, Sonneck K, Kondo R, Martin-Lannerée S, et al. Oncogenic Kit Controls Neoplastic Mast Cell Growth Through a Stat5/ PI3-Kinase Signaling Cascade. Blood (2008) 112(6):2463-73. doi: 10.1182/ blood-2007-09-115477

61. Dressler GR. The Cellular Basis of Kidney Development. Annu Rev Cell Dev Biol (2006) 22:509-29. doi: 10.1146/annurev.cellbio.22.010305.104340

62. Messaoudi S, He Y, Gutsol A, Wight A, Hébert RL, Vilmundarson RO, et al. Endothelial Gata5 Transcription Factor Regulates Blood Pressure. Nat Commun (2015) 6:8835. doi: 10.1038/ncomms 9835

63. Fenton K, Fismen S, Hedberg A, Seredkina N, Fenton C, Mortensen ES, et al. Anti-Dsdna Antibodies Promote Initiation, and Acquired Loss of Renal Dnase1 Promotes Progression of Lupus Nephritis in Autoimmune (Nzbxnzw)F1 Mice. PLoS One (2009) 4(12):e8474. doi: 10.1371/journal. pone. 0008474

64. Wright RD, Dimou P, Northey SJ, Beresford MW. Mesangial Cells are Key Contributors to the Fibrotic Damage Seen in the Lupus Nephritis Glomerulus. J Inflamm (Lond) (2019) 16:22. doi: 10.1186/s12950-0190227-x

65. Zhang ZY, Zhang H, Liu D, Lu YY, Wang X, Li P, et al. Pharmacokinetics, Tissue Distribution and Excretion of a Novel Diuretic (PU-48) in Rats. Pharmaceutics (2018) 10(3):124. doi: 10.3390/pharmaceutics10030124

66. Bagnasco SM, Peng T, Janech MG, Karakashian A, Sands JM. Cloning and Characterization of the Human Urea Transporter UT-A1 and Mapping of the Human Slc14a2 Gene. Am J Physiol Renal Physiol (2001) 281(3):F400-6. doi: 10.1152/ajprenal.2001.281.3.F400

67. Smith CP, Lee WS, Martial S, Knepper MA, You G, Sands JM, et al. Cloning and Regulation of Expression of the Rat Kidney Urea Transporter (Rut2). J Clin Invest (1995) 96(3):1556-63. doi: 10.1172/jci118194

68. Terris JM, Knepper MA, Wade JB. UT-A3: Localization and Characterization of an Additional Urea Transporter Isoform in the IMCD. Am J Physiol Renal Physiol (2001) 280(2):F325-32. doi: 10.1152/ ajprenal.2001.280.2.F325

69. Timmer RT, Klein JD, Bagnasco SM, Doran JJ, Verlander JW, Gunn RB, et al. Localization of the Urea Transporter UT-B Protein in Human and Rat Erythrocytes and Tissues. Am J Physiol Cell Physiol (2001) 281(4):C1318-25. doi: 10.1152/ajpcell.2001.281.4.C1318

70. Promeneur D, Rousselet G, Bankir L, Bailly P, Cartron JP, Ripoche P, et al. Evidence for Distinct Vascular and Tubular Urea Transporters in the Rat Kidney. J Am Soc Nephrol (1996) 7(6):852-60. doi: 10.1681/asn.V76852

71. Fenton RA, Yang B. Urea Transporter Knockout Mice and Their Renal Phenotypes. Subcell Biochem (2014) 73:137-52. doi: 10.1007/978-94-0179343-8_9

72. Cutler CP, Maciver B, Cramb G, Zeidel M. Aquaporin 4 is a Ubiquitously Expressed Isoform in the Dogfish (Squalus Acanthias) Shark. Front Physiol (2011) 2(107):107. doi: 10.3389/fphys.2011.00107

73. Echevarria M, Windhager EE, Tate SS, Frindt G. Cloning and Expression of AQP3, a Water Channel From the Medullary Collecting Duct of Rat Kidney. Proc Natl Acad Sci U S A (1994) 91(23):10997-1001. doi: 10.1073/ pnas.91.23.10997

74. Ishibashi K, Kuwahara M, Gu Y, Tanaka Y, Marumo F, Sasaki S. Cloning and Functional Expression of a New Aquaporin (AQP9) Abundantly
Expressed in the Peripheral Leukocytes Permeable to Water and Urea, But Not to Glycerol. Biochem Biophys Res Commun (1998) 244(1):268-74. doi: 10.1006/bbrc.1998.8252

75. Ishibashi K, Morinaga T, Kuwahara M, Sasaki S, Imai M. Cloning and Identification of a New Member of Water Channel (AQP10) as an Aquaglyceroporin. Biochim Biophys Acta (2002) 1576(3):335-40. doi: 10.1016/s0167-4781(02)00393-7

76. Walpole ME, Schurmann BL, Górka P, Penner GB, Loewen ME, Mutsvangwa T. Serosal-to-Mucosal Urea Flux Across the Isolated Ruminal Epithelium is Mediated via Urea Transporter-B and Aquaporins When Holstein Calves Are Abruptly Changed to a Moderately Fermentable Diet. J Dairy Sci (2015) 98(2):1204-13. doi: 10.3168/jds.2014-8757

77. Zhong C, Farrell A, Stewart GS. Localization of Aquaporin-3 Proteins in the Bovine Rumen. J Dairy Sci (2020) 103(3):2814-20. doi: 10.3168/jds.201917735

78. Sun Y, Lau CW, Jia Y, Li Y, Wang W, Ran J, et al. Functional Inhibition of Urea Transporter UT-B Enhances Endothelial-Dependent Vasodilatation and Lowers Blood Pressure via L-Arginine-Endothelial Nitric Oxide Synthase-Nitric Oxide Pathway. Sci Rep (2016) 6:18697. doi: 10.1038/ srep 18697

79. Levin MH, de la Fuente R, Verkman AS. Urearetics: A Small Molecule Screen Yields Nanomolar Potency Inhibitors of Urea Transporter UT-B. FASEB J (2007) 21(2):551-63. doi: 10.1096/fj.06-6979com

80. Wang Y, Klein JD, Blount MA, Martin CF, Kent KJ, Pech V, et al. Epac Regulates UT-A1 to Increase Urea Transport in Inner Medullary Collecting Ducts. J Am Soc Nephrol (2009) 20(9):2018-24. doi: 10.1681/asn.2008121225

81. Su W, Cao R, Zhang XY, Guan Y. Aquaporins in the Kidney: Physiology and Pathophysiology. Am J Physiol Renal Physiol (2020) 318(1):F193-f203. doi: 10.1152/ajprenal.00304.2019

82. Blount MA, Klein JD, Martin CF, Tchapyjnikov D, Sands JM. Forskolin Stimulates Phosphorylation and Membrane Accumulation of UT-A3. Am J Physiol Renal Physiol (2007) 293(4):F1308-13. doi: 10.1152/ ajprenal.00197.2007

83. Zhang C, Sands JM, Klein JD. Vasopressin Rapidly Increases Phosphorylation of UT-A1 Urea Transporter in Rat Imcds Through PKA. Am J Physiol Renal Physiol (2002) 282(1):F85-90. doi: 10.1152/ajprenal. 0054.2001

84. Blessing NW, Blount MA, Sands JM, Martin CF, Klein JD. Urea Transporters UT-A1 and UT-A3 Accumulate in the Plasma Membrane in Response to Increased Hypertonicity. Am J Physiol Renal Physiol (2008) 295 (5):F1336-41. doi: 10.1152/ajprenal.90228.2008

85. Kim D, Sands JM, Klein JD. Role of Vasopressin in Diabetes MellitusInduced Changes in Medullary Transport Proteins Involved in Urine Concentration in Brattleboro Rats. Am J Physiol Renal Physiol (2004) 286 (4):F760-6. doi: 10.1152/ajprenal.00369.2003

86. Jung JY, Madsen KM, Han KH, Yang CW, Knepper MA, Sands JM, et al. Expression of Urea Transporters in Potassium-Depleted Mouse Kidney. Am J Physiol Renal Physiol (2003) 285(6):F1210-24. doi: 10.1152/ ajprenal.00111.2003

87. Klein JD, Rouillard P, Roberts BR, Sands JM. Acidosis Mediates the Upregulation of UT-a Protein in Livers From Uremic Rats. J Am Soc Nephrol (2002) 13(3):581-7. doi: 10.1681/asn.V133581

88. Verlander JW, Chu D, Lee HW, Handlogten ME, Weiner ID. Expression of Glutamine Synthetase in the Mouse Kidney: Localization in Multiple Epithelial Cell Types and Differential Regulation by Hypokalemia. Am J Physiol Renal Physiol (2013) 305(5):F701-13. doi: 10.1152/ajprenal. 00030.2013

89. Weiner ID, Verlander JW. Renal Ammonia Metabolism and Transport. Compr Physiol (2013) 3(1):201-20. doi: 10.1002/cphy.c120010

90. Pitts RF, Pilkington LA. The Relation Between Plasma Concentrations of Glutamine and Glycine and Utilization of Their Nitrogens as Sources of Urinary Ammonia. J Clin Invest (1966) 45(1):86-93. doi: 10.1172/jci105326

91. Solbu TT, Boulland JL, Zahid W, Lyamouri Bredahl MK, AmiryMoghaddam M, Storm-Mathisen J, et al. Induction and Targeting of the Glutamine Transporter SN1 to the Basolateral Membranes of Cortical Kidney Tubule Cells During Chronic Metabolic Acidosis Suggest a Role in Ph Regulation. J Am Soc Nephrol (2005) 16(4):869-77. doi: 10.1681/ asn. 2004060433 
92. Bourgeois S, Meer LV, Wootla B, Bloch-Faure M, Chambrey R, Shull GE, et al. NHE4 is Critical for the Renal Handling of Ammonia in Rodents. J Clin Invest (2010) 120(6):1895-904. doi: 10.1172/jci36581

93. Kikeri D, Sun A, Zeidel ML, Hebert SC. Cell Membranes Impermeable to NH3. Nature (1989) 339(6224):478-80. doi: 10.1038/339478a0

94. Lee S, Lee HJ, Yang HS, Thornell IM, Bevensee MO, Choi I. SodiumBicarbonate Cotransporter Nbcn1 in the Kidney Medullary Thick Ascending Limb Cell Line is Upregulated Under Acidic Conditions and Enhances Ammonium Transport. Exp Physiol (2010) 95(9):926-37. doi: 10.1113/ expphysiol.2010.053967

95. Weiner ID, Verlander JW. Role of NH3 and NH4+ Transporters in Renal Acid-Base Transport. Am J Physiol Renal Physiol (2011) 300(1):F11-23. doi: 10.1152/ajprenal.00554.2010

96. Bishop JM, Verlander JW, Lee HW, Nelson RD, Weiner AJ, Handlogten ME, et al. Role of the Rhesus Glycoprotein, Rh B Glycoprotein, in Renal Ammonia Excretion. Am J Physiol Renal Physiol (2010) 299(5):F1065-77. doi: 10.1152/ajprenal.00277.2010

97. Lee HW, Verlander JW, Bishop JM, Igarashi P, Handlogten ME, Weiner ID. Collecting Duct-Specific Rh C Glycoprotein Deletion Alters Basal and Acidosis-Stimulated Renal Ammonia Excretion. Am J Physiol Renal Physiol (2009) 296(6):F1364-75. doi: 10.1152/ajprenal.90667.2008

98. Wall SM. Ammonium Transport and the Role of the Na,K-Atpase. Miner Electrolyte Metab (1996) 22(5-6):311-7.

99. Caso G, Garlick PJ. Control of Muscle Protein Kinetics by Acid-Base Balance. Curr Opin Clin Nutr Metab Care (2005) 8(1):73-6. doi: 10.1097/ 00075197-200501000-00011

100. Lee HW, Osis G, Handlogten ME, Guo H, Verlander JW, Weiner ID. Effect of Dietary Protein Restriction on Renal Ammonia Metabolism. Am J Physiol Renal Physiol (2015) 308(12):F1463-73. doi: 10.1152/ajprenal.00077.2015

101. Weiner ID, Mitch WE, Sands JM. Urea and Ammonia Metabolism and the Control of Renal Nitrogen Excretion. Clin J Am Soc Nephrol (2015) 10 (8):1444-58. doi: 10.2215/cjn.10311013

102. Morato-Conceicao YT, Alves-Junior ER, Arruda TA, Lopes JC, Fontes CJ. Serum Uric Acid Levels During Leprosy Reaction Episodes. PeerJ (2016) 4: e1799. doi: 10.7717/peerj.1799

103. Welbourne TC, Givens G, Joshi S. Renal Ammoniagenic Response to Chronic Acid Loading: Role of Glucocorticoids. Am J Physiol (1988) 254(1 Pt 2):F134-8. doi: 10.1152/ajprenal.1988.254.1.F134

104. Han KH, Lee HW, Handlogten ME, Bishop JM, Levi M, Kim J, et al. Effect of Hypokalemia on Renal Expression of the Ammonia Transporter Family Members, Rh B Glycoprotein and Rh C Glycoprotein, in the Rat Kidney. Am J Physiol Renal Physiol (2011) 301(4):F823-32. doi: 10.1152/ ajprenal.00266.2011

105. Tannen RL. Diuretic-Induced Hypokalemia. Kidney Int (1985) 28(6):9881000. doi: $10.1038 / \mathrm{ki} .1985 .229$

106. Bounoure L, Ruffoni D, Müller R, Kuhn GA, Bourgeois S, Devuyst O, et al. The Role of the Renal Ammonia Transporter Rhcg in Metabolic Responses to Dietary Protein. J Am Soc Nephrol (2014) 25(9):2040-52. doi: 10.1681/ asn.2013050466

107. Chen X, Chen T, Sun J, Luo J, Liu J, Zeng B, et al. Lower Methionine/Cystine Ratio in Low-Protein Diet Improves Animal Reproductive Performance by Modulating Methionine Cycle. Food Sci Nutr (2019) 7(9):2866-74. doi: $10.1002 / \mathrm{fsn} 3.1128$

108. Gonzalez-Vicente A, Garvin JL. Effects of Reactive Oxygen Species on Tubular Transport Along the Nephron. Antioxid (Basel) (2017) 6(2):23. doi: 10.3390/antiox6020023

109. Wilding JP. The Role of the Kidneys in Glucose Homeostasis in Type 2 Diabetes: Clinical Implications and Therapeutic Significance Through Sodium Glucose Co-Transporter 2 Inhibitors. Metabolism (2014) 63 (10):1228-37. doi: 10.1016/j.metabol.2014.06.018

110. Liang Y, Arakawa K, Ueta K, Matsushita Y, Kuriyama C, Martin T, et al. Effect of Canagliflozin on Renal Threshold for Glucose, Glycemia, and Body Weight in Normal and Diabetic Animal Models. PLoS One (2012) 7(2): e30555. doi: 10.1371/journal.pone.0030555

111. Fujita Y, Inagaki N. Renal Sodium Glucose Cotransporter 2 Inhibitors as a Novel Therapeutic Approach to Treatment of Type 2 Diabetes: Clinical Data and Mechanism of Action. J Diabetes Investig (2014) 5(3):265-75. doi: $10.1111 /$ jdi.12214
112. Bays H. From Victim to Ally: The Kidney as an Emerging Target for the Treatment of Diabetes Mellitus. Curr Med Res Opin (2009) 25(3):671-81. doi: 10.1185/03007990802710422

113. Good DW, Knepper MA. Mechanisms of Ammonium Excretion: Role of the Renal Medulla. Semin Nephrol (1990) 10(2):166-73.

114. Nguyen HT, Vu TY, Dakal TC, Dhabhai B, Nguyen XHQ, Tatipamula VB. Cleroda-4(18),13-Dien-15,16-Olide as Novel Xanthine Oxidase Inhibitors: An Integrated In Silico and In Vitro Study. PLoS One (2021) 16(6):e0253572. doi: 10.1371/journal.pone.0253572

115. Wang X, Yuan Y, Didelija IC, Mohammad MA, Marini JC. Ex Vivo Enteroids Recapitulate In Vivo Citrulline Production in Mice. J Nutr (2018) 148 (9):1415-20. doi: 10.1093/jn/nxy126

116. Marini JC, Agarwal U, Robinson JL, Yuan Y, Didelija IC, Stoll B, et al. The Intestinal-Renal Axis for Arginine Synthesis is Present and Functional in the Neonatal Pig. Am J Physiol Endocrinol Metab (2017) 313(2):E233-e242. doi: 10.1152/ajpendo.00055.2017

117. Kobayashi M, Shu S, Marunaka K, Matsunaga T, Ikari A. Weak Ultraviolet B Enhances the Mislocalization of Claudin-1 Mediated by Nitric Oxide and Peroxynitrite Production in Human Keratinocyte-Derived Hacat Cells. Int $J$ Mol Sci (2020) 21(19):7138. doi: 10.3390/ijms21197138

118. Garvin JL, Herrera M, Ortiz PA. Regulation of Renal Nacl Transport by Nitric Oxide, Endothelin, and ATP: Clinical Implications. Annu Rev Physiol (2011) 73:359-76). doi: 10.1146/annurev-physiol-012110-142247

119. Mount PF, Power DA. Nitric Oxide in the Kidney: Functions and Regulation of Synthesis. Acta Physiol (Oxf) (2006) 187(4):433-46. doi: 10.1111/j.17481716.2006.01582.x

120. Hu X, Atzler D, Xu X, Zhang P, Guo H, Lu Z, et al. Dimethylarginine Dimethylaminohydrolase-1 is the Critical Enzyme for Degrading the Cardiovascular Risk Factor Asymmetrical Dimethylarginine. Arterioscler Thromb Vasc Biol (2011) 31(7):1540-6. doi: 10.1161/atvbaha. 110.222638

121. Garibotto G, Valli A, Anderstam B, Eriksson M, Suliman ME, Balbi M, et al. The Kidney is the Major Site of s-Adenosylhomocysteine Disposal in Humans. Kidney Int (2009) 76(3):293-6. doi: 10.1038/ki.2009.117

122. Møller N, Meek S, Bigelow M, Andrews J, Nair KS, et al. The Kidney is an Important Site for In Vivo Phenylalanine-to-Tyrosine Conversion in Adult Humans: A Metabolic Role of the Kidney. Proc Natl Acad Sci U S A (2000) 97 (3):1242-6. doi: 10.1073/pnas.97.3.1242

123. Ayling JE, Pirson WD, al-Janabi JM, Helfand GD. Kidney Phenylalanine Hydroxylase From Man and Rat. Comparison With the Liver Enzyme. Biochemistry (1974) 13(1):78-85. doi: 10.1021/bi00698a013

124. Tessari P, Deferrari G, Robaudo C, Vettore M, Pastorino N, De Biasi L, et al. Phenylalanine Hydroxylation Across the Kidney in Humans Rapid Communication. Kidney Int (1999) 56(6):2168-72. doi: 10.1038/ sj.ki.4491156

125. Cao W, Li A, Wang L, Zhou Z, Su Z, Bin W, et al. A Salt-Induced RenoCerebral Reflex Activates Renin-Angiotensin Systems and Promotes CKD Progression. J Am Soc Nephrol (2015) 26(7):1619-33. doi: 10.1681/ asn. 2014050518

126. Fehrenbach DJ, Mattson DL. Inflammatory Macrophages in the Kidney Contribute to Salt-Sensitive Hypertension. Am J Physiol Renal Physiol (2020) 318(3):F544-f548. doi: 10.1152/ajprenal.00454.2019

127. Hernandez AL, Kitz A, Wu C, Lowther DE, Rodriguez DM, Vudattu N, et al. Sodium Chloride Inhibits the Suppressive Function of FOXP3+ Regulatory T Cells. J Clin Invest (2015) 125(11):4212-22. doi: 10.1172/ jci81151

128. Asai H, Hirata J, Hirano A, Hirai K, Seki S, Watanabe-Akanuma M. Activation of Aryl Hydrocarbon Receptor Mediates Suppression of Hypoxia-Inducible Factor-Dependent Erythropoietin Expression by Indoxyl Sulfate. Am J Physiol Cell Physiol (2016) 310(2):C142-50. doi: 10.1152/ajpcell.00172.2015

129. Vaziri ND, Yuan J, Norris K. Role of Urea in Intestinal Barrier Dysfunction and Disruption of Epithelial Tight Junction in Chronic Kidney Disease. Am J Nephrol (2013) 37(1):1-6. doi: 10.1159/000345969

130. Gryp T, Huys GRB, Joossens M, Van Biesen W, Glorieux G, Vaneechoutte $\mathrm{M}$, et al. Isolation and Quantification of Uremic Toxin Precursor-Generating Gut Bacteria in Chronic Kidney Disease Patients. Int J Mol Sci (2020) 21 (6):1986. doi: 10.3390/ijms21061986 
131. Howie D, Ten Bokum A, Cobbold SP, Yu Z, Kessler BM, Waldmann H. A Novel Role for Triglyceride Metabolism in Foxp3 Expression. Front Immunol (2019) 10:1860. doi: 10.3389/fimmu.2019.01860

132. Grzes KM, Field CS, Pearce EJ. Treg Cells Survive and Thrive in Inhospitable Environments. Cell Metab (2017) 25(6):1213-5. doi: 10.1016/j.cmet.2017. 05.012

133. Wang W, Wang X, Lu S, Lv H, Zhao T, Xie G, et al. Metabolic Disturbance and Th17/Treg Imbalance are Associated With Progression of Gingivitis. Front Immunol (2021) 12:670178. doi: 10.3389/fimmu.2021.670178

134. Hasegawa S, Tanaka T, Saito T, Fukui K, Wakashima T, Susaki EA, et al. The Oral Hypoxia-Inducible Factor Prolyl Hydroxylase Inhibitor Enarodustat Counteracts Alterations in Renal Energy Metabolism in the Early Stages of Diabetic Kidney Disease. Kidney Int (2020) 97(5):934-50. doi: 10.1016/ j.kint.2019.12.007

135. Guo Z, Li Z, Deng Y, Chen SL. Photoacoustic Microscopy for Evaluating a Lipopolysaccharide-Induced Inflammation Model in Mice. J Biophotonics (2019) 12(3):e201800251. doi: 10.1002/jbio.201800251

136. Dang EV, Barbi J, Yang HY, Jinasena D, Yu H, Zheng Y, et al. Control of T (H)17/T(Reg) Balance by Hypoxia-Inducible Factor 1. Cell (2011) 146 (5):772-84. doi: 10.1016/j.cell.2011.07.033

137. Allocco JB, Alegre M-L. Exploiting Immunometabolism and T Cell Function for Solid Organ Transplantation. Cell Immunol (2020) 351:104068. doi: 10.1016/j.cellimm.2020.104068

138. Sharabi A, Tsokos GC. T Cell Metabolism: New Insights in Systemic Lupus Erythematosus Pathogenesis and Therapy. Nat Rev Rheumatol (2020) 16 (2):100-12. doi: 10.1038/s41584-019-0356-x

139. Wawman RE, Bartlett H, Oo YH. Regulatory T Cell Metabolism in the Hepatic Microenvironment. Front Immunol (2017) 8:1889. doi: 10.3389/ fimmu.2017.01889

140. Cluxton D, Petrasca A, Moran B, Fletcher JM. Differential Regulation of Human Treg and Th17 Cells by Fatty Acid Synthesis and Glycolysis. Front Immunol (2019) 10:115. doi: 10.3389/fimmu.2019.00115

141. Zala D, Hinckelmann MV, Yu H, Lyra da Cunha MM, Liot G, Cordelières FP, et al. Vesicular Glycolysis Provides on-Board Energy for Fast Axonal Transport. Cell (2013) 152(3):479-91. doi: 10.1016/j.cell.2012.12.029

142. Charbonnier LM, Cui Y, Stephen-Victor E, Harb H, Lopez D, Bleesing JJ, et al. Functional Reprogramming of Regulatory $\mathrm{T}$ Cells in the Absence of Foxp3. Nat Immunol (2019) 20(9):1208-19. doi: 10.1038/s41590-019-0442-x

143. Basu S, Hubbard B, Shevach EM. Foxp3-Mediated Inhibition of Akt Inhibits Glut1 (Glucose Transporter 1) Expression in Human T Regulatory Cells. J Leukoc Biol (2015) 97(2):279-83. doi: 10.1189/jlb.2AB0514-273RR

144. Gerriets VA, Kishton RJ, Nichols AG, Macintyre AN, Inoue M, Ilkayeva O, et al. Metabolic Programming and PDHK1 Control CD4+ T Cell Subsets and Inflammation. J Clin Invest (2015) 125(1):194-207. doi: 10.1172/jci76012

145. Eleftheriadis T, Pissas G, Karioti A, Antoniadi G, Antoniadis N, Liakopoulos V, et al. Dichloroacetate at Therapeutic Concentration Alters Glucose Metabolism and Induces Regulatory T-Cell Differentiation in Alloreactive Human Lymphocytes. J Basic Clin Physiol Pharmacol (2013) 24(4):271-6. doi: 10.1515/jbcpp-2013-0001

146. Shi LZ, Wang R, Huang G, Vogel P, Neale G, Green DR, et al. HIFlalphaDependent Glycolytic Pathway Orchestrates a Metabolic Checkpoint for the Differentiation of TH17 and Treg Cells. J Exp Med (2011) 208(7):1367-76. doi: $10.1084 /$ jem.20110278

147. Porta-Pardo E, Godzik A. E-Driver: A Novel Method to Identify Protein Regions Driving Cancer. Bioinformatics (2014) 30(21):3109-14. doi: 10.1093/ bioinformatics/btu499

148. De Rosa V, Galgani M, Porcellini A, Colamatteo A, Santopaolo M, Zuchegna C, et al. Glycolysis Controls the Induction of Human Regulatory T Cells by Modulating the Expression of FOXP3 Exon 2 Splicing Variants. Nat Immunol (2015) 16(11):1174-84. doi: 10.1038/ni.3269

149. MacIver NJ, Michalek RD, Rathmell JC, et al. Metabolic Regulation of T Lymphocytes. Annu Rev Immunol (2013) 31:259-83. doi: 10.1146/annurevimmunol-032712-095956

150. Comito G, Iscaro A, Bacci M, Morandi A, Ippolito L, Parri M, et al. Lactate Modulates CD4(+) T-Cell Polarization and Induces an Immunosuppressive Environment, Which Sustains Prostate Carcinoma Progression via TLR8/ Mir21 Axis. Oncogene (2019) 38(19):3681-95. doi: 10.1038/s41388-019$0688-7$
151. Nilaweera K, Herwig A, Bolborea M, Campbell G, Mayer CD, Morgan PJ, et al. Photoperiodic Regulation of Glycogen Metabolism, Glycolysis, and Glutamine Synthesis in Tanycytes of the Siberian Hamster Suggests Novel Roles of Tanycytes in Hypothalamic Function. Glia (2011) 59(11):1695-705. doi: 10.1002/glia.21216

152. Ippolito L, Morandi A, Taddei ML, Parri M, Comito G, Iscaro A, et al. Cancer-Associated Fibroblasts Promote Prostate Cancer Malignancy via Metabolic Rewiring and Mitochondrial Transfer. Oncogene (2019) 38 (27):5339-55. doi: 10.1038/s41388-019-0805-7

153. Patsoukis N, Bardhan K, Chatterjee P, Sari D, Liu B, Bell LN, et al. PD-1 Alters T-Cell Metabolic Reprogramming by Inhibiting Glycolysis and Promoting Lipolysis and Fatty Acid Oxidation. Nat Commun (2015) 6:6692. doi: $10.1038 /$ ncomms 7692

154. Fischer HJ, Sie C, Schumann E, Witte A-K, Dressel R, van den Brandt J, et al. The Insulin Receptor Plays a Critical Role in T Cell Function and Adaptive Immunity. J Immunol (2017) 198(5):1910-20. doi: 10.4049/jimmunol. 1601011

155. Pompura SL, Dominguez-Villar M. The PI3K/AKT Signaling Pathway in Regulatory T-Cell Development, Stability, and Function. J Leukocyte Biol (2018) 103(6):1065-76. doi: 10.1002/jlb.2mir0817-349r

156. Kim JY, Hickner RC, Cortright RL, Dohm GL, Houmard JA. Lipid Oxidation is Reduced in Obese Human Skeletal Muscle. Am J Physiol Endocrinol Metab (2000) 279(5):E1039-44. doi: 10.1152/ajpendo.2000.279.5.E1039

157. Nouws J, Nijtmans L, Houten SM, van den Brand M, Huynen M, Venselaar $\mathrm{H}$, et al. Acyl-Coa Dehydrogenase 9 is Required for the Biogenesis of Oxidative Phosphorylation Complex I. Cell Metab (2010) 12(3):283-94. doi: 10.1016/j.cmet.2010.08.002

158. Rogers RP, Rogina B. The Role of INDY in Metabolism, Health and Longevity. Front Genet (2015) 6:204. doi: 10.3389/fgene.2015.00204

159. Jeong SY, Jeong DY, Kim DS, Park S. Chungkookjang With High Contents of Poly- $\gamma$-Glutamic Acid Improves Insulin Sensitizing Activity in Adipocytes and Neuronal Cells. Nutrients (2018) 10(11). doi: 10.3390/nu10111588

160. Tarbier M, Mackowiak SD, Frade J, Catuara-Solarz S, Biryukova I, Gelali E, et al. Nuclear Gene Proximity and Protein Interactions Shape Transcript Covariations in Mammalian Single Cells. Nat Commun (2020) 11(1):5445. doi: 10.1038/s41467-020-19011-5

161. Sheikh BN, Guhathakurta S, Akhtar A. The non-Specific Lethal (NSL) Complex at the Crossroads of Transcriptional Control and Cellular Homeostasis. EMBO Rep (2019) 20(7):e47630. doi: 10.15252/ embr.201847630

162. Ralto KM, Rhee EP, Parikh SM. NAD Homeostasis in Renal Health and Disease. Nature Reviews. Nephrology (2020) 16(2):99-111. doi: 10.1038/ s41581-019-0216-6

163. Pulinilkunnil T, He H, Kong D, Asakura K, Peroni OD, Lee A, et al. Adrenergic Regulation of AMP-Activated Protein Kinase in Brown Adipose Tissue In Vivo. J Biol Chem (2011) 286(11):8798-809. doi: 10.1074/ jbc.M111.218719

164. Schönke M, Massart J, Zierath JR. Effects of High-Fat Diet and AMPActivated Protein Kinase Modulation on the Regulation of Whole-Body Lipid Metabolism. J Lipid Res (2018) 59(7):1276-82. doi: 10.1194/ jlr.D082370

165. O'Neill LA, Hardie DG. Metabolism of Inflammation Limited by AMPK and Pseudo-Starvation. Nature (2013) 493(7432):346-55. doi: 10.1038/ nature 11862

166. Xu X, Wang Y, Wei Z, Wei W, Zhao P, Tong B, et al. Madecassic Acid, the Contributor to the Anti-Colitis Effect of Madecassoside, Enhances the Shift of Th17 Toward Treg Cells via the Ppary/Ampk/Acc1 Pathway. Cell Death Dis (2017) 8(3):e2723. doi: 10.1038/cddis.2017.150

167. Field CS, Baixauli F, Kyle RL, Puleston DJ, Cameron AM, Sanin DE, et al. Mitochondrial Integrity Regulated by Lipid Metabolism is a Cell-Intrinsic Checkpoint for Treg Suppressive Function. Cell Metab (2020) 31(2):422437.e5. doi: 10.1016/j.cmet.2019.11.021

168. Pacella, Procaccini C, Focaccetti C, Miacci S, Timperi E, Faicchia D, et al. Fatty Acid Metabolism Complements Glycolysis in the Selective Regulatory T Cell Expansion During Tumor Growth. Proc Natl Acad Sci United States America (2018) 115(28):E6546-55. doi: 10.1073/pnas.1720113115

169. Siska PJ, Singer K, Evert K, Renner K, Kreutz M. The Immunological Warburg Effect: Can a Metabolic-Tumor-Stroma Score (Mets) Guide 
Cancer Immunotherapy? Immunol Rev (2020) 295(1):187-202. doi: 10.1111/ imr. 12846

170. Zhou X, Tang J, Cao H, Fan H, Li B. Tissue Resident Regulatory T Cells: Novel Therapeutic Targets for Human Disease. Cell Mol Immunol (2015) 12 (5):543-52. doi: $10.1038 / \mathrm{cmi} .2015 .23$

171. Procaccini C, Galgani M, De Rosa V, Matarese G. Intracellular Metabolic Pathways Control Immune Tolerance. Trends Immunol (2012) 33(1):1-7. doi: 10.1016/j.it.2011.09.002

172. Feuerer M, Herrero L, Cipolletta D, Naaz A, Wong J, Nayer A, et al. Lean, But Not Obese, Fat is Enriched for a Unique Population of Regulatory T Cells That Affect Metabolic Parameters. Nat Med (2009) 15(8):930-9. doi: $10.1038 / \mathrm{nm} .2002$

173. Park J, Kim M, Kang SG, Jannasch AH, Cooper B, Patterson J, et al. ShortChain Fatty Acids Induce Both Effector and Regulatory T Cells by Suppression of Histone Deacetylases and Regulation of the Mtor-S6K Pathway. Mucosal Immunol (2015) 8(1):80-93. doi: 10.1038/mi.2014.44

174. Cholan PM, Han A, Woodie BR, Watchon M, Kurz AR, Laird AS, et al. Conserved Anti-Inflammatory Effects and Sensing of Butyrate in Zebrafish. Gut Microbes (2020) 12(1):1-11. doi: 10.1080/19490976.2020.1824563

175. Robak T. Novel Drugs for Chronic Lymphoid Leukemias: Mechanism of Action and Therapeutic Activity. Curr Med Chem (2009) 16(18):2212-34. doi: $10.2174 / 092986709788453122$

176. Park J, Goergen CJ, HogenEsch H, Kim CH. Chronically Elevated Levels of Short-Chain Fatty Acids Induce $\mathrm{T}$ Cell-Mediated Ureteritis and Hydronephrosis. J Immunol (2016) 196(5):2388-400. doi: 10.4049/ jimmunol.1502046

177. Zeng H, Yang K, Cloer C, Neale G, Vogel P, Chi H. Mtorc1 Couples Immune Signals and Metabolic Programming to Establish T(Reg)-Cell Function. Nature (2013) 499(7459):485-90. doi: 10.1038/nature12297

178. Kim M, Kim CH. Regulation of Humoral Immunity by Gut Microbial Products. Gut Microbes (2017) 8(4):392-9. doi: 10.1080/19490976. 2017.1299311

179. Piconese S, Procaccini C, Focaccetti C, Miacci S, Timperi E, Faicchia D, et al. Human OX40 Tunes the Function of Regulatory T Cells in Tumor and Nontumor Areas of Hepatitis C Virus-Infected Liver Tissue. Hepatology (2014) 60(5):1494-507. doi: 10.1002/hep.27188

180. Xu HE, Timperi E, Pacella I, Schinzari V, Tripodo C, Rossi M, et al. Molecular Recognition of Fatty Acids by Peroxisome ProliferatorActivated Receptors. Mol Cell (1999) 3(3):397-403. doi: 10.1016/s1097$2765(00) 80467-0$

181. Xu T, Lambert MH, Montana VG, Parks DJ, Blanchard SG, Brown PJ, et al. Metabolic Control of TH17 and Induced Treg Cell Balance by an Epigenetic Mechanism. Nature (2017) 548(7666):228-33. doi: 10.1038/ nature 23475

182. Mezrich JD, Fechner JH, Zhang X, Johnson BP, Burlingham WJ, Bradfield CA. An Interaction Between Kynurenine and the Aryl Hydrocarbon Receptor can Generate Regulatory T Cells. J Immunol (2010) 185(6):31908. doi: 10.4049/jimmunol.0903670

183. Buck MD, O'Sullivan D, Pearce EL. T Cell Metabolism Drives Immunity. J Exp Med (2015) 212(9):1345-60. doi: 10.1084/jem.20151159

184. Cobbold SP, Adams E, Farquhar CA, Nolan KF, Howie D, Lui KO, et al. Infectious Tolerance via the Consumption of Essential Amino Acids and Mtor Signaling. PANS (2009).

185. Munn DH, Sharma MD, Johnson TS. Treg Destabilization and Reprogramming: Implications for Cancer Immunotherapy. Cancer Res (2018) 78(18):5191-9. doi: 10.1158/0008-5472.CAN-18-1351

186. Munoz-Suano A, Hamilton AB, Betz AG. Gimme Shelter: The Immune System During Pregnancy. Immunol Rev (2011) 241(1):20-38. doi: 10.1111/ j.1600-065X.2011.01002.x

187. Rescigno M. Dendritic Cell Functions: Learning From Microbial Evasion Strategies. Semin Immunol (2015) 27(2):119-24. doi: 10.1016/j.smim.2015. 03.012

188. Wang R, Dillon CP, Shi LZ, Milasta S, Carter R, Finkelstein D, et al. The Transcription Factor Myc Controls Metabolic Reprogramming Upon $\mathrm{T}$ Lymphocyte Activation. Immunity (2011) 35(6):871-82. doi: 10.1016/ j.immuni.2011.09.021

189. Sauer S, Bruno L, Hertweck A, Finlay D, Leleu M, Spivakov M, et al. T Cell Receptor Signaling Controls Foxp3 Expression via PI3K, Akt, and
Mtor. Proc Natl Acad Sci USA (2008) 105(22):7797-802. doi: 10.1073/ pnas.0800928105

190. Yang J, Wang HX, Xie J, Li L, Wang J, Wan ECK, et al. Dgk $\alpha$ and $\zeta$ Activities Control $\mathrm{T}(\mathrm{H}) 1$ and $\mathrm{T}(\mathrm{H}) 17$ Cell Differentiation. Front Immunol (2019) 10:3048. doi: 10.3389/fimmu.2019.03048

191. Apostolidis SA, Rodríguez-Rodríguez N, Suárez-Fueyo A, Dioufa N, Ozcan E, Crispín JC, et al. Phosphatase PP2A is Requisite for the Function of Regulatory T Cells. Nat Immunol (2016) 17(5):556-64. doi: 10.1038/ni.3390

192. Yu X, Teng XL, Wang F, Zheng Y, Qu G, Zhou Y, et al. Metabolic Control of Regulatory T Cell Stability and Function by TRAF3IP3 at the Lysosome. J Exp Med (2018) 215(9):2463-76. doi: 10.1084/jem.20180397

193. Ergen AV, Boles NC, Goodell MA. Rantes/Ccl5 Influences Hematopoietic Stem Cell Subtypes and Causes Myeloid Skewing. Blood (2012) 119 (11):2500-9. doi: 10.1182/blood-2011-11-391730

194. Rosner M, Hengstschläger M. Cytoplasmic and Nuclear Distribution of the Protein Complexes Mtorc1 and Mtorc2: Rapamycin Triggers Dephosphorylation and Delocalization of the Mtorc2 Components Rictor and Sin1. Hum Mol Genet (2008) 17(19):2934-48. doi: 10.1093/hmg/ddn192

195. Kawata T, Tada K, Kobayashi M, Sakamoto T, Takiuchi Y, Iwai F, et al. Dual Inhibition of the Mtorc1 and Mtorc2 Signaling Pathways is a Promising Therapeutic Target for Adult T-Cell Leukemia. Cancer Sci (2018) 109 (1):103-11. doi: $10.1111 /$ cas.13431

196. Gui Y, Lu Q, Gu M, Wang M, Liang Y, Zhu X, et al. Fibroblast Mtor/Ppary/ HGF Axis Protects Against Tubular Cell Death and Acute Kidney Injury. Cell Death Differ (2019) 26(12):2774-89. doi: 10.1038/s41418-019-0336-3

197. Huang B, Mao CP, Peng S, Hung CF, Wu TC. Rna Interference-Mediated In Vivo Silencing of Fas Ligand as a Strategy for the Enhancement of DNA Vaccine Potency. Hum Gene Ther (2008) 19(8):763-73. doi: 10.1089/ hum.2007.059

198. Perumalsamy LR, Marcel N, Kulkarni S, Radtke F, Sarin A. Distinct Spatial and Molecular Features of Notch Pathway Assembly in Regulatory T Cells. Sci Signal (2012) 5(234):ra53. doi: 10.1126/scisignal.2002859

199. Michalek RD, Gerriets VA, Jacobs SR, Macintyre AN, MacIver NJ, Mason EF, et al. Cutting Edge: Distinct Glycolytic and Lipid Oxidative Metabolic Programs are Essential for Effector and Regulatory CD4+ T Cell Subsets. J Immunol (Baltimore Md. 1950) (2011) 186(6):3299-303. doi: 10.4049/ jimmunol.1003613

200. Wu D, Luo Y, Guo W, Niu Q, Xue T, Yang F, et al. Lkb1 Maintains T Cell Lineage Identity. Nat Commun (2017) 8:15876. doi: 10.1038/ncomms15876

201. Luo Y, Xue Y, Wang J, Dang J, Fang Q, Huang G, et al. Negligible Effect of Sodium Chloride on the Development and Function of TGF- $\beta$-Induced Cd4 (+) Foxp3(+) Regulatory T Cells. Cell Rep (2019) 26(7):1869-79.e3. doi: 10.1016/j.celrep.2019.01.066

202. Zhang J, Hua G, Zhang X, Tong R, Du X, Li Z. Regulatory T Cells/T-Helper Cell 17 Functional Imbalance in Uraemic Patients on Maintenance Haemodialysis: A Pivotal Link Between Microinflammation and Adverse Cardiovascular Events. Nephrol (Carlton) (2010) 15(1):33-41. doi: 10.1111/ j.1440-1797.2009.01172.x

203. Hendrikx TK, van Gurp EA, Mol WM, Schoordijk W, Sewgobind VD, Ijzermans JN, et al. End-Stage Renal Failure and Regulatory Activities of CD4 +CD25bright+Foxp3+ T-Cells. Nephrol Dial Transplant (2009) 24(6):196978. doi: $10.1093 / \mathrm{ndt} / \mathrm{gfp} 005$

204. Tang S, Hou Y, Zhang H, Tu G, Yang L, Sun Y, et al. Oxidized ATM Promotes Abnormal Proliferation of Breast Cafs Through Maintaining Intracellular Redox Homeostasis and Activating the PI3K-AKT, MEK-ERK, and Wnt- $\beta$ Catenin Signaling Pathways. Cell Cycle (Georgetown Tex.) (2015) 14(12):190824. doi: 10.1080/15384101.2015.1041685

205. Mougiakakos D. The Induction of a Permissive Environment to Promote T Cell Immune Evasion in Acute Myeloid Leukemia: The Metabolic Perspective. Front Oncol (2019) 9:1166. doi: 10.3389/fonc.2019.01166

206. Josefowicz SZ, Rudensky A. Control of Regulatory T Cell Lineage Commitment and Maintenance. Immunity (2009) 30(5):616-25. doi: 10.1016/j.immuni.2009.04.009

207. Lio C-WJ, Yuita H, Rao A. Dysregulation of the TET Family of Epigenetic Regulators in Lymphoid and Myeloid Malignancies. Blood (2019) 134 (18):1487-97. doi: 10.1182/blood.2019791475

208. Reinert-Hartwall L, Honkanen J, Härkönen T, Ilonen J, Simell O, Peet A, et al. No Association Between Vitamin D and $\beta$-Cell Autoimmunity in 
Finnish and Estonian Children. Diabetes/Metabol Res Rev (2014) 30(8):74960. doi: $10.1002 / \mathrm{dmr} .2550$

209. Yin Y, Choi S-C, Xu Z, Perry DJ, Seay H, Croker BP, et al. Normalization of CD4+ T Cell Metabolism Reverses Lupus. Sci Trans Med (2015) 7 (274):274ra18. doi: 10.1126/scitranslmed.aaa0835

210. Sharma R, Kinsey GR. Regulatory T Cells in Acute and Chronic Kidney Diseases. Am J Physiol Renal Physiol (2018) 314(5):F679-f698. doi: 10.1152/ ajprenal.00236.2017

211. Lai ZW, Kelly R, Winans T, Marchena I, Shadakshari A, Yu J, et al. Sirolimus in Patients With Clinically Active Systemic Lupus Erythematosus Resistant to, or Intolerant of, Conventional Medications: A Single-Arm, Open-Label, Phase 1/2 Trial. Lancet (2018) 391(10126):1186-96. doi: 10.1016/s0140-6736 (18)30485-9

212. Andrade L, Rodrigues CE, Gomes SA, Noronha IL. Acute Kidney Injury as a Condition of Renal Senescence. Cell Transplant (2018) 27(5):739-53. doi: 10.1177/0963689717743512

213. Hoste EAJ, Kellum JA, Selby NM, Zarbock A, Palevsky PM, Bagshaw SM, et al. Global Epidemiology and Outcomes of Acute Kidney Injury. Nat Rev Nephrol (2018) 14(10):607-25. doi: 10.1038/s41581-018-0052-0

214. Sato Y, Takahashi M, Yanagita M. Pathophysiology of AKI to CKD Progression. Semin Nephrol (2020) 40(2):206-15. doi: 10.1016/ j.semnephrol.2020.01.011

215. Chan L. Harnessing Regulatory T Cells for Therapeutic Purposes. Kidney Int (2012) 81(10):935-6. doi: 10.1038/ki.2012.29

216. Zhao YY, Vaziri ND, Lin RC. Lipidomics: New Insight Into Kidney Disease. Adv Clin Chem (2015) 68:153-75. doi: 10.1016/bs.acc.2014.11.002

217. Portilla D. Energy Metabolism and Cytotoxicity. Semin Nephrol (2003) 23 (5):432-8. doi: 10.1016/s0270-9295(03)00088-3

218. Weinberg JM. Lipotoxicity. Kidney Int (2006) 70(9):1560-6. doi: 10.1038/ sj.ki.5001834

219. Wu J, Chen L, Zhang D, Huo M, Zhang X, Pu D, et al. Peroxisome Proliferator-Activated Receptors and Renal Diseases. Front Biosci (Landmark Ed) (2009) 14:995-1009). doi: 10.2741/3291

220. Li W, Qu G, Choi S-C, Cornaby C, Titov A, Kanda N, et al. Targeting T Cell Activation and Lupus Autoimmune Phenotypes by Inhibiting Glucose Transporters. Front Immunol (2019) 10:833. doi: 10.3389/fimmu.2019.00833

221. Liu R-T, Zhang M, Yang C-L, Zhang P, Zhang N, Du T, et al. Enhanced Glycolysis Contributes to The Pathogenesis of Experimental Autoimmune Neuritis. J Neuroinflamm (2018) 15(1):51. doi: 10.1186/s12974-018-1095-7

222. Stacpoole PW. The Dichloroacetate Dilemma: Environmental Hazard Versus Therapeutic Goldmine-Both or Neither? Environ Health Perspect (2011) 119(2):155-8. doi: 10.1289/ehp.1002554

223. Gerriets VA, Kishton RJ, Nichols AG, Macintyre AN, Inoue M, Ilkayeva O, et al. Metabolic Programming and PDHK1 Control CD4+ T Cell Subsets and Inflammation. J Clin Invest (2015) 125(1):194-207. doi: 10.1172/JCI76012

224. Andrejeva G, Rathmell JC. Similarities and Distinctions of Cancer and Immune Metabolism in Inflammation and Tumors. Cell Metab (2017) 26 (1):49-70. doi: 10.1016/j.cmet.2017.06.004

225. Cipolletta D, Feuerer M, Li A, Kamei N, Lee J, Shoelson SE, et al. PPAR- $\gamma$ is a Major Driver of the Accumulation and Phenotype of Adipose Tissue Treg cells. Nature (2012) 486(7404):549-53. doi: 10.1038/nature11132

226. Elrashidy RA, Asker ME, Mohamed HE. Pioglitazone attenuates Cardiac Fibrosis and Hypertrophy in a Rat Model of Diabetic Nephropathy. J Cardiovasc Pharmacol Ther (2012) 17(3):324-33. doi: 10.1177/ 1074248411431581

227. Jump DB, Torres-Gonzalez M, Olson LK. Soraphen A, an Inhibitor of Acetyl CoA Carboxylase Activity, Interferes With Fatty Acid Elongation. Biochem Pharmacol (2011) 81(5):649-60. doi: 10.1016/j.bcp.2010.12.014

228. Guseva NV, Rokhlin OW, Glover RA, Cohen MB. TOFA (5-tetradecyl-oxy2 -furoic acid) Reduces Fatty Acid Synthesis, Inhibits Expression of AR, Neuropilin-1 and Mcl-1 and Kills Prostate Cancer Cells Independent of p53 Status. Cancer Biol Ther (2011) 12(1):80-5. doi: 10.4161/cbt.12.1.15721

229. Rupp H, Zarain-Herzberg A, Maisch B. The Use of Partial Fatty Acid Oxidation Inhibitors for Metabolic Therapy of Angina Pectoris and Heart Failure. Herz (2002) 27(7):621-36. doi: 10.1007/s00059-002-2428-x

230. Shriver LP, Manchester M. Inhibition of fatty Acid Metabolism Ameliorates Disease Activity in an Animal Model of Multiple Sclerosis. Sci Rep (2011) 1:79. doi: $10.1038 /$ srep00079
231. Lee C-F, Lo Y-C, Cheng C-H, Furtmüller GJ, Oh B, Andrade-Oliveira V, et al. Preventing Allograft Rejection by Targeting Immune Metabolism. Cell Rep (2015) 13(4):760-70. doi: 10.1016/j.celrep.2015.09.036

232. Kulkarni RM, Dakoulas EW, Miller KE, Terse PS. Evaluation of Genetic Toxicity of 6-Diazo-5-oxo-1-Norleucine (DON). Toxicol Mech Methods (2017) 27(7):518-27. doi: 10.1080/15376516.2017.1333552

233. Monti P, Scirpoli M, Maffi P, Piemonti L, Secchi A, Bonifacio E, et al. Rapamycin Monotherapy in Patients With Type 1 Diabetes Modifies CD4 +CD25+FOXP3+ Regulatory T-Cells. Diabetes (2008) 57(9):2341-7. doi: $10.2337 / \mathrm{db} 08-0138$

234. Friščić J, Böttcher M, Reinwald C, Bruns H, Wirth B, Popp S-J, et al. The Complement System Drives Local Inflammatory Tissue Priming by Metabolic Reprogramming of Synovial Fibroblasts. Immunity (2021) 54 (5):1002-1021.e10. doi: 10.1016/j.immuni.2021.03.003

235. Takeuchi H, Kondo Y, Fujiwara K, Kanzawa T, Aoki H, Mills GB, et al. Synergistic Augmentation of Rapamycin-Induced Autophagy in Malignant Glioma Cells by Phosphatidylinositol 3-Kinase/Protein Kinase B Inhibitors. Cancer Res (2005) 65(8):3336-46. doi: 10.1158/00085472.CAN-04-3640

236. Lee S-Y, Lee SH, Yang E-J, Kim E-K, Kim J-K, Shin D-Y, et al. Metformin Ameliorates Inflammatory Bowel Disease by Suppression of the STAT3 Signaling Pathway and Regulation of the Between Th17/Treg Balance. PloS One (2015) 10(9):e0135858. doi: 10.1371/journal.pone. 0135858

237. Zhou G, Myers R, Li Y, Chen Y, Shen X, Fenyk-Melody J, et al. Role of AMPActivated Protein Kinase in Mechanism of Metformin Action. J Clin Invest (2001) 108(8):1167-74. doi: 10.1172/JCI13505

238. Maslowski KM, Vieira AT, Ng A, Kranich J, Sierro F, Yu D, et al. Regulation of Inflammatory Responses by Gut Microbiota and Chemoattractant Receptor GPR43. Nature (2009) 461(7268):1282-6. doi: 10.1038/ nature 08530

239. Jesinkey SR, Funk JA, Stallons LJ, Wills LP, Megyesi JK, Beeson CC, et al. Formoterol Restores Mitochondrial and Renal Function After IschemiaReperfusion Injury. J Am Soc Nephrol (2014) 25(6):1157-62. doi: 10.1681/ asn.2013090952

240. Leverve X, Mustafa I, Novak I, Krouzecky A, Rokyta R, Matejovic M, et al. Lactate Metabolism in Acute Uremia. J Ren Nutr (2005) 15(1):58-62. doi: 10.1053/j.jrn.2004.09.023

241. Pacella I, Piconese S. Immunometabolic Checkpoints of Treg Dynamics: Adaptation to Microenvironmental Opportunities and Challenges. Front Immunol (2019) 10:1889. doi: 10.3389/fimmu.2019.01889

242. Angelin A, Gil-de-Gómez L, Dahiya S, Jiao J, Guo L, Levine MH, et al. Foxp3 Reprograms T Cell Metabolism to Function in Low-Glucose, High-Lactate Environments. Cell Metab (2017) 25(6):1282-1293.e7. doi: 10.1016/ j.cmet.2016.12.018

243. Singer P, Bendavid I, BenArie I, Stadlander L, Kagan I. Feasibility of Achieving Different Protein Targets Using a Hypocaloric High-Protein Enteral Formula in Critically Ill Patients. Crit Care (Lond Engl) (2021) 25 (1):204. doi: 10.1186/s13054-021-03625-2

244. Franz M, Hörl WH. Protein Catabolism in Acute Renal Failure. Miner Electrolyte Metab (1997) 23(3-6):189-93.

245. Rahmani S, Defferrari MS, Wakarchuk WW, Antonescu CN. Energetic Adaptations: Metabolic Control of Endocytic Membrane Traffic. Traffic (Copenhagen Denmark) (2019) 20(12):912-31. doi: 10.1111/tra.12705

246. Wang Z, Wen J, Zhou C, Wang Z, Wei M. Gene Expression Profiling Analysis to Investigate the Role of Remote Ischemic Postconditioning in Ischemia-Reperfusion Injury in Rats. BMC Genomics (2019) 20(1):361. doi: 10.1186/s12864-019-5743-9

247. Hesketh EE, Czopek A, Clay M, Borthwick G, Ferenbach D, Kluth D, et al. Renal Ischaemia Reperfusion Injury: A Mouse Model of Injury and Regeneration. J Vis Exp (2014) 2014(88):51816. doi: 10.3791/51816

248. Yamamoto R, Saito M, Saito T, Sagehashi R, Koizumi A, Nara T, et al. Treg Expansion With Trichostatin a Ameliorates Kidney Ischemia/Reperfusion Injury in Mice by Suppressing the Expression of Costimulatory Molecules. Transpl Immunol (2020) 63:101330. doi: 10.1016/j.trim.2020.101330

249. Agarwal A, Dong Z, Harris R, Murray P, Parikh SM, Rosner MH, et al. Cellular and Molecular Mechanisms of AKI. J Am Soc Nephrol (2016) 27 (5):1288-99. doi: 10.1681/asn.2015070740 
250. Zhou Y, Du D, Liu S, Zhao M, Yuan Y, Li L, et al. Polyacetylene Glycoside Attenuates Ischemic Kidney Injury by Co-Inhibiting Inflammation, Mitochondria Dysfunction and Lipotoxicity. Life Sci (2018) 204:55-64. doi: 10.1016/j.lfs.2018.05.009

251. Wei Q, Xiao X, Fogle P, Dong Z. Changes in Metabolic Profiles During Acute Kidney Injury and Recovery Following Ischemia/Reperfusion. PLoS One (2014) 9(9):e106647. doi: 10.1371/journal.pone.0106647

252. Luan H, Wang C, Sun J, Zhao L, Li L, Zhou B, et al. Resolvin D1 Protects Against Ischemia/Reperfusion-Induced Acute Kidney Injury by Increasing Treg Percentages via the ALX/FPR2 Pathway. Front Physiol (2020) 11:285. doi: $10.3389 /$ fphys.2020.00285

253. Aversa F, Pierini A, Ruggeri L, Martelli MF, Velardi A. The Evolution of T Cell Depleted Haploidentical Transplantation. Front Immunol (2019) 10 (2769):2769. doi: 10.3389/fimmu.2019.02769

254. Lee SY, Lee YS, Choi HM, Ko YS, Lee HY, Jo SK, et al. Distinct Pathophysiologic Mechanisms of Septic Acute Kidney Injury: Role of Immune Suppression and Renal Tubular Cell Apoptosis in Murine Model of Septic Acute Kidney Injury. Crit Care Med (2012) 40(11):2997-3006. doi: 10.1097/CCM.0b013e31825b912d

255. Bagshaw SM, Lapinsky S, Dial S, Arabi Y, Dodek P, Wood G, et al. Acute Kidney Injury in Septic Shock: Clinical Outcomes and Impact of Duration of Hypotension Prior to Initiation of Antimicrobial Therapy. Intensive Care Med (2009) 35(5):871-81. doi: 10.1007/s00134-008-1367-2

256. Morrell ED, Kellum JA, Pastor-Soler NM, Hallows KR. Septic Acute Kidney Injury: Molecular Mechanisms and the Importance of Stratification and Targeting Therapy. Crit Care (2014) 18(5):501. doi: 10.1186/s13054-0140501-5

257. Han M, Li Y, Wen D, Liu M, Ma Y, Cong B. NGAL Protects Against Endotoxin-Induced Renal Tubular Cell Damage by Suppressing Apoptosis. BMC Nephrol (2018) 19(1):168. doi: 10.1186/s12882-018-0977-3

258. Song GY, Chung CS, Chaudry IH, Ayala A. What is the Role of Interleukin 10 in Polymicrobial Sepsis: Anti-Inflammatory Agent or Immunosuppressant? Surgery (1999) 126(2):378-83.

259. Pabla N, Dong Z. Cisplatin Nephrotoxicity: Mechanisms and Renoprotective Strategies. Kidney Int (2008) 73(9):994-1007. doi: 10.1038/sj.ki.5002786

260. Tadagavadi RK, Reeves WB. Endogenous IL-10 Attenuates Cisplatin Nephrotoxicity: Role of Dendritic Cells. J Immunol (2010) 185(8):4904-11. doi: 10.4049/jimmunol.1000383

261. Daley-Yates PT, McBrien DC. A Study of the Protective Effect of Chloride Salts on Cisplatin Nephrotoxicity. Biochem Pharmacol (1985) 34(13):2363-9. doi: 10.1016/0006-2952(85)90795-6

262. Santoso JT, Lucci JA3rd, Coleman RL, Schafer I, Hannigan EV. Saline, Mannitol, and Furosemide Hydration in Acute Cisplatin Nephrotoxicity: A Randomized Trial. Cancer Chemother Pharmacol (2003) 52(1):13-8. doi: $10.1007 / \mathrm{s} 00280-003-0620-1$

263. dos Santos NA, Carvalho Rodrigues MA, Martins NM, dos Santos AC. Cisplatin-Induced Nephrotoxicity and Targets of Nephroprotection: An Update. Arch Toxicol (2012) 86(8):1233-50. doi: 10.1007/s00204-0120821-7

264. Lee H, Nho D, Chung HS, Lee H, Shin MK, Kim SH, et al. CD4+CD25+ Regulatory T Cells Attenuate Cisplatin-Induced Nephrotoxicity in Mice. Kidney Int (2010) 78(11):1100-9. doi: 10.1038/ki.2010.139

265. Li Y, Li X, Wong YS, Chen T, Zhang H, Liu C, et al. The Reversal of Cisplatin-Induced Nephrotoxicity by Selenium Nanoparticles Functionalized With 11-Mercapto-1-Undecanol by Inhibition of ROSMediated Apoptosis. Biomaterials (2011) 32(34):9068-76. doi: 10.1016/ j.biomaterials.2011.08.001

266. Baliga R, Ueda N, Walker PD, Shah SV. Oxidant Mechanisms in Toxic Acute Renal Failure. Drug Metab Rev (1999) 31(4):971-97. doi: 10.1081/dmr100101947

267. Benedetti G, Fredriksson L, Herpers B, Meerman J, van de Water B, de Graauw M. Tnf- $\alpha$-Mediated Nf- $\kappa b$ Survival Signaling Impairment by Cisplatin Enhances JNK Activation Allowing Synergistic Apoptosis of Renal Proximal Tubular Cells. Biochem Pharmacol (2013) 85(2):274-86. doi: 10.1016/j.bcp.2012.10.012

268. Kim H, Hong JY, Jeon W-J, Baek SH, Ha I-H. Bee Venom Melittin Protects Against Cisplatin-Induced Acute Kidney Injury in Mice via the Regulation of
M2 Macrophage Activation. Toxins (2020) 12(9):574. doi: 10.3390/ toxins 12090574

269. Yu X, Xia Y, Zeng L, Zhang X, Chen L, Yan S, et al. A Blockade of PI3K $\gamma$ Signaling Effectively Mitigates Angiotensin II-Induced Renal Injury and Fibrosis in a Mouse Model. Sci Rep (2018) 8(1):10988. doi: 10.1038/ s41598-018-29417-3

270. McLean MR, Lu LL, Kent SJ, Chung AW. An Inflammatory Story: Antibodies in Tuberculosis Comorbidities. Front Immunol (2019) 10:2846. doi: 10.3389/fimmu.2019.02846

271. Musgrove J, Wolf M. Regulation and Effects of FGF23 in Chronic Kidney Disease. Annu Rev Physiol (2020) 82:365-90. doi: 10.1146/annurev-physiol021119-034650

272. Tang PC, Chan AS, Zhang CB, García Córdoba CA, Zhang YY, To KF, et al. Tgf- $\beta 1$ Signaling: Immune Dynamics of Chronic Kidney Diseases. Front Med (Lausanne) (2021) 8:628519. doi: 10.3389/fmed.2021.628519

273. Bendickova K, Fric J. Roles of IL-2 in Bridging Adaptive and Innate Immunity, and as a Tool for Cellular Immunotherapy. J Leukocyte Biol (2020) 108(1):427-37. doi: 10.1002/JLB.5MIR0420-055R

274. Hu Y, Cui Q, Ye Y, Luo Y, Tan Y, Shi J, et al. Reduction of Foxp3+ T Cell Subsets Involved in Incidence of Chronic Graft-Versus-Host Disease After Allogeneic Hematopoietic Stem Cell Transplantation. Hematol Oncol (2017) 35(1):118-24. doi: 10.1002/hon.2255

275. Wu WP, Tsai YG, Lin TY, Wu MJ, Lin CY. The Attenuation of Renal Fibrosis by Histone Deacetylase Inhibitors is Associated With the Plasticity of FOXP3(+)IL-17(+) T Cells. BMC Nephrol (2017) 18(1):225. doi: 10.1186/ s12882-017-0630-6

276. Irazabal MV, Torres VE. Reactive Oxygen Species and Redox Signaling in Chronic Kidney Disease. Cells (2020) 9(6):1342. doi: 10.3390/cells9061342

277. Inoue T, Ikeda H, Nakamura T, Abe S, Taguchi I, Kikuchi M, et al. Potential Benefit of Statin Therapy for Dyslipidemia With Chronic Kidney Disease: Fluvastatin Renal Evaluation Trial (FRET). Intern Med (2011) 50(12):12738. doi: 10.2169/internalmedicine.50.4059

278. Vaziri ND, Liu S-M, Lau WL, Khazaeli M, Nazertehrani S, Farzaneh SH, et al. High Amylose Resistant Starch Diet Ameliorates Oxidative Stress, Inflammation, and Progression of Chronic Kidney Disease. PLoS One (2014) 9(12):e114881. doi: 10.1371/journal.pone.0114881

279. Gisterå A, Hansson GK. The Immunology of Atherosclerosis. Nat Rev Nephrol (2017) 13(6):368-80. doi: 10.1038/nrneph.2017.51

280. Kempkes RWM, Joosten I, Koenen HJPM, He X. Metabolic Pathways Involved in Regulatory T Cell Functionality. Front Immunol (2019) 10:2839. doi: 10.3389/fimmu.2019.02839

281. Weinberg SE, Singer BD, Steinert EM, Martinez CA, Mehta MM, MartínezReyes I, et al. Mitochondrial Complex III is Essential for Suppressive Function of Regulatory T Cells. Nature (2019) 565(7740):495-9. doi: 10.1038/s41586-018-0846-Z

282. Wang M, Hu R, Wang Y, Liu L, You H, Zhang J, et al. Atractylenolide III Attenuates Muscle Wasting in Chronic Kidney Disease via the Oxidative Stress-Mediated PI3K/AKT/Mtor Pathway. Oxid Med Cell Longev (2019) 2019:1875471. doi: 10.1155/2019/1875471

283. Clement M, Charles N, Escoubet B, Guedj K, Chauveheid M-P, Caligiuri G, et al. CD4+CXCR3+ T Cells and Plasmacytoid Dendritic Cells Drive Accelerated Atherosclerosis Associated With Systemic Lupus Erythematosus. J Autoimmun (2015) 63(59-67). doi: 10.1016/ j.jaut.2015.07.001

284. Xu G, Gong Y, et al. Deregulation From CD4+ Memory T Cells to Regulatory Cells in Patients With Chronic Renal Failure: A Pilot Study. J Clin Lab Anal (2013) 27(6):423-6. doi: 10.1002/jcla.21622

285. Cai T, Ke Q, Fang Y, Wen P, Chen H, Yuan Q, et al. Sodium-Glucose Cotransporter 2 Inhibition Suppresses Hif-1 $\alpha$-Mediated Metabolic Switch From Lipid Oxidation to Glycolysis in Kidney Tubule Cells of Diabetic Mice. Cell Death Dis (2020) 11(5):390. doi: 10.1038/s41419-020-2544-7

286. Zhao L, Gao H, Lian F, Liu X, Zhao Y, Lin D, et al. ${ }^{1} \mathrm{H}-\mathrm{NMR}-B a s e d$ Metabonomic Analysis of Metabolic Profiling in Diabetic Nephropathy Rats Induced by Streptozotocin. American Journal of Physiology. Renal Physiol (2011) 300(4):F947-56. doi: 10.1152/ajprenal.00551.2010

287. Levey AS, Coresh J. Chronic Kidney Disease. Lancet (2012) 379(9811):16580. doi: 10.1016/s0140-6736(11)60178-5 
288. Kato M, Natarajan R. Diabetic Nephropathy-Emerging Epigenetic Mechanisms. Nat Rev Nephrol (2014) 10(9):517-30. doi: 10.1038/ nrneph.2014.116

289. Heerspink HJL, Parving HH, Andress DL, Bakris G, Correa-Rotter R, Hou FF, et al. Atrasentan and Renal Events in Patients With Type 2 Diabetes and Chronic Kidney Disease (SONAR): A Double-Blind, Randomised, PlaceboControlled Trial. Lancet (2019) 393(10184):1937-47. doi: 10.1016/s01406736(19)30772-x

290. Guilbert JJ. The World Health Report 2006: Working Together for Health. Educ Health (Abingdon) (2006) 19(3):385-7. doi: 10.1080/13576280600937911

291. Ryba-Stanisławowska M, Skrzypkowska M, Myśliwiec M, Myśliwska J. Loss of the Balance Between CD4(+)Foxp3(+) Regulatory T Cells and CD4(+) IL17A(+) Th17 Cells in Patients With Type 1 Diabetes. Hum Immunol (2013) 74(6):701-7. doi: 10.1016/j.humimm.2013.01.024

292. Sabapathy V, Stremska ME, Mohammad S, Corey RL, Sharma PR, Sharma R. Novel Immunomodulatory Cytokine Regulates Inflammation, Diabetes, and Obesity to Protect From Diabetic Nephropathy. Front Pharmacol (2019) 10:572. doi: 10.3389/fphar.2019.00572

293. Wu CC, Chen JS, Lu KC, Chen CC, Lin SH, Chu P, et al. Aberrant Cytokines/ Chemokines Production Correlate With Proteinuria in Patients With Overt Diabetic Nephropathy. Clin Chim Acta (2010) 411(9-10):700-4. doi: 10.1016/j.cca.2010.01.036

294. Nakamura T, Sugaya T, Kawagoe Y, Ueda Y, Osada S, Koide H. Effect of Pitavastatin on Urinary Liver-Type Fatty Acid-Binding Protein Levels in Patients With Early Diabetic Nephropathy. Diabetes Care (2005) 28 (11):2728-32. doi: 10.2337/diacare.28.11.2728

295. Srivastava SP, Zhou H, Setia O, Liu B, Kanasaki K, Koya D, et al. Loss of Endothelial Glucocorticoid Receptor Accelerates Diabetic Nephropathy. Nat Commun (2021) 12(1):2368. doi: 10.1038/s41467-021-22617-y

296. Ge D, Han L, Huang S, Peng N, Wang P, Jiang Z, et al. Identification of a Novel MTOR Activator and Discovery of a Competing Endogenous RNA Regulating Autophagy in Vascular Endothelial Cells. Autophagy (2014) 10 (6):957-71. doi: 10.4161/auto.28363

297. Calder PC, Jensen GL, Koletzko BV, Singer P, Wanten GJA. Lipid Emulsions in Parenteral Nutrition of Intensive Care Patients: Current Thinking and Future Directions. Intensive Care Med (2010) 36(5):735-49. doi: 10.1007/ s00134-009-1744-5

298. Lee PG, Halter JB. The Pathophysiology of Hyperglycemia in Older Adults: Clinical Considerations. Diabetes Care (2017) 40(4):444-52. doi: 10.2337/ dc16-1732

299. Higgins GC, Coughlan MT. Mitochondrial Dysfunction and Mitophagy: The Beginning and End to Diabetic Nephropathy? Br J Pharmacol (2014) 171(8). doi: 10.1111/bph.2014.171.issue-8

300. Xu Z-G, Lanting L, Vaziri ND, Li Z, Sepassi L, Rodriguez-Iturbe B, et al. Upregulation of Angiotensin II Type 1 Receptor, Inflammatory Mediators, and Enzymes of Arachidonate Metabolism in Obese Zucker Rat Kidney: Reversal by Angiotensin II Type 1 Receptor Blockade. Circulation (2005) 111 (15):1962-9. doi: 10.1161/01.CIR.0000161831.07637.63

301. Hyvonen ME, Saurus P, Wasik A, Heikkila E, Havana M, Trokovic R, et al. Lipid Phosphatase SHIP2 Downregulates Insulin Signalling in Podocytes. Mol Cell Endocrinol (2010) 328(1-2):70-9. doi: 10.1016/ j.mce.2010.07.016

302. He N, Fan W, Henriquez B, Yu RT, Atkins AR, Liddle C, et al. Metabolic Control of Regulatory T Cell (Treg) Survival and Function by Lkb1. Proc Natl Acad Sci USA (2017) 114(47):12542-7. doi: 10.1073/pnas.1715363114

303. Yang Y, Wang J, Qin L, Shou Z, Zhao J, Wang H, et al. Rapamycin Prevents Early Steps of the Development of Diabetic Nephropathy in Rats. Am J Nephrol (2007) 27(5):495-502. doi: 10.1159/000106782

304. Yang D, Livingston MJ, Liu Z, Dong G, Zhang M, Chen JK, et al. Autophagy in Diabetic Kidney Disease: Regulation, Pathological Role and Therapeutic Potential. Cell Mol Life Sci (2018) 75(4):669-88. doi: 10.1007/s00018-0172639-1

305. Han F, Xue M, Chang Y, Li X, Yang Y, Sun B, et al. Erratum: Triptolide Suppresses Glomerular Mesangial Cell Proliferation in Diabetic Nephropathy is Associated With Inhibition of PDK1/Akt/Mtor Pathway: Erratum. Int J Biol Sci (2020) 16(15):3037-8. doi: 10.7150/ijbs.53769

306. Das F, Ghosh-Choudhury N, Mariappan MM, Kasinath BS, Choudhury GG. Hydrophobic Motif Site-Phosphorylated Protein Kinase C $\beta$ ii Between
Mtorc2 and Akt Regulates High Glucose-Induced Mesangial Cell Hypertrophy. Am J Physiol Cell Physiol (2016) 310(7):C583-96. doi: 10.1152/ajpcell.00266.2015

307. Lieberthal W, Levine JS. The Role of the Mammalian Target of Rapamycin (Mtor) in Renal Disease. J Am Soc Nephrol (2009) 20(12):2493-502. doi: 10.1681/asn.2008111186

308. Fantus D, Rogers NM, Grahammer F, Huber TB, Thomson AW. Roles of Mtor Complexes in the Kidney: Implications for Renal Disease and Transplantation. Nat Rev Nephrol (2016) 12(10):587-609. doi: 10.1038/ nrneph.2016.108

309. Jiang SH, Athanasopoulos V, Ellyard JI, Chuah A, Cappello J, Cook A, et al. Functional Rare and Low Frequency Variants in BLK and BANK1 Contribute to Human Lupus. Nat Commun (2019) 10(1):2201. doi: 10.1038/s41467-019-10242-9

310. Du J, Li M, Zhang D, Zhu X, Zhang W, Gu W, et al. Flow Cytometry Analysis of Glucocorticoid Receptor Expression and Binding in Steroid-Sensitive and Steroid-Resistant Patients With Systemic Lupus Erythematosus. Arthritis Res Ther (2009) 11(4):R108. doi: 10.1186/ar2763

311. Mun CH, Kim J-O, Ahn SS, Yoon T, Kim SJ, Ko E, et al. Atializumab, a Humanized Anti-Aminoacyl-Trna Synthetase-Interacting Multifunctional Protein-1 (AIMP1) Antibody Significantly Improves Nephritis in (NZB/ NZW) F1 Mice. Biomaterials (2019) 220:119408. doi: 10.1016/ j.biomaterials.2019.119408

312. Yan J-B, Luo M-M, Chen Z-Y, He B-H. The Function and Role of the Th17/ Treg Cell Balance in Inflammatory Bowel Disease. J Immunol Res (2020) 2020:8813558. doi: 10.1155/2020/8813558

313. Fuseini H, Cephus J-Y, Wu P, Davis JB, Contreras DC, Gandhi VD, et al. Ero Signaling Increased IL-17a Production in Th17 Cells by Upregulating IL-23r Expression, Mitochondrial Respiration, and Proliferation. Front Immunol (2019) 10:2740. doi: 10.3389/fimmu.2019.02740

314. Rajasagi NK, Rouse BT, et al. The Role of T Cells in Herpes Stromal Keratitis. Front Immunol (2019) 10:512. doi: 10.3389/fimmu.2019.00512

315. Shan J, Jin H, Xu Y. T Cell Metabolism: A New Perspective on Th17/Treg Cell Imbalance in Systemic Lupus Erythematosus. Front Immunol (2020) 11:1027. doi: 10.3389/fimmu.2020.01027

316. Chavele KM, Ehrenstein MR. Regulatory T-Cells in Systemic Lupus Erythematosus and Rheumatoid Arthritis. FEBS Lett (2011) 585(23):360310. doi: 10.1016/j.febslet.2011.07.043

317. Giang S, La Cava A. Regulatory T Cells in SLE: Biology and Use in Treatment. Curr Rheumatol Rep (2016) 18(11):67. doi: 10.1007/s11926-016-0616-6

318. Piranavan P, Perl A. Improvement of Renal and non-Renal SLE Outcome Measures on Sirolimus Therapy - a 21-Year Follow-Up Study of 73 Patients. Clin Immunol (2021) 229:108781. doi: 10.1016/j.clim.2021.108781

319. Wahl D, Petersen B, Warner R, Richardson BC, Glick GD, Opipar AW. Characterization of the Metabolic Phenotype of Chronically Activated Lymphocytes. Arthritis Rheum (2010) 19(13):1492-501. doi: 10.1177/ 0961203310373109

320. Gergely P, Grossman C, Niland B, Puskas F, Neupane H, et al. Mitochondrial Hyperpolarization and ATP Depletion in Patients With Systemic Lupus Erythematosus. (2002) 46(1):175-90. doi: 10.1002/art.10015

321. Doherty E, Oaks Z, Perl A. Increased Mitochondrial Electron Transport Chain Activity at Complex I is Regulated by N-Acetylcysteine in Lymphocytes of Patients With Systemic Lupus Erythematosus. Antioxid Redox Signal (2014) 21(1):56-65. doi: 10.1089/ars.2013.5702

322. Myers DR, Petersen B, Warner R, Richardson BC, Glick GD, Opipari AW. Mtor and Other Effector Kinase Signals That Impact T Cell Function and Activity. Immunol Rev (2019) 291(1):134-53. doi: 10.1111/imr.12796

323. Caza TN, Fernandez DR, Talaber G, Oaks Z, Haas M, Madaio MP, et al. HRES-1/Rab4-Mediated Depletion of Drp1 Impairs Mitochondrial Homeostasis and Represents a Target for Treatment in SLE. Ann Rheum Dis (2014) 73(10):1888-97. doi: 10.1136/annrheumdis-2013-203794

324. Palmer CS, Ostrowski M, Balderson B, Christian N, Crowe SM. Glucose Metabolism Regulates T Cell Activation, Differentiation, and Functions. Front Immunol (2015) 6(1):1. doi: 10.3389/fimmu.2015.00001

325. Fernandez DR, Telarico T, Bonilla E, Li Q, Banerjee S, Middleton FA, et al. Activation of Mammalian Target of Rapamycin Controls the Loss of Tcrzeta in Lupus T Cells Through HRES-1/Rab4-Regulated Lysosomal Degradation. J Immunol (2009) 182(4):2063-73. doi: 10.4049/jimmunol.0803600 
326. Jones RG, Pearce EJ. Mentoring Immunity: Mtor Signaling in the Development and Function of Tissue-Resident Immune Cells. Immunity (2017) 46(5):730-42. doi: 10.1016/j.immuni.2017.04.028

327. Ramachandran R, Wierzbicki AS. Statins, Muscle Disease and Mitochondria. J Clin Med (2017) 6(8). doi: 10.3390/jcm6080075

328. McDonald G, Deepak S, Miguel L, Hall CJ, Isenberg DA, Magee AI, et al. Normalizing Glycosphingolipids Restores Function in CD4+ T Cells From Lupus Patients. J Clin Invest (2014) 124(2):712-24. doi: 10.1172/ JCI69571

329. Koizumi S-I, Ishikawa H. Transcriptional Regulation of Differentiation and Functions of Effector T Regulatory Cells. Cells (2019) 8(8):939. doi: 10.3390/ cells 8080939

330. Nakamura T, Shima T, Saeki A, Hidaka T, Nakashima A, Takikawa O, et al. Expression of Indoleamine 2, 3-Dioxygenase and the Recruitment of Foxp3Expressing Regulatory $\mathrm{T}$ Cells in the Development and Progression of Uterine Cervical Cancer. Cancer Sci (2007) 98(6):874-81. doi: 10.1111/ j.1349-7006.2007.00470.x

331. Mostaid MS, Lee TT, Chana G, Sundram S, Shannon Weickert C, Pantelis C, et al. Peripheral Transcription of Pathway Genes are Upregulated in Treatment-Resistant Schizophrenia. Front Psychiatry (2017) 8:225. doi: $10.3389 /$ fpsyt.2017.00225

332. Gan L, Shen H, Li X, Han Z, Jing Y, Yang X, et al. Mesenchymal Stem Cells Promote Chemoresistance by Activating Autophagy in Intrahepatic Cholangiocarcinoma. Oncol Rep (2021) 45(1):107-18. doi: 10.3892/ or.2020.7838

333. Wong P-M, Feng Y, Wang J, Shi R, Jiang X. Regulation of Autophagy by Coordinated Action of Mtorcl and Protein Phosphatase 2A. Nat Commun (2015) 6:8048. doi: 10.1038/ncomms 9048

334. Yang Q, Guan K-L. Expanding Mtor Signaling. Cell Res (2007) 17(8):666-81. doi: 10.1038/cr.2007.64

335. Sohrabi Y, Sonntag GVH, Braun LC, Lagache SMM, Liebmann M, Klotz L, et al. LXR Activation Induces a Proinflammatory Trained Innate ImmunityPhenotype in Human Monocytes. Front Immunol (2020) 11:353. doi: 10.3389/fimmu.2020.00353

336. Zhang D, Jin W, Wu R, Li J, Park S-A, Tu E, et al. High Glucose Intake Exacerbates Autoimmunity Through Reactive-Oxygen-Species-Mediated Tgf- $\beta$ Cytokine Activation. Immunity (2019) 51(4):671-681.e5. doi: 10.1016/j.immuni.2019.08.001

337. Chen T, Xia E, Chen T, Zeng C, Liang S, Xu F, et al. Identification and External Validation of Iga Nephropathy Patients Benefiting From Immunosuppression Therapy. EBioMedicine (2020) 52:102657. doi: 10.1016/ j.ebiom.2020.102657

338. Yang M, Liu JW, Zhang YT, Wu G. The Role of Renal Macrophage, AIM, and TGF- $\beta 1$ Expression in Renal Fibrosis Progression in Igan Patients. Front Immunol (2021) 12:646650. doi: 10.3389/fimmu.2021.646650

339. Kurts C, Panzer U, Anders HJ, Rees AJ, et al. The Immune System and Kidney Disease: Basic Concepts and Clinical Implications. Nat Rev Immunol (2013) 13 (10):738-53. doi: 10.1038/nri3523

340. Cho K, Choi SH. ASK1 Mediates Apoptosis and Autophagy During OxldlCD36 Signaling in Senescent Endothelial Cells. Oxid Med Cell Longev (2019) 2019:2840437. doi: 10.1155/2019/2840437

341. Meier P, Golshayan D, Blanc E, Pascual M, Burnier M. Oxidized LDL Modulates Apoptosis of Regulatory T Cells in Patients With ESRD. J Am Soc Nephrol (2009) 20(6):1368-84. doi: 10.1681/asn.2008070734

342. Zhai Y, Liu Y, Qi Y, Long X, Gao J, Yao X, et al. The Soluble VEGF Receptor Sflt-1 Contributes to Endothelial Dysfunction in Iga Nephropathy. PLoS One (2020) 15(8):e0234492. doi: 10.1371/journal.pone.0234492

343. Liu D, Liu Y, Chen G, He L, Tang C, Wang C, et al. Rapamycin Enhances Repressed Autophagy and Attenuates Aggressive Progression in a Rat Model of Iga Nephropathy. Am J Nephrol (2017) 45(4):293-300. doi: 10.1159/ 000456039

344. Chen Z, Cheng L, Zhang J, Cui X. Angelica Sinensis Polysaccharide Prevents Mitochondrial Apoptosis by Regulating the Treg/Th17 Ratio in Aplastic Anemia. BMC Complement Med Ther (2020) 20(1):192. doi: 10.1186/s12906020-02995-4

345. Zheng J, Lu C. Oxidized LDL Causes Endothelial Apoptosis by Inhibiting Mitochondrial Fusion and Mitochondria Autophagy. Front Cell Dev Biol (2020) 8:600950. doi: 10.3389/fcell.2020.600950
346. Lee K, Won HY, Bae MA, Hong JH, Hwang ES. Spontaneous and AgingDependent Development of Arthritis in NADPH Oxidase 2 Deficiency Through Altered Differentiation of CD11b+ and Th/Treg Cells. Proc Natl Acad Sci U S A (2011) 108(23):9548-53. doi: 10.1073/pnas.1012645108

347. Guo N, Liu S, Bow LM, Cui X, Zhang L, Xu S, et al. The Protective Effect and Mechanism of Rapamycin in the Rat Model of Iga Nephropathy. Ren Fail (2019) 41(1):334-9. doi: 10.1080/0886022x.2019.1577257

348. Tian J, Wang Y, Guo H, Li R. The Akt/Mtor/P70s6k Pathway is Activated in Iga Nephropathy and Rapamycin may Represent a Viable Treatment Option. Exp Mol Pathol (2015) 99(3):435-40. doi: 10.1016/j.yexmp.2015.08.004

349. Diefenhardt P, Nosko A, Kluger MA, Richter JV, Wegscheid C, Kobayashi Y, et al. IL-10 Receptor Signaling Empowers Regulatory T Cells to Control Th17 Responses and Protect From GN. J Am Soc Nephrol (2018) 29(7):1825-37. doi: 10.1681 /asn.2017091044

350. Kluger MA, Meyer MC, Nosko A, Goerke B, Luig M, Wegscheid C, et al. Roryt(+)Foxp3(+) Cells are an Independent Bifunctional Regulatory T Cell Lineage and Mediate Crescentic GN. J Am Soc Nephrol (2016) 27(2):454-65. doi: 10.1681 /asn.2014090880

351. Li S, Zeng Y-C, Peng K, Liu C, Zhang Z-R, Zhang L. Design and Evaluation of Glomerulus Mesangium-Targeted PEG-PLGA Nanoparticles Loaded With Dexamethasone Acetate. Acta Pharmacol Sin (2019) 40(1):143-50. doi: 10.1038/s41401-018-0052-4

352. Lurbe E, Álvarez J, Redon J. Diagnosis and Treatment of Hypertension in Children. Curr Hyperten Rep (2010) 12(6):480-6. doi: 10.1007/s11906-0100155-x

353. Wolf D, Hochegger K, Wolf AM, Rumpold HF, Gastl G, Tilg H, et al. CD4 $+\mathrm{CD} 25+$ Regulatory T Cells Inhibit Experimental Anti-Glomerular Basement Membrane Glomerulonephritis in Mice. J Am Soc Nephrol (2005) 16(5):1360-70. doi: 10.1681/asn.2004100837

354. Lyu M, Li Y, Hao Y, Lyu C, Huang Y, Sun B, et al. CCR6 Defines a Subset of Activated Memory T Cells of Th17 Potential in Immune Thrombocytopenia. Clin Exp Immunol (2019) 195(3):345-57. doi: 10.1111/cei.13233

355. Liu J, Merritt JR. CC Chemokine Receptor Small Molecule Antagonists in the Treatment of Rheumatoid Arthritis and Other Diseases: A Current View. Curr Topics Med Chem (2010) 10(13):1250-67. doi: 10.2174/ 156802610791561192

356. Herrnstadt GR, Steinmetz OM. The Role of Treg Subtypes in Glomerulonephritis. Cell Tissue Res (2020). doi: 10.1007/s00441-02003359-7

357. Nishio J, Honda K. Immunoregulation by the Gut Microbiota. Cell Mol Life Sci CMLS (2012) 69(21):3635-50. doi: 10.1007/s00018-012-0993-6

358. Nosko, Kluger MA, Diefenhardt P, Melderis S, Wegscheid C, Tiegs G, et al. T-Bet Enhances Regulatory T Cell Fitness and Directs Control of Th1 Responses in Crescentic GN. J Am Soc Nephrol (2017) 28(1):185-96. doi: $10.1681 /$ asn. 2015070820

359. Neumann K, Ostmann A, Breda PC, Ochel A, Tacke F, Paust HJ, et al. The CoInhibitory Molecule PD-L1 Contributes to Regulatory T Cell-Mediated Protection in Murine Crescentic Glomerulonephritis. Sci Rep (2019) 9(1):2038. doi: 10.1038/s41598-018-38432-3

360. Saeki S, Ohba H, Ube Y, Tanaka K, Haruyama W, Uchii M, et al. Positron Emission Tomography Imaging of Renal Mitochondria is a Powerful Tool in the Study of Acute and Progressive Kidney Disease Models. Kidney Int (2020) 98(1):88-99. doi: 10.1016/j.kint.2020.02.024

361. Arif E, Solanki AK, Srivastava P, Rahman B, Fitzgibbon WR, Deng P, et al. Mitochondrial Biogenesis Induced by the Beta2-Adrenergic Receptor Agonist Formoterol Accelerates Podocyte Recovery From Glomerular Injury. Kidney Int (2019) 96(3):656-73. doi: 10.1016/j.kint.2019.03.023

362. Nagasu H, Sogawa Y, Kidokoro K, Itano S, Yamamoto T, Satoh M, et al. Bardoxolone Methyl Analog Attenuates Proteinuria-Induced Tubular Damage by Modulating Mitochondrial Function. FASEB J (2019) 33 (11):12253-63. doi: 10.1096/fj.201900217R

363. Jha MK, Jeon S, Suk K. Pyruvate Dehydrogenase Kinases in the Nervous System: Their Principal Functions in Neuronal-Glial Metabolic Interaction and Neuro-Metabolic Disorders. Curr Neuropharmacol (2012) 10(4):393403. doi: 10.2174/157015912804143586

364. Howie D, Cobbold SP, Adams E, Ten Bokum A, Necula AS, Zhang W, et al. Foxp3 Drives Oxidative Phosphorylation and Protection From Lipotoxicity. JCI Insight (2017) 2(3):e89160. doi: 10.1172/jci.insight.89160 
365. Sethi S, Gamez JD, Vrana JA, Theis JD, Bergen HR3rd, Zipfel PF, et al. Glomeruli of Dense Deposit Disease Contain Components of the Alternative and Terminal Complement Pathway. Kidney Int (2009) 75(9):952-60. doi: 10.1038/ki.2008.657

366. Gao L-N, Zhou X, Lu Y-R, Li K, Gao S, Yu C-Q, et al. Dan-Lou Prescription Inhibits Foam Cell Formation Induced by Ox-LDL via the TLR4/NF-kb and Ppary Signaling Pathways. Front Physiol (2018) 9:590. doi: 10.3389/ fphys.2018.00590

367. Fernandez-Mosquera L, Yambire KF, Couto R, Pereyra L, Pabis K, Ponsford AH, et al. Mitochondrial Respiratory Chain Deficiency Inhibits Lysosomal Hydrolysis. Autophagy (2019) 15(9):1572-91. doi: 10.1080/15548627.2019. 1586256

368. Soypacaci Z, Cakmak O, Cakalagoglu F, Gercik O, Ertekin I, Uzum A, et al. The Role of Mammalian Target of Rapamycin Pathway in the Pathogenesis of Pauci-Immune Glomerulonephritis. Ren Fail (2019) 41(1):907-13. doi: 10.1080/0886022X.2019.1667829

369. Atif M, Mohr A, Conti F, Scatton O, Gorochov G, Miyara M. Metabolic Optimisation of Regulatory T Cells in Transplantation. Front Immunol (2020) 11:2005. doi: 10.3389/fimmu.2020.02005

370. Wen Y, Rudemiller NP, Zhang J, Robinette T, Lu X, Ren J, et al. Tnf- $\alpha$ in T Lymphocytes Attenuates Renal Injury and Fibrosis During Nephrotoxic Nephritis. Am J Physiol Renal Physiol (2020) 318(1):F107-f116. doi: 10.1152/ ajprenal.00347.2019

371. Wang T, Fu X, Chen Q, Patra JK, Wang D, Wang Z, et al. Arachidonic Acid Metabolism and Kidney Inflammation. Int J Mol Sci (2019) 20(15):3683. doi: 10.3390/ijms20153683

372. Eller K, Wolf D, Huber JM, Metz M, Mayer G, McKenzie AN, et al. IL-9 Production by Regulatory T Cells Recruits Mast Cells That are Essential for Regulatory T Cell-Induced Immune Suppression. J Immunol (2011) 186 (1):83-91. doi: 10.4049/jimmunol.1001183

373. Baba N, Shimokama T, Watanabe T. Effects of Hypercholesterolemia on Initial and Chronic Phases of Rat Nephrotoxic Serum Nephritis: Development of Focal Segmental Glomerulosclerosis, Analogous to Atherosclerosis. Virchows Arch B Cell Pathol Incl Mol Pathol (1993) 64 (2):97-105. doi: 10.1007/bf02915101

374. Aringer I, Artinger K, Schabhüttl C, Bärnthaler T, Mooslechner AA, Kirsch A, et al. Agonism of Prostaglandin E2 Receptor 4 Ameliorates Tubulointerstitial Injury in Nephrotoxic Serum Nephritis in Mice. J Clin Med (2021) 10(4):832. doi: 10.3390/jcm10040832

375. Liu Y, Sun L, Yang G, Yang Z. Nephrotoxicity and Genotoxicity of Silver Nanoparticles in Juvenile Rats and Possible Mechanisms of Action. Arh Hig Rada Toksikol (2020) 71(2):121-9. doi: 10.2478/aiht-2020-71-3364

376. Kim EY, Shotorbani PY, Dryer SE. TRPC6 Inactivation Does Not Affect Loss of Renal Function in Nephrotoxic Serum Glomerulonephritis in Rats, But Reduces Severity of Glomerular Lesions. Biochem Biophys Rep (2019) 17:139-50. doi: 10.1016/j.bbrep.2018.12.006

377. Casalena G, Krick S, Daehn I, Yu L, Ju W, Shi S, et al. Mpv17 in Mitochondria Protects Podocytes Against Mitochondrial Dysfunction and Apoptosis In Vivo and In Vitro. Am J Physiol Renal Physiol (2014) 306(11): F1372-80. doi: 10.1152/ajprenal.00608.2013

378. Eller K, Weber T, Pruenster M, Wolf AM, Mayer G, Rosenkranz AR, et al. CCR7 Deficiency Exacerbates Injury in Acute Nephritis Due to Aberrant Localization of Regulatory T Cells. J Am Soc Nephrol (2010) 21(1):42-52. doi: $10.1681 /$ asn.2009020133

379. Lu J, Chen Z, Zhao H, Dong H, Zhu L, Zhang Y, et al. ABAT and ALDH6A1, Regulated by Transcription Factor HNF4A, Suppress Tumorigenic Capability in Clear Cell Renal Cell Carcinoma. J Trans Med (2020) 18 (1):101. doi: 10.1186/s12967-020-02268-1

380. D'Avella C, Abbosh P, Pal SK, Geynisman DM. Mutations in Renal Cell Carcinoma. Urol Oncol (2020) 38(10):763-73. doi: 10.1016/j.urolonc. 2018.10.027

381. López-Soto A, Kroemer G. Cancer-Induced Endoplasmic Reticulum Stress in T Cells Subverts Immunosurveillance. Cell Metab (2018) 28(6):803-5. doi: 10.1016/j.cmet.2018.11.003

382. Le Bourgeois T, Strauss L, Aksoylar HI, Daneshmandi S, Seth P, Patsoukis N, et al. Targeting $\mathrm{T}$ Cell Metabolism for Improvement of Cancer Immunotherapy. Front Oncol (2018) 8(237):237. doi: 10.3389/fonc. 2018.00237
383. Nguyen T, Le A. The Metabolism of Renal Cell Carcinomas and Liver Cancer. Adv Exp Med Biol (2018) 1063:107-18. doi: 10.1007/978-3-31977736-8_8

384. Noman MZ, Desantis G, Janji B, Hasmim M, Karray S, Dessen P, et al. PDL1 is a Novel Direct Target of HIF-1 $\alpha$, and its Blockade Under Hypoxia Enhanced MDSC-Mediated T Cell Activation. J Exp Med (2014) 211(5):78190. doi: $10.1084 /$ jem. 20131916

385. Ben-Shoshan J, Maysel-Auslender S, Mor A, Keren G, George J. Hypoxia Controls CD4+CD25+ Regulatory T-Cell Homeostasis via HypoxiaInducible Factor-1alpha. Eur J Immunol (2008) 38(9):2412-8. doi: 10.1002/ eji. 200838318

386. Giddings EL, Champagne DP, Wu M-H, Laffin JM, Thornton TM, ValencaPereira F, et al. Mitochondrial ATP Fuels ABC Transporter-Mediated Drug Efflux in Cancer Chemoresistance. Nat Commun (2021) 12(1):2804. doi: 10.1038/s41467-021-23071-6

387. Fu Q, Xu L, Wang Y, Jiang Q, Liu Z, Zhang J, et al. Tumor-Associated Macrophage-Derived Interleukin-23 Interlinks Kidney Cancer Glutamine Addiction With Immune Evasion. Eur Urol (2019) 75(5):752-63. doi: 10.1016/j.eururo.2018.09.030

388. Ross SJ, Critchlow SE. Emerging Approaches to Target Tumor Metabolism. Curr Opin Pharmacol (2014) 17:22-9. doi: 10.1016/j.coph.2014.07.001

389. Rathmell JC. T Cell Myc-Tabolism. Immunity (2011) 35(6):845-6. doi: 10.1016/j.immuni.2011.12.001

390. Yu H, Kortylewski M, Pardoll D. Crosstalk Between Cancer and Immune Cells: Role of STAT3 in the Tumour Microenvironment. Nat Rev Immunol (2007) 7(1):41-51. doi: 10.1038/nri1995

391. Díaz-Montero CM, Rini BI, Finke JH. The Immunology of Renal Cell Carcinoma. Nat Rev Nephrol (2020) 16(12):721-35. doi: 10.1038/s41581020-0316-3

392. Tanizaki Y, Kobayashi A, Toujima S, Shiro M, Mizoguchi M, Mabuchi Y. Indoleamine 2,3-Dioxygenase Promotes Peritoneal Metastasis of Ovarian Cancer by Inducing an Immunosuppressive Environment. Cancer Sci (2014) 105(8):966-73. doi: $10.1111 /$ cas. 12445

393. Meng H, Nel AE. Use of Nano Engineered Approaches to Overcome the Stromal Barrier in Pancreatic Cancer. Adv Drug Deliv Rev (2018) 130:50-7. doi: 10.1016/j.addr.2018.06.014

394. Qian F, Villella J, Wallace PK, Mhawech-Fauceglia P, Tario JD, Andrews C, et al. Efficacy of Levo-1-Methyl Tryptophan and Dextro-1-Methyl Tryptophan in Reversing Indoleamine-2,3-Dioxygenase-Mediated Arrest of T-Cell Proliferation in Human Epithelial Ovarian Cancer. Cancer Res (2009) 69(13):5498-504. doi: 10.1158/0008-5472.CAN-08-2106

395. Mohib K, Guan Q, Diao H, Du C, Jevnikar AM. Proapoptotic Activity of Indoleamine 2,3-Dioxygenase Expressed in Renal Tubular Epithelial Cells. Am J Physiol Renal Physiol (2007) 293(3):F801-12. doi: 10.1152/ ajprenal.00044.2007

396. Hou D-Y, Muller AJ, Sharma MD, DuHadaway J, Banerjee T, Johnson M, et al. Inhibition of Indoleamine 2,3-Dioxygenase in Dendritic Cells by Stereoisomers of 1-Methyl-Tryptophan Correlates With Antitumor Responses. Cancer Res (2007) 67(2):792-801. doi: 10.1158/00085472.CAN-06-2925

397. Sharma MD, Shinde R, McGaha TL, Huang L, Holmgaard RB, Wolchok JD, et al. The PTEN Pathway in Tregs is a Critical Driver of the Suppressive Tumor Microenvironment. Sci Adv (2015) 1(10):e1500845. doi: 10.1126/ sciadv. 1500845

398. Tan SK, Welford SM. Lipid in Renal Carcinoma: Queen Bee to Target? Trends Cancer (2020) 6(6):448-50. doi: 10.1016/j.trecan.2020.02.017

399. Radovanovic M, Vidicevic S, Tasic J, Tomonjic N, Stanojevic Z, Nikic P, et al. Role of AMPK/Mtor-Independent Autophagy in Clear Cell Renal Cell Carcinoma. J Investig Med (2020) 68(8):1386-93. doi: 10.1136/jim-2020001524

400. Berod L, Friedrich C, Nandan A, Freitag J, Hagemann S, Harmrolfs K, et al. De Novo Fatty Acid Synthesis Controls the Fate Between Regulatory T and T Helper 17 Cells. Nat Med (2014) 20(11):1327-33. doi: 10.1038/nm.3704

401. Lochner M, Berod L, Sparwasser T. Fatty Acid Metabolism in the Regulation of T Cell Function. Trends Immunol (2015) 36(2):81-91. doi: 10.1016/ j.it.2014.12.005

402. Stokman G, Kors L, Bakker PJ, Rampanelli E, Claessen N, Teske GJD, et al. NLRX1 Dampens Oxidative Stress and Apoptosis in Tissue Injury via 
Control of Mitochondrial Activity. J Exp Med (2017) 214(8):2405-20. doi: $10.1084 / \mathrm{jem} .20161031$

403. Yin Y, Choi SC, Xu Z, Zeumer L, Kanda N, Croker BP, et al. Glucose Oxidation is Critical for CD4+ T Cell Activation in a Mouse Model of Systemic Lupus Erythematosus. J Immunol (2016) 196(1):80-90. doi: 10.4049/jimmunol.1501537

404. Fernandez D, Perl A. Mtor Signaling: A Central Pathway to Pathogenesis in Systemic Lupus Erythematosus? Discov Med (2010) 9(46):173-8.

405. Kato H, Perl A. Mechanistic Target of Rapamycin Complex 1 Expands Th17 and IL-4+ CD4-CD8- Double-Negative T Cells and Contracts Regulatory T Cells in Systemic Lupus Erythematosus. J Immunol (2014) 192(9):4134-44. doi: 10.4049/jimmunol.1301859

406. Deng GM, Tsokos GC. Cholera Toxin B Accelerates Disease Progression in Lupus-Prone Mice by Promoting Lipid Raft Aggregation. J Immunol (2008) 181(6):4019-26. doi: 10.4049/jimmunol.181.6.4019

407. Jury EC, Isenberg DA, Mauri C, Ehrenstein MR. Atorvastatin Restores Lck Expression and Lipid Raft-Associated Signaling in T Cells From Patients With Systemic Lupus Erythematosus. J Immunol (2006) 177(10):7416-22. doi: 10.4049/jimmunol.177.10.7416

408. Yap DYH, Tang C, Chan GCW, Kwan LPY, Ma MKM, Mok MMY, et al. Longterm Data on Sirolimus Treatment in Patients With Lupus Nephritis. J Rheumatol (2018) 45(12):1663-70. doi: 10.3899/jrheum. 180507

409. Herold M, Richmond NA, Montuno MA, Wesson SK, Motaparthi K. Rapamycin for Refractory Discoid Lupus Erythematosus. Dermatol Ther (2018) 31(5):e12631. doi: 10.1111/dth.12631

410. Haghikia A, Jorg S, Duscha A, Berg J, Manzel A, Waschbisch A, et al. Dietary Fatty Acids Directly Impact Central Nervous System Autoimmunity via the
Small Intestine. Immunity (2015) 43(4):817-29. doi: 10.1016/ j.immuni.2015.09.007

411. Marino E, Richards JL, McLeod KH, Stanley D, Yap YA, Knight J, et al. Gut Microbial Metabolites Limit the Frequency of Autoimmune T Cells and Protect Against Type 1 Diabetes. Nat Immunol (2017) 18(5):552-62. doi: 10.1038/ni.3713

412. Luu M, Pautz S, Kohl V, Singh R, Romero R, Lucas S, et al. The Short-Chain Fatty Acid Pentanoate Suppresses Autoimmunity by Modulating the Metabolic-Epigenetic Crosstalk in Lymphocytes. Nat Commun (2019) 10 (1):760. doi: 10.1038/s41467-019-08711-2

Conflict of Interest: The authors declare that the research was conducted in the absence of any commercial or financial relationships that could be construed as a potential conflict of interest.

Publisher's Note: All claims expressed in this article are solely those of the authors and do not necessarily represent those of their affiliated organizations, or those of the publisher, the editors and the reviewers. Any product that may be evaluated in this article, or claim that may be made by its manufacturer, is not guaranteed or endorsed by the publisher.

Copyright (C) 2022 Han, Ma, Tao, Liu, Zhang, Sai, Li, Chi, Nian, Song and Liu. This is an open-access article distributed under the terms of the Creative Commons Attribution License (CC BY). The use, distribution or reproduction in other forums is permitted, provided the original author(s) and the copyright owner(s) are credited and that the original publication in this journal is cited, in accordance with accepted academic practice. No use, distribution or reproduction is permitted which does not comply with these terms. 